\title{
Guidelines on the radical management of patients with lung cancer
}

\author{
Eric Lim, ${ }^{1}$ David Baldwin, ${ }^{2}$ Michael Beckles, ${ }^{3}$ John Duffy, ${ }^{2}$ James Entwisle, \\ Corinne Faivre-Finn, ${ }^{5}$ Keith Kerr, ${ }^{6}$ Alistair Macfie, ${ }^{7}$ Jim McGuigan, ${ }^{8}$ Simon Padley, ${ }^{9}$ \\ Sanjay Popat, ${ }^{10}$ Nicholas Screaton, ${ }^{11}$ Michael Snee, ${ }^{12}$ David Waller, ${ }^{13}$ \\ Chris Warburton, ${ }^{14}$ Thida Win, ${ }^{15}$ British Thoracic Society and the Society for \\ Cardiothoracic Surgery in Great Britain and Ireland
}

\begin{abstract}
- Appendix 2 is published online only. To view this file, please visit the journal online (http://thorax.bmj.com).

${ }^{1}$ Royal Brompton Hospital, London, UK

${ }^{2}$ Nottingham University Hospitals, Nottingham, UK

${ }^{3}$ Royal Free Hospital, London, UK

${ }^{4}$ University Hospitals of Leicester NHS Trust, Glenfield Hospital, Leicester, UK ${ }^{5}$ Christie Hospital, Manchester, UK

${ }^{6}$ Grampian University Hospitals NHS Trust, Aberdeen, UK ${ }^{7}$ Golden Jubilee National Hospital, Clydebank, UK ${ }^{8}$ Royal Victoria Hospital, Belfast, UK

${ }^{9}$ Chelsea and Westminster Hospital, London, UK

${ }^{10}$ Royal Marsden Hospital, London, UK

${ }^{11}$ Papworth Hospital NHS Trust, Papworth Hospital, Papworth Everard, Cambridge, UK

${ }^{12}$ Leeds Teaching Hospitals

Trust, Leeds, UK

${ }^{13}$ Glenfield Hospital, Leicester, Leicester, UK

${ }^{14}$ Aintree Chest Centre, University Hospital Aintree, Liverpool, UK

${ }^{15}$ Lister Hospital, Stevenage, Hertfordshire, UK
\end{abstract}

Correspondence to Eric Lim, Imperial College and the Academic Division of Thoracic Surgery, Royal Brompton Hospital, Sydney Street, London SW3 6NP, UK; e.lim@rbht.nhs.uk

Received 28 June 2010 Accepted 29 June 2010

\begin{abstract}
A joint initiative by the British Thoracic Society and the Society for Cardiothoracic Surgery in Great Britain and Ireland was undertaken to update the 2001 guidelines for the selection and assessment of patients with lung cancer who can potentially be managed by radical treatment.
\end{abstract}

\section{SYNOPSIS OF RECOMMENDATIONS}

The recommendations of the Guideline Development Committee (GDC) are listed below and can be cross-referenced in the main document. The list includes recommendations for research denoted by the abbreviation $R R$. The recommendations should be read in conjunction with figure 1 (mediastinal diagnosis and staging), figure 2 (tripartite risk assessment) and figure 3 (risk assessment for postoperative dyspnoea).

\section{SECTION 1: SELECTION OF PATIENTS FOR RADICAL TREATMENT \\ 1.1 Diagnosis and staging}

1.1.1 Imaging

1. View all available historical images at the onset of the diagnostic pathway and review them prior to treatment. [C]

2. Ensure contemporaneous imaging is available at the time of radical treatment. [C]

3. Ensure a CT scan that is $<4$ weeks old is available at the time of radical treatment of borderline lesions. [D]

4. Arrange a CT scan of the chest, lower neck and upper abdomen with intravenous contrast medium administration early in the diagnostic pathway for all patients with suspected lung cancer potentially suitable for radical treatment. [C]

5. Avoid relying on a CT scan of the chest as the sole investigation to stage the mediastinal lymph nodes. [B]

6. Ensure positron emission tomography (PET)-CT scanning is available for all patients being considered for radical treatment. [B]

7. Offer radical treatment without further mediastinal lymph node sampling if there is no significant uptake in normal sized mediastinal lymph nodes on PET-CT scanning. [C]

8. Evaluate PET positive mediastinal nodes by further mediastinal sampling. [C]

9. Confirm the presence of isolated distant metastases/synchronous tumours by biopsy or further imaging in patients being considered for radical treatment. [C]

10. Consider MRI or CT scanning of the head in patients selected for radical treatment, especially in stage III disease. [C]

11. Evaluate patients with features suggestive of intracranial pathology by an initial CT scan of the head followed by MRI if normal or MRI as an initial test. [C]

12. Biopsy adrenal lesions that show abnormal uptake on PET-CT scanning before radical treatment. [D]

13. RR The role of PET-CT scanning in patients with small cell lung cancer considered suitable for radical treatment should be evaluated in clinical trials.

1.1.2 Endoscopic procedures for diagnosis and staging 14. When obtaining diagnostic and staging samples, consider the adequacy of these in the context of selection of patients for targeted therapy. [D]

15. Ensure biopsy samples are taken in adequate numbers and size where there is negligible additional risk to the patient. [D]

16. Use transbronchial needle aspiration (TBNA) and endobronchial ultrasound/endoscopic ultrasound (EBUS/EUS)-guided TBNA as an initial diagnostic and staging procedure according to findings on CT or PET-CT scans. [C]

17. Consider EBUS/EUS-guided TBNA to stage the mediastinum. [C]

18. Confirm negative results obtained by TBNA and EBUS/EUS-guided TBNA by mediastinoscopy and lymph node biopsy where clinically appropriate. [C]

19. RR The use of narrow band and autofluorescence imaging should be investigated in clinical trials.

\subsubsection{7th Edition of TNM for lung tumours}

20. The 7th edition of the TNM classification of lung cancer should be used for staging patients with lung cancer. [B]

21. The IASLC international nodal map should be used in the assessment and staging of lymph node disease. [C]

\subsection{Management of specific disease subsets} 1.2.1 T3 disease

22. Offer patients with T3N0-1M0 disease radical treatment. [D] 


\subsubsection{T4 disease}

23. Consider selected patients with $\mathrm{T} 4 \mathrm{~N} 0-1 \mathrm{M} 0$ disease for radical multimodality treatment. [D]

24. RR Consider clinical trials of radical treatment for T4 disease.

\subsubsection{N2 disease}

25. Consider radical radiotherapy or chemoradiotherapy in patients with T1-4N2 (bulky or fixed) M0 disease. [B]

26. Consider surgery as part of multimodality management in patients with T1-3N2 (non-fixed, non-bulky, single zone) M0 disease. [B]

27. RR Consider further randomised trials of surgery added to multimodality management in patients with multi-zone N2 disease to establish if any subgroups of patients might benefit more from the addition of surgery.

\subsubsection{N3 disease}

28. RR Consider clinical trials of radical treatment for patients with T1-4N3M0 disease.

\subsubsection{M1 disease}

29. RR Consider clinical trials of radical treatment for patients with M1a and M1b disease.

\subsubsection{Bronchioloalveolar carcinoma}

30. Offer suitable patients with single-site bronchioloalveolar carcinoma anatomical lung resection. [C]

31. Consider multiple wedge resections in suitable patients with a limited number of sites of bronchioloalveolar carcinoma. [C]

\subsubsection{Open and close thoracotomy}

32. Surgical units should have an open and close thoracotomy rate of around $5 \%$. [D]

\section{SECTION 2: SURGERY}

\subsection{Assessment of the risks of surgery}

\subsubsection{Risk assessment for operative mortality}

33. Consider using a global risk score such as Thoracoscore to estimate the risk of death when evaluating and consenting patients with lung cancer for surgery. [C]

\subsubsection{Risk assessment for cardiovascular morbidity}

34. Use the American College of Cardiology guidelines 2007 as a basis for assessing perioperative cardiovascular risk. [C]

35. Avoid lung resection within 30 days of myocardial infarction. [B]

36. Seek a cardiology review in patients with an active cardiac condition or $\geq 3$ risk factors or poor cardiac functional capacity.

[C]

37. Offer surgery without further investigations to patients with

$\leq 2$ risk factors and good cardiac functional capacity. [B]

38. Begin optimisation of medical therapy and secondary prophylaxis for coronary disease as early in the patient pathway as possible. [C]

39. Continue anti-ischaemic treatment in the perioperative period including aspirin, statins and $\beta$ blockade. [B]

40. Discuss management of patients with a coronary stent with a cardiologist to determine perioperative antiplatelet management. [C]

41. Consider patients with chronic stable angina and conventional ACC/AHA indications for treatment (coronary artery bypass grafting and percutaneous coronary intervention) for revascularisation prior to thoracic surgery. [C]
2.1.3 Assessment of lung function

42. Measure lung carbon monoxide transfer factor in all patients regardless of spirometric values. [C]

43. Offer surgical resection to patients with low risk of postoperative dyspnoea. [C]

44. Offer surgical resection to patients at moderate to high risk of postoperative dyspnoea if they are aware of and accept the risks of dyspnoea and associated complications. [D]

45. Consider using ventilation scintigraphy or perfusion scintigraphy to predict postoperative lung function if a ventilation or perfusion mismatch is suspected. [C]

46. Consider using quantitative CTor MRI to predict postoperative lung function if the facility is available. [C]

47. Consider using shuttle walk testing as functional assessment in patients with moderate to high risk of postoperative dyspnoea using a distance walked of $>400 \mathrm{~m}$ as a cut-off for good function. [C]

48. Consider cardiopulmonary exercise testing to measure peak oxygen consumption as functional assessment in patients with moderate to high risk of postoperative dyspnoea using $>15 \mathrm{ml} /$ $\mathrm{kg} / \mathrm{min}$ as a cut-off for good function. [D]

49. RR Further studies with specific outcomes are required to define the role of exercise testing in the selection of patients for surgery.

\subsubsection{Postoperative quality of life/dyspnoea}

50. Avoid pneumonectomy where possible by performing bronchoangioplastic resection or non-anatomical resection. [C] 51. Avoid taking pulmonary function and exercise tests as sole surrogates for quality of life evaluation. [C]

52. When estimating quality of life, use a validated instrument. [D]

\subsection{Surgical approach}

\subsubsection{Pulmonary resection}

53. Employ segment counting to estimate postoperative lung function as part of risk assessment for postoperative dyspnoea. [D]

54. Consider patients with moderate to high risk of postoperative dyspnoea for lung parenchymal sparing surgery. [D]

55. Consider bronchoangioplastic procedures in suitable patients to preserve pulmonary function. [D]

56. Consider patients with limited pulmonary reserve for sublobar resection as an acceptable alternative to lobectomy. [B]

57. RR Consider randomised trials of segmental resection versus wedge resection.

58. Consider patients with concomitant lung cancer within severe heterogeneous emphysema for lung resection based on lung volume reduction surgery criteria. [B]

\subsubsection{Lymph node management}

59. Perform systematic nodal dissection in all patients undergoing resection for lung cancer. [A]

60. Remove or sample a minimum of six lymph nodes or stations. [D]

\subsection{Chemotherapy}

\subsubsection{Preoperative chemotherapy}

61. Patients with resectable lung cancer should not routinely be offered preoperative chemotherapy. [B]

\subsubsection{Postoperative chemotherapy}

62. Offer postoperative chemotherapy to patients with TNM $7^{\text {th }}$ edition T1-3N1-2M0 non-small cell lung cancer. [A] 
63. Consider postoperative chemotherapy in patients with TNM $7^{\text {th }}$ edition T2-3N0M0 non-small cell lung cancer with tumours $>4 \mathrm{~cm}$ diameter. [B]

64. Use a cisplatin-based combination therapy regimen in postoperative chemotherapy. [A]

65. RR Consider further trials of novel chemotherapeutic agents in conjunction with surgical resection.

\subsection{Postoperative radiotherapy}

66. Postoperative radiotherapy (PORT) is not indicated after R0 complete resection. [A]

67. Consider PORT for patients with residual microscopic disease at the resection margin where the benefit of reduction in local recurrence outweighs the risk of mortality and morbidity related to PORT. [C]

68. Use CT-planned three-dimensional conformal radiotherapy for patients receiving PORT. [B]

69. Consider PORT after completion of adjuvant chemotherapy. [B]

70. RR Randomised trials looking at the effect of PORT in pN2 non-small cell lung cancer are recommended.

\section{SECTION 3: RADICAL RADIOTHERAPY}

\subsection{Assessment of the risks of radiotherapy}

\subsubsection{Risks of radical radiotherapy}

71. Perform three-dimensional treatment planning in patients undergoing radical thoracic radiotherapy. [B]

72. A clinical oncologist specialising in lung oncology should determine suitability for radical radiotherapy, taking into account performance status and comorbidities. [D]

73. RR Clinical trials of radical radiotherapy should include measures of lung function, outcome and toxicity.

\subsection{Radiotherapy and chemoradiotherapy regimens}

3.2.1 Early stage disease

74. Offer radical radiotherapy to patients with early stage non-small cell lung cancer who have an unacceptable risk of surgical complications. [B]

75. Consider CHART as a treatment option in patients with early stage non-small cell lung cancer and unacceptable risk of surgical complications. [A]

76. Consider stereotactic body irradiation in patients with early stage non-small cell lung cancer and unacceptable risk of surgical complications. [C]

\subsubsection{Locally advanced disease}

77. Offer chemoradiotherapy to patients with locally advanced non-small cell lung cancer and good performance status who are unsuitable for surgery. [A]

78. Offer selected patients with good performance status concurrent chemoradiotherapy with a cisplatin-based chemotherapy combination. [A]

79. Offer patients unsuitable for concurrent chemoradiotherapy sequential chemoradiotherapy. [A]

80. Consider CHART as a treatment option for patients with locally advanced non-small cell lung cancer. [A]

\subsection{Other radical treatment}

81. RR Randomised controlled trials are recommended comparing conventional radical treatment (surgery, radical radiotherapy) with other radical treatments where there is evidence of efficacy in case series.

82. Consider alternative radical treatment in early stage lung cancer in patients at high risk of morbidity and mortality with conventional radical treatment. [D]
83. Consider radical brachytherapy in patients with early invasive mucosal or submucosal non-small cell lung cancer. [D]

\section{SECTION 4: SMALL CELL LUNG CANCER 4.1 Chemoradiotherapy}

84. Offer selected patients with $\mathrm{T} 1-4 \mathrm{~N} 0-3 \mathrm{M} 0$ limited stage small cell lung cancer both chemotherapy and radiotherapy. [A] 85. Offer patients with $\mathrm{T} 1-4 \mathrm{~N} 0-3 \mathrm{M} 0$ limited stage small cell lung cancer and good performance status concurrent chemoradiotherapy. [A]

86. Recommended treatment options for concurrent chemoradiotherapy are twice daily thoracic radiotherapy (45 Gy in 3 weeks) with cisplatin and etoposide and 40 Gy once daily delivered in 3 weeks. [A]

87. Offer patients unsuitable for concurrent chemoradiotherapy sequential chemoradiotherapy. [A]

88. Offer prophylactic cranial irradiation to patients with response to treatment and stable disease. [A]

\subsection{Surgery}

89. Consider patients with $\mathrm{T} 1-3 \mathrm{~N} 0-1 \mathrm{M} 0$ small cell lung cancer for surgery as part of multi-modality management. [D]

90. Surgical management of patients with T1-3N2M0 small cell lung cancer should only be considered in the context of a clinical trial. [C]

\section{SECTION 5: PROVISION OF TREATMENT OPTIONS}

91. All available treatment options, including those that are the subject of research, should be discussed with patients and their carers and the risks and benefits presented so that they may make an informed choice. [D]

\section{INTRODUCTION}

This document is the result of a joint initiative by the British Thoracic Society (BTS) and the Society for Cardiothoracic Surgery in Great Britain and Ireland (SCTS) to update the 2001 guidelines for the selection and assessment of patients with lung cancer $^{1[\mathrm{~N} / \mathrm{A}]}$ who can potentially be managed by radical treatment. In the previous guidelines it was hoped that more uniform selection and assessment might lead to improvement in resection and survival rates of patients with lung cancer. Despite good uptake of the guidelines, data from the 2008 National Lung Cancer Audit show that the lung resection rate in the UK was $11 \%$ and that there was considerable variation between networks (from $5 \%$ to $>25 \%$ ). ${ }^{2[3]}$ Lung cancer survival in the UK is still among the lowest in Europe. ${ }^{3[3]}$

Changes to the layout and approach of this update are intended to provide comprehensive guidance on selection (by stage criteria) and risk assessment but also on the wider management of patients suitable for radical treatment. The treatment options have also become less distinct with a move towards multi-modality management. The risk assessment algorithm was revised to take into consideration not only mortality but also postoperative dyspnoea, an outcome of great importance to the patient. In accordance with General Medical Council recommendations, ${ }^{4[\mathrm{~N} / \mathrm{A}]}$ risks of treatments are presented to allow patients to weigh risks and benefits of each modality and facilitate a joint clinician-patient decision making process.

\section{Definition of radical and palliative treatment}

The Guideline Development Committee (GDC) considered it important to clarify the definition of radical and palliative 
treatment, as some recommendations are based on the management intent. Thus, radical treatment is defined as treatment given with the intention to improve survival substantially, which may amount to a cure. Palliative treatment is defined as treatment given with the intention to improve quality of life and may include prolonging the length of life as a secondary benefit.

\section{The terms 'operable' and 'resectable'}

The GDC noted that these terms were used by some multidisciplinary teams (MDTs). 'Resectable' indicates that the primary tumour can be completely excised by surgery with clear pathological margins. 'Operable' indicates that the patient has an acceptable risk of death or morbidity. These terms are useful to focus attention on these aspects of surgical treatment. However, MDTs and patients may have different thresholds for operability and surgeons may have different thresholds for resection. What is important is the parameters set to define thresholds and the implication for the patient in terms of mortality and morbidity. This guideline has therefore not used these terms but rather addressed the thresholds, indicating where patient choice may be pivotal.

\section{Guideline development}

The scope of the guideline was determined by the GDC and based on the previous guideline and consultation with both societies and with input from members from associated specialities including radiology, anaesthesia and pathology. The topics covered by the scope are listed in appendix 1.The comprehensive search strategy (see appendix 2 in online supplement) found over 5500 references revealed that, since the publication of the 2001 guidelines, the evidence base for selection and management of patients suitable for radical treatment increased considerably. Evidence was graded according to the Scottish Intercollegiate Guidelines Network (SIGN) system (appendix 3). References are followed by the level of evidence in square brackets. Where it is not appropriate to apply SIGN levels, the brackets contain N/A (not applicable).

The aim of this updated guideline is to assist in raising standards of the delivery of radical treatments in the UK. The draft document was circulated to the membership of the BTS, the membership of the SCTS, and presented at BTS, SCTS and British Thoracic Oncology Group meetings. Comments were incorporated into the final draft from the Royal College of Physicians, the Association of Cancer Physicians, the Royal College of Anaesthesia and Royal College of Pathologists.

The guidelines will be reviewed 3 years from the date of publication.

\section{SECTION 1: SELECTION OF PATIENTS FOR RADICAL TREATMENT \\ 1.1 Diagnosis and staging}

The selection of patients for radical treatment requires an investigation pathway directed towards providing as much diagnostic and staging information as possible. This is particularly important in patients who are at risk of post-treatment complications and those where it is unclear if complete surgical resection or radical radiotherapy can be successfully delivered. However, in patients without a positive histological diagnosis and at low risk of complications, surgical treatment may be offered on a presumptive basis in patients following a limited number of essential tests. It is important that the logic underlying this approach is discussed with the patient and the consequences of resection of a benign lesion discussed. It is best practice for the diagnosis to be confirmed prior to definitive surgical resection. Treatment with radical radiotherapy or chemoradiotherapy usually requires a pretreatment diagnosis because no specimens are obtained as part of the treatment. Diagnostic samples will need to be sufficient to allow adequate classification of tumours, especially given the possibility of targeted treatment.

In this document, the 7th edition of the TNM classification of lung cancer ${ }^{5[\mathrm{~N} / \mathrm{A}]}$ is used throughout and applies to non-small cell lung cancer, small cell lung cancer ${ }^{6[\mathrm{~N} / \mathrm{A}]}$ and pulmonary neuroendocrine tumours. ${ }^{7 \mathrm{~N} / \mathrm{A}]}$ Almost all of the evidence upon which recommendations are made relates to the 6 th edition.

\subsubsection{Imaging}

Imaging plays an essential role in establishing an accurate diagnosis and stage for patients with lung cancer. The current pace of technological development is rapid and consequently the evidence for the effectiveness of the newer techniques such as multidetector CT, positron emission tomography (PET) and PET-CT is limited. Moreover, much of the evidence on cost effectiveness for lung cancer is derived from studies conducted outside the UK and so their applicability to the UK healthcare system is limited.

\section{Contemporaneous imaging}

All diagnostic images should be available to the multidisciplinary team to allow the evaluation of growth rate/malignant potential of a tumour. The absence of growth over 2 years suggests a benign lesion. ${ }^{8[2+]}$ When delays occur as a result of additional tests, imaging may need to be repeated, especially when initial imaging indicates a borderline lesion for resection (eg, T3/4). While there is no evidence for an acceptable interval, it is recommended as a minimum for patients with a T3/T4 tumour that a CT scan $<4$ weeks old is available at the time of radical treatment.

\section{Recommendations}

- View all available historical images at the onset of the diagnostic pathway and review them prior to treatment. [C]

- Ensure contemporaneous imaging is available at the time of radical treatment. [C]

- Ensure a CT scan that is $<4$ weeks old is available at the time of radical treatment of borderline lesions. [D]

\subsubsection{Plain radiography}

A plain x-ray (high quality posteroanterior image) is an essential tool for initial investigation of symptoms that might indicate lung cancer, but only has a minimal contribution to diagnosis and staging once it has been decided to proceed to CT. A routine lateral image is not required.

\subsubsection{Computed tomography (CT)}

CT is the initial imaging modality of choice for diagnosis and staging of suspected lung cancer, and serves as a tool for triage that determines the most appropriate further investigation. ${ }^{9[1+]}$ CT also provides information on coexistent disease such as emphysema, pulmonary embolism, cardiac and vascular disease.

Multidector CT (MDCT) with administration of intravenous contrast medium (in the absence of contraindications) provides rapid coverage of the chest and upper abdomen, and multiplanar image reconstruction may be helpful in demonstrating tumour anatomy, location and volume for staging. ${ }^{10[2+]}$ The extent of CT coverage should include the lower neck (defined as the level of the vocal cords) for the detection of supraclavicular nodal 
metastases. If there are lower abdominal symptoms or signs or a previous history of abdominal malignancy, the pelvis should also be imaged. CT usually gives accurate measurement of T stage, except where there is doubt about mediastinal invasion (table 1). There is little published evidence on the accuracy of MDCT, but this is likely to be superior to axial CT imaging in view of its multiplanar capability. However, if there is equivocal evidence of T4 invasion, CT should not be relied upon to rule this out and further evaluation is necessary.

The size and site of enlarged nodes at CT scanning should be reported in accordance with the International Association for the Study of Lung Cancer (IASLC) nodal map. ${ }^{22[\mathrm{~N} / \mathrm{A}]}$ In addition, CT may be able to detect features of nodal involvement such as a rounded heterogeneous appearance with central necrosis.

A maximal short axis diameter in the transverse plane of $>10 \mathrm{~mm}$ is widely regarded as the cut-off point to indicate abnormal enlargement. However, it is recognised that lymph node enlargement can occur as a reaction to tumour, distal atelectasis/pneumonia or associated pulmonary disease, and that microscopic tumour involvement may be found in normal sized nodes (table 1).

Therefore, unless there is clear involvement of the mediastinal lymph nodes by tumour extension, further evaluation of mediastinal lymph node involvement should be undertaken by PET-CT or mediastinal sampling.

CT may identify sites of metastatic disease but, if there is any doubt, further evaluation is required before excluding patients from radical treatment.

\section{Recommendations}

- Arrange a CT scan of the chest, lower neck and upper abdomen with intravenous contrast medium administration early in the diagnostic pathway for all patients with suspected lung cancer potentially suitable for radical treatment. [C]

- Avoid relying on a CT scan of the chest as the sole investigation to stage the mediastinal lymph nodes. [B]

\subsubsection{Positron emission tomography (PET) and PET-CT}

PET is most commonly performed using $\left[{ }^{18} \mathrm{~F}\right]$-2-fluoro-deoxy-Dglucose (FDG) as a tracer to provide a measure of glucose uptake. Although much of the literature is based on older PET technology, a number of small studies indicate that PET-CT is equal or superior to PET alone. ${ }^{11[2-], 12[3], 13[2-], 23[2+]}$ Limitations of the technique are well recognised. False negative scans may result from disease with low metabolic activity or FDG uptake (carcinoid, bronchioloalveolar cell carcinoma), misregistration due to breathing artefact, uncontrolled diabetes and small lesion size $(<8 \mathrm{~mm}$ ), and false positive uptake may be seen in inflammatory conditions. Nevertheless, PET now has an established role in the evaluation of patients for radical treatment.

PET-CT is valuable in assigning a $\mathrm{T}$ stage and also for radiotherapy planning (table 1). However, in proximal tumours both CT and PET techniques may have difficulty differentiating the primary tumour from contiguous lymphadenopathy.

PET is more accurate than CT in assessing lymph node status (table 1). False negative results can occur either due to small volume disease or low metabolic activity. Sampling of enlarged PET-CT negative nodes is generally advocated, particularly when the primary tumour uptake is intermediate (see section on N2 disease). False positive results can occur due to inflammation, especially if there is associated coexistent disease such as consolidation distal to the tumour.

PET-CT misses very few occult macroscopic metastases except in the brain (table 1). False positives do occur and patients should not be denied radical treatment on the basis of occult metastatic disease on PET-CT alone (especially if it is isolated). Confirmation by biopsy or further imaging is required. By inference, from the fact that around $20 \%$ of patients go on to develop distant metastases despite complete resection of the primary tumour, PET-CT does miss micrometastases. However, there are no other reliable methods to detect these.

Prognostic information. Several studies have shown that tumours with an increased metabolic activity measured by maximal standardised uptake value ( $\left.\mathrm{SUV}_{\max }\right)$ have a worse prognosis. ${ }^{24[2++]}$ Based on limited available evidence, $\mathrm{SUV}_{\max }$ should be reported but not influence the decision to offer radical treatment. When assessing the mediastinal lymph nodes after induction treatment for patients with stage IIIA non-small cell lung cancer, a negative PET is less reliable than a pretreatment scan but may be more reliable than repeat mediastinoscopy. ${ }^{25[2-]}$

Radiotherapy planning. Evidence to support the use of PETor PET-CT prior to radical radiotherapy is limited. In a report evaluating

Table 1 Role of commonly used imaging modalities in the diagnosis and staging of patients suitable for radical treatment

\begin{tabular}{|c|c|c|c|c|c|}
\hline $\begin{array}{l}\text { Imaging } \\
\text { modality }\end{array}$ & Diagnosis & T stage & N stage & M stage & Comment \\
\hline Chest x-ray & $\begin{array}{l}\text { Often included as part of initial } \\
\text { investigation in primary care } \\
\text { and useful to differentiate } \\
\text { benign from malignant disease }\end{array}$ & $\begin{array}{l}\text { Limited information compared } \\
\text { with MDCT }\end{array}$ & Provides little information & $\begin{array}{l}\text { Obvious metastases may be } \\
\text { visible (eg, lung or rib) }\end{array}$ & $\begin{array}{l}\text { Now sometimes omitted from } \\
\text { investigation pathway if other } \\
\text { presenting factors suggest } \\
\text { cancer* }\end{array}$ \\
\hline MDCT & $\begin{array}{l}\text { Often helpful to differentiate } \\
\text { benign from malignant disease }\end{array}$ & $\begin{array}{l}\text { Able to measure tumour size } \\
\text { accurately. Less reliable for } \\
\text { distinguishing T3 from T4; } 55 \% \\
\text { sensitivity, } 89 \% \text { specificity } \\
\text { (axial CT) }\end{array}$ & 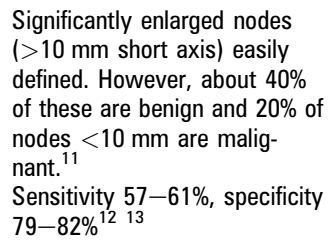 & $\begin{array}{l}\text { May show clear evidence of } \\
\text { mediastinal invasion or } \\
\text { metastatic disease but } \\
\text { histological confirmation or } \\
\text { further staging required if any } \\
\text { doubt }\end{array}$ & $\begin{array}{l}\text { Provides excellent triage of } \\
\text { patients by identifying clear } \\
\text { evidence of cancer, no } \\
\text { evidence of cancer } \pm \text { other } \\
\text { diagnoses or uncertainty. } \\
\text { Guides the next test. May } \\
\text { detect other significant } \\
\text { coexistent disease }\end{array}$ \\
\hline PET-CT & $\begin{array}{l}\text { Not currently performed for } \\
\text { initial diagnostic purposes }\end{array}$ & $\begin{array}{l}\text { Complements MDCT and can } \\
\text { help estimate tumour extent } \\
\text { where tumour abuts abnormal } \\
\text { tissue (eg, lobar collapse) }\end{array}$ & $\begin{array}{l}\text { More accurate than CT. } \\
\text { Sensitivity } 84 \% \text {, specificity } \\
89 \% \text {. Further mediastinal } \\
\text { sampling deemed unnecessary } \\
\text { if PET negative and nodes } \\
<1 \mathrm{~cm} . \dagger 10 \% \text { will have occult } \\
\text { disease }{ }^{12}\end{array}$ & $\begin{array}{l}\text { Sensitivity and specificity to } \\
\text { detect distant metastases } 93 \% \\
\text { and } 96 \% \text {, respectively. May } \\
\text { detect metastases in up to } \\
15 \% \text {. Sensitivity for brain } \\
\text { metastases only } 60 \%^{17-21}\end{array}$ & $\begin{array}{l}\text { Also useful in radiotherapy } \\
\text { planning and may have a role in } \\
\text { predicting outcome }\end{array}$ \\
\hline
\end{tabular}


the economic impact of PET for radiotherapy planning, it was noted that the use of PET resulted in 32\% fewer courses of futile radical radiotherapy. ${ }^{26[\mathrm{~N} / \mathrm{A}]} \mathrm{PET}-\mathrm{CT}$ has also been shown to modify potential fields in radiotherapy planning, ${ }^{14[3], 15[2-], 16[2+]}$ although there are few outcome data to confirm that this is effective.

\section{Recommendations}

- Ensure PET-CT is available for all patients being considered for radical treatment. [B]

- Offer radical treatment without further mediastinal lymph node sampling if there is no significant uptake in normal sized mediastinal lymph nodes on PET-CT scanning. [C]

- Evaluate PET positive mediastinal nodes by further mediastinal sampling. [C]

- Confirm the presence of isolated distant metastases/synchronous tumours by biopsy or further imaging in patients being considered for radical treatment. [C]

\subsubsection{Other imaging techniques}

Further imaging and sampling may be required to clarify the tumour stage when more extensive disease is suspected from clinical features or initial investigations.

While CT is a sensitive method for detecting fluid in the pleura and pericardium, not all effusions are malignant so pathological confirmation by aspiration is required before excluding patients from radical treatment. Pleural enhancement is always abnormal and, although CT features of malignant pleural disease (such as circumferential pleural thickening, nodular thickening, parietal pleural thickening $>1 \mathrm{~cm}$ and mediastinal pleural involvement) have limited sensitivity, they are highly specific for malignancy. ${ }^{17[3]}$ Table 2 lists the common uses for further imaging and tissue sampling.

Ultrasound-guided fine needle aspiration has a good diagnostic yield and is a relatively safe method to screen for cervical lymph node metastases identified on CT scanning.

\subsubsection{Evaluation of distant metastases}

Brain. The yield of CT or MRI of the brain in patients without clinical features of intracranial disease is $<10 \%{ }^{19[3], 20[3], 21[2-], 27[3], 28[3], 29[2+], 30[3]}$ and the cost effectiveness of this approach is uncertain. ${ }^{31[3]}$ Most of the evidence on image-detected brain metastases relates to the era before PET. It is likely that the high sensitivity of PET in detecting metastases at sites elsewhere in the body will further reduce the yield of brain imaging.

MRI of the brain detects more and smaller lesions than $\mathrm{CT}^{32[2+], 33[2-]}$ The prevalence of cerebral metastases may be influenced by both stage and cell type. In patients with clinical features suggestive of intracranial pathology, CT may be the preferred first test because it is generally more easily accessed

Table 2 Utility of commonly used imaging modalities

\begin{tabular}{ll}
\hline Imaging modality & Scenario where radical treatment is considered \\
\hline MRI & $\begin{array}{l}\text { To evaluate indeterminate lesions of the bone, adrenal } \\
\text { glands and liver }\end{array}$ \\
& $\begin{array}{l}\text { To evaluate superior sulcus tumours: superior to axial CT, } \\
\text { complementary }{ }^{18[3]} \text { to MDCT } \\
\text { To evaluate tumours in close proximity to spinal cord }\end{array}$ \\
Ultrasound & $\begin{array}{l}\text { For image-guided sampling of cervical lymph nodes, pleural } \\
\text { disease, pleural effusion and metastatic deposits (eg, liver) }\end{array}$ \\
Bone scintigraphy & $\begin{array}{l}\text { To screen for bone metastases when there is clinical or } \\
\text { biochemical evidence of bone metastases (PET may be } \\
\text { avoided in the early diagnostic pathway) }\end{array}$ \\
\hline
\end{tabular}

MDCT, multidetector computed tomography; PET, positron emission tomography. than MRI. However, a normal CT scan of the head should always be followed by an MRI owing to the better sensitivity of MRI.

The use of routine MRI in staging patients with negative clinical evaluation findings has not been adequately studied. In the post-PET era it may be prudent to consider cerebral imaging, using contrast-enhanced MRI or CT if contraindicated, in patients with stage III non-small cell lung cancer.

\section{Recommendations}

- Consider MRI or CT scanning of the head in patients selected for radical treatment, especially in stage III disease. [C]

- Evaluate patients with features suggestive of intracranial pathology by an initial CT scan of the head followed by MRI if normal or MRI as an initial test. [C]

Adrenal glands. Adrenal lesions are commonly found on CT scans and many of these are benign. The likelihood of malignancy increases with primary tumour stage and adrenal lesion size. $^{34[3]}$ PET is currently the most common method to distinguish between benign and malignant adrenal lesions with a sensitivity of $94-100 \%$ and specificity of 80-100\%. ${ }^{35[2+], 36[2-], 37[2-], 38[3], 39[2-], 40[2-]}$ Blake et al reported a sensitivity and specificity of $100 \%$ and $93.8 \%$ for PET-CT, and this can be combined with contrast-enhanced CT to improve the specificity to $100 \%{ }^{41[2-]}$ However, this impressive performance may not be repeated in all centres and benign entities (eg, lipid-poor adenomas) may show increased uptake on PET and may be indeterminate on standard CT. In this setting, a biopsy is required to confirm the presence of metastatic disease. Other imaging options include in and out of phase $\mathrm{MRI}^{42[2+]}$ non-contrast ${ }^{43[3]}$ and washout $\mathrm{CT}^{44[2+]}$ Biopsy specimens may be obtained by percutaneous techniques, ${ }^{45[3]}$ endoscopic ultrasound or laparoscopy.

Liver. Indeterminate lesions in the liver identified on CT may mimic metastases, but most are benign cysts. Ultrasound, dynamic contrast-enhanced MRI or percutaneous biopsy may be performed for further evaluation.

Bones. PET is more sensitive in detecting bone metastases than conventional bone scintigraphy, ${ }^{46[2-]}$ and PET-CT is likely to be superior. The role of bone scintigraphy is limited to those with a high clinical suspicion of metastatic disease as a positive result will effectively exclude a patient from further radical treatment.

\section{Recommendation}

- Biopsy adrenal lesions that show abnormal uptake on PET-CT scanning before radical treatment. [D]

\subsubsection{Small cell lung cancer}

In early stage small cell lung cancer where radical treatment is contemplated, a number of studies indicate that PET, $47[3], 48[2-]$, $49[3], 50[2+], 51[3], 52[3]$ CT scan of the head ${ }^{53[3], 54[3], 55[2+], 56[2-]}$ and contrast-enhanced MRI of the brain ${ }^{57[3]}$ may pick up occult disease. However, most patients still undergo chemotherapy and radiotherapy as planned, and the role of PET-CT in these circumstances is not defined. These screening investigations should therefore be reserved for the small group of patients who present with early stage disease in whom radical management is contemplated and if the results of detection of occult disease would alter the management.

\section{Research recommendation}

- The role of PET-CT scanning in patients with small cell lung cancer considered suitable for radical treatment should be evaluated in clinical trials. 
1.1.2 Endoscopic procedures for diagnosis and staging Type of sample in relation to treatment planning

Emerging data on differential responses to chemotherapy according to non-small cell carcinoma subtype have heightened the emphasis on the need to obtain tissue that gives enough information to plan the best treatment. It is important that diagnostic samples enable distinction between squamous cell and adenocarcinoma if active treatment is to be offered. This distinction may require more in-depth evaluation using immunohistochemistry. Furthermore, emerging prognostic and/or predictive tumour markers, measured by immunohistochemistry, in situ hybridisation and mutation analysis, may be needed to inform therapeutic decisions. These additional analyses require a sample of adequate size, yet the trend towards less invasive sampling techniques for diagnosis and staging means samples are often more limited. Improved laboratory techniques may go some way to mitigate the problems of small samples but cannot overcome all the inherent limitations. These limitations need to be considered in the context of planned treatment and safety and there needs to be involvement of the histopathologist in the design of the diagnostic pathway.

\section{Recommendation}

- When obtaining diagnostic and staging samples, consider the adequacy of these in the context of selection of patients for targeted therapy. [D]

- Ensure biopsy samples are taken in adequate numbers and size where there is negligible additional risk to the patient. [D]

\subsubsection{Bronchoscopy}

Flexible bronchoscopy is a safe and effective diagnostic and staging investigation. As well as conventional biopsy, blind transbronchial needle aspiration (TBNA) can be performed to sample mediastinal lymph nodes. With central tumours, direct invasion and tumour relations to the main bronchus and trachea can be assessed and the information used to guide the extent of surgical resection required for complete clearance. Such information should be documented.

\subsubsection{Blind transbronchial needle aspiration, endobronchial ultrasound transbronchial needle spiration and endoscopic ultrasound}

Blind TBNA, endobronchial ultrasound (EBUS) TBNA and endoscopic ultrasound (EUS) are extensions of endoscopic techniques and are currently used for assessment and staging.

Blind TBNA is an inexpensive way to screen for metastases in enlarged lymph nodes at stations 2, 4 and 7 . This technique is guided by CT images and, although studies report a sensitivity of $60-70 \%$ for a simple diagnosis of malignancy, the results are operator-dependent. ${ }^{58[2+]}$

EBUS can sample lymph node stations $2,3,4,7$, hilar station 10 and lobar station 11. EUS can sample lymph node stations $4 \mathrm{~L}, 7,8,9$, the left adrenal gland and the left lobe of the liver. Neither EBUS nor EUS are generally able to access the para-aortic station 6 or aortopulmonary station 5 .

For EBUS TBNA, systematic reviews now report sensitivity and specificity for staging the mediastinal lymph nodes as $88-93 \%$ and $100 \%$, respectively. ${ }^{59[2++], 60[1+]}$ These results come from expert groups, and it is therefore important to consider if the local test performance is equivalent. If so, these procedures can be considered as alternatives to mediastinoscopy and lymph node biopsy. Mediastinoscopy is still performed to confirm negative results obtained by endoscopic biopsies, although this has to be balanced against the intended treatment (patients for radical radiotherapy may not be fit for general anaesthetic) and the local performance of EBUS or EUS.

\section{Recommendations}

- Use TBNA and EBUS/EUS-guided TBNA as an initial diagnostic and staging procedure according to findings on CT or PET-CT scans. [C]

- Consider EBUS/EUS-guided TBNA to stage the mediastinum. [C]

- Confirm negative results obtained by TBNA and EBUS/ EUS-guided TBNA by mediastinoscopy and lymph node biopsy where clinically appropriate. [C]

\subsubsection{Narrow band imaging and autofluorescence imaging}

Autofluorescence bronchoscopy and narrow band imaging can detect early and preinvasive lesions. This may prove to be important when considering radical treatment of early endobronchial lesions with techniques such as endobronchial brachytherapy, cryotherapy and photodynamic therapy. The results of randomised trials are awaited.

\section{Research recommendation}

- The use of narrow band and autofluorescence imaging should be investigated in clinical trials.

\subsubsection{Mediastinoscopy and mediastinotomy}

Mediastinoscopy is the current gold standard procedure for staging the mediastinum prior to thoracotomy and systematic nodal dissection. The indications for cervical mediastinoscopy have evolved with the increasing availability of PET, EBUS, EUS and broader selection criteria for surgery. With a sensitivity of $85 \%$ for PET imaging, many consider that confirmatory mediastinoscopy and lymph node biopsies are not required following a 'negative' PET. Microscopic N2 disease may have a better prognosis, but this will only be confirmed if appropriate lymph node sampling is performed. Although the specificity of PET is high, minimally invasive sampling followed by mediastinoscopy is indicated to screen for false positive results in order not to deny the small proportion of patients the potential of radical treatment. As broader selection criteria are in place, the clinical utility of pretreatment lymph node staging has evolved to assess the location and number of lymph stations that are involved rather than the presence or absence of mediastinal lymph node metastases.

\subsubsection{Video-assisted thoracoscopic assessment}

Video-assisted thoracoscopic assessment can be used as a diagnostic and staging modality. Biopsies may be obtained from the tumour mass, direct ascertainment of tumour invasion into the central mediastinal structures can be performed and access can be obtained to the hilar, aortopulmonary window, paraoesophageal and inferior pulmonary ligament stations. With the increasing diagnostic accuracy of CT, PET, EBUS and EUS for staging, the requirement for video-assisted thoracoscopic assessment is becoming less common, although it remains the best assessment to determine if it is possible to completely resect a tumour prior to thoracotomy.

\subsubsection{Approach to mediastinal lymph node staging}

The purpose of preoperative mediastinal staging is to assist in the selection of patients for radical treatment. The often pivotal question is whether or not there is disease in N2 or N3 stations. Disease in N1 nodes may change management according to the type of operation that can be performed in patients with borderline lung function. Most MDTs will agree that N3 disease precludes surgery, but radical treatment may still be possible. The MDT should decide whether or not the knowledge that 


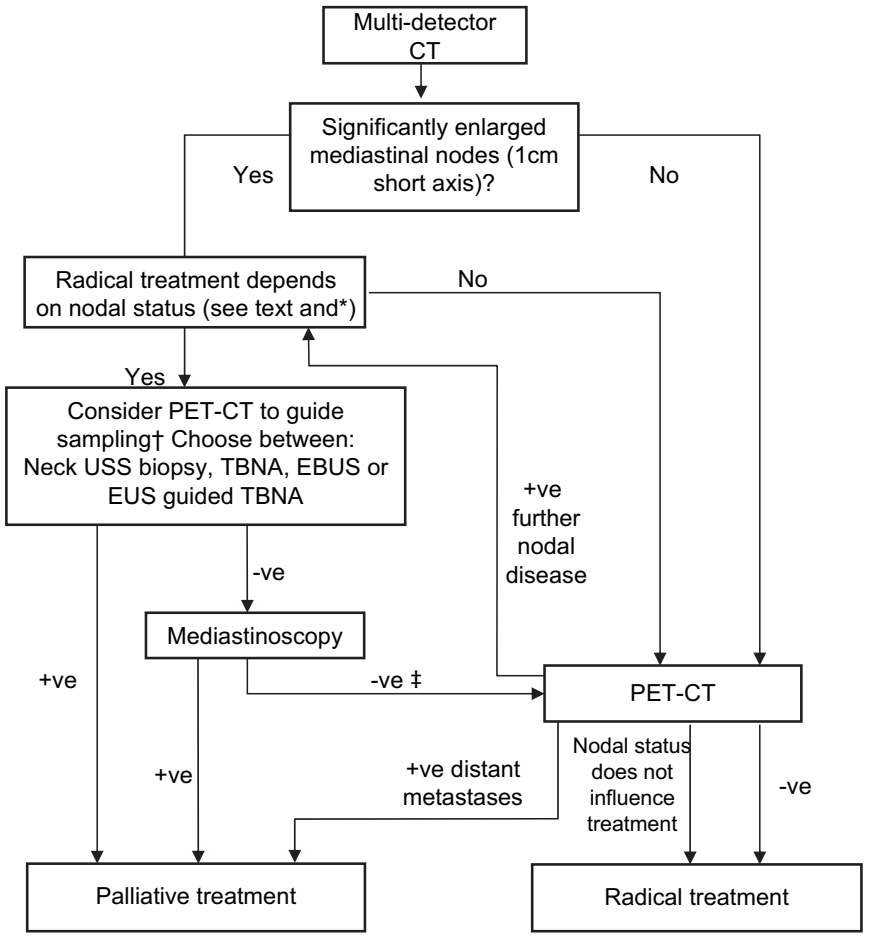

\begin{abstract}
* For example, if a positive node would preclude or modify radical treatment

+ MDTs may choose to clarify if certain stations are FDG avid prior to sampling

¥ Further PET-CT not required if done as part of earlier investigation
\end{abstract}

Figure 1 Investigation pathway for mediastinal diagnosis and staging. EBUS, endobronchial ultrasound; EUS, endoscopic ultrasound; FDG, $\left[{ }^{18} \mathrm{~F}\right]$-2-fluoro-deoxy-D-glucose; MDT, multidisciplinary team; PET, positron emission tomography; TBNA, transbronchial needle aspiration.

a suspicious N3 node would alter the treatment offered and only proceed with staging if management would be altered. The management of $\mathrm{N} 2$ disease is more controversial and some MDTs may consider that radical treatment, including surgery, should be offered, particularly for single station disease (see section 1.2.3). Figure 1 shows the suggested approach to mediastinal staging. This diagram has been simplified to reflect the considerable variation in the sequence of tests based on initial appearances on the CT scan, the approach of the MDT where treatment options are debatable and on the preferences of the patient.

\subsubsection{Seventh edition of TNM for lung tumours}

A full description of the 7th edition of the TNM classification of lung cancer can be obtained from the 2009 editions of the IASLC Staging Handbook ${ }^{61[\mathrm{~N} / \mathrm{A}]}$ and Staging Manual in Thoracic Oncology. ${ }^{6[\mathrm{~N} / \mathrm{A}]}$ Appendix 4 shows a comparison with the 6 th edition of the TNM staging and the new surgical stage groupings.

No changes have been made in nodal staging in the 7th edition, however the differences between the M D Anderson/ ATS and the Naruke lymph node maps have been acknowledged and a unified IASLC lymph node staging map introduced. ${ }^{22[\mathrm{~N} / \mathrm{A}]} 61$

It was reported that patients with single zone N2 disease had a similar survival to patients with multiple-zone N1 disease, ${ }^{63[\mathrm{~N} / \mathrm{A}]}$ questioning the practice of blanket exclusion of patients with N2 disease for surgical resection.

\section{Recommendations}

- The 7th edition of the TNM classification of lung cancer should be used for staging patients with lung cancer. [B]
- The IASLC international nodal map should be used in the assessment and staging of lymph node disease. [C]

\subsection{Management of specific disease subsets}

There have been no randomised trials comparing the outcome of surgery compared with no intervention. ${ }^{64[1-]}$ Indirect evidence from the Early Lung Cancer Action Project (ELCAP), a large screening study for lung cancer, reported that all eight patients with screen-detected stage I lung cancer who did not have surgery died within 5 years while $92 \%$ of those who received surgical treatment survived 5 years. ${ }^{65[2+]}$ One trial published in 1963 that compared surgery with radiotherapy for lung cancer showed better survival in patients randomised to surgery ${ }^{66[1-]}$ in early stage ( $11 \mathrm{a}-3 \mathrm{~N} 0-1 \mathrm{M} 0)$ lung cancer.

Based largely on retrospective and observational studies, radical management (surgery or radiotherapy in those who have an unacceptable surgical risk) is the accepted standard. The remainder of this section focuses on specific disease subgroups.

\subsubsection{T3 disease}

A T3 designation is assigned to tumours $>7 \mathrm{~cm}$ in diameter or by virtue of local invasion or for separate nodules within the same lobe of the primary tumour. ${ }^{5[\mathrm{~N} / \mathrm{A}]}$ Acceptable results after radical treatment have been reported in those patients with involvement of the chest wall ${ }^{67[3], 68[3], 69[3]}$ or with separate nodules within the same lobe. ${ }^{70[2+], 71[3]}$

\section{Recommendation}

- Offer patients with T3N0-1M0 disease radical treatment. [D]

\subsubsection{T4 disease}

T4 designation is assigned to any tumour with invasion of the mediastinum, heart, great vessels, trachea, recurrent laryngeal nerve, oesophagus, vertebral body, carina and for separate tumours in a different ipsilateral lobe. In the specific case of patients with separate tumours in a different ipsilateral lobe, the good survival in patients undergoing surgical resection ${ }^{70[2+], 71[3]}$ led to downstaging of this subgroup in the 7th edition of TNM for lung tumours.

The majority in this subgroup with central mediastinal invasion have disease that is not amenable to surgery. However, centres with a specific interest and expertise in resection of locally advanced tumours invading into structures such as the spine, ${ }^{72[3], 73[3]}$ carina, ${ }^{74[3], 75[3]}$ heart and great vessels ${ }^{76[3]}$ report technical feasibility and acceptable mid-term results, usually in the absence of N2 or M1 disease. An initial safety and feasibility study in patients with stage IIIA/IIIB disease undergoing induction chemoradiotherapy and surgery as part of multimodality management ${ }^{77[2-]}$ has led to a phase II clinical trial reporting favourable survival in patients with T1-4N3M0 and T4N0-3M0 disease when compared with a historical cohort. $^{78[2-]}$ While the results of the study are not conclusive for better outcomes, they highlight what can be achieved with appropriate case selection and multidisciplinary management.

\section{Recommendations}

- Consider selected patients with T4N0-1M0 disease for radical multimodality treatment. [D]

\section{Research recommendation}

- Consider clinical trials of radical treatment for T4 disease.

\subsubsection{N2 disease}

N2 disease describes any metastatic involvement of ipsilateral or subcarinal mediastinal nodes. This term encompasses 
a spectrum of disease from micrometastatic disease in one node to extranodal extension from malignant disease in several lymph node stations. The management of N2 disease should therefore be considered separately for each subgroup with different prognoses.

The IASLC Lung Cancer Staging Project identified that overall disease burden (in the lymph nodes) had more influence on prognosis than anatomical site of lymph node involvement, ${ }^{63[\mathrm{~N} / \mathrm{A}]}$ hence nodal stations are now consolidated into lymph node zones. ${ }^{2[\mathrm{~N} / \mathrm{A}]}$ The prognosis of single zone $\mathrm{N} 2$ disease (N2a) was better than multi-zone N2 (N2b) disease with post-resection 5 -year survivals of $34 \%$ and $20 \%$, respectively $(\mathrm{p}<0.001){ }^{63[\mathrm{~N} / \mathrm{A}]}$

The diagnostic and staging pathway in patients with N2 disease should be directed by the intended treatment. When radical treatment is not possible, histological confirmation of N2 disease is not required. When radical treatment is intended, investigations should proceed as described (section 1.1.2) with mediastinoscopy as the final gold standard to confirm the presence and location of N2 disease (in as many mediastinal stations as possible). Ideally, mediastinal lymph node staging in patients considered for radical radiotherapy should be as rigorous as that carried out in patients considered for surgery. This may, however, be difficult as these former patients tend to have more comorbidity.

\section{Occult N2 disease}

Occult N2 disease is found during or after resection. If preoperative PET-CT and/or mediastinoscopy have excluded N2 disease and positive N2 nodes are found at operation, the lymph nodes should be resected with the primary tumour and adjuvant chemotherapy offered. ${ }^{79[1++]}$ There is currently no evidence for adjuvant chemoradiotherapy.

\section{Single zone N2 disease}

Resection may be considered in patients with single zone N2 disease as survival is similar to patients with multi-zone N1b disease. $^{63[\mathrm{~N} / \mathrm{A}]}$ There may also be a role for surgery when the tumour volume or the primary tumour plus nodal disease cannot be encompassed in a radical radiotherapy field. Surgery followed by chemotherapy in this setting may be an alternative to palliative treatment, although there is no direct evidence for this approach.

\section{Multi-zone disease}

Patients with bulky or fixed N2 disease are not considered for surgery and are treated by combinations of chemotherapy, radical radiotherapy or concurrent chemoradiotherapy.

For patients with non-fixed non-bulky multi-zone N2 disease, the results of a number of studies exploring induction treatment have been published with similar survival in patients randomised to surgery and chemotherapy or radiotherapy and chemotherapy. ${ }^{80[1-], 81[1-]}$ In a study of 579 patients in whom induction chemotherapy was administered, responders were randomised to surgery or radiotherapy and similar survival was reported between the two treatment modalities. ${ }^{82[1+]}$ A more recent study of induction chemoradiotherapy followed by surgical resection or radiotherapy in 396 patients, however, reported improved progression-free survival in patients randomised to surgery. $^{83[1+]}$

Results and outcomes based on response to induction treatment are less clear. The results from a meta-analysis indicate a survival advantage with surgical resection in patients downstaged to $\mathrm{N} 0 .^{84[1+]}$ However, it is the relative difference in survival in patients who have not been downstaged that is more important in the clinical decision. Albain et al ${ }^{85[1+]}$ showed that, in patients who underwent surgery, the 5-year survival was $41 \%$ for $\mathrm{N} 0$ disease, $24 \%$ for $\mathrm{N} 1-3$ disease and $8 \%$ for those who did not undergo surgery (for whatever reason).

From the available evidence, no management regimen has consistently proved superior. The GDC recognised that some patients with multi-zone N2 disease, having been fully appraised of the evidence, may wish to undergo surgery as part of multimodality management. The majority of the GDC felt that this option should be within the context of further randomised trials.

\section{Recommendations}

- Consider radical radiotherapy or chemoradiotherapy in patients with T1-4N2 (bulky or fixed) M0 disease. [B]

- Consider surgery as part of multimodality management in patients with T1-3N2 (non-fixed, non-bulky, single zone) M0 disease. [B]

\section{Research recommendation}

- Consider further randomised trials of surgery added to multimodality management in patients with multi-zone N2 disease to establish if any subgroups of patients might benefit more from the addition of surgery.

\subsubsection{N3 disease}

N3 disease describes any metastatic involvement of contralateral mediastinal or hilar nodes or any scalene or supraclavicular nodes. Based on limited available evidence in support of radical management, the standard treatment in this group of patients is chemotherapy and/or radiotherapy. Feasibility studies have recently reported favourable outcomes with induction regimens, with impressive 5 -year survival results ranging from $40 \%$ to $52 \%$. $^{78[2-], 86[2-], 87[1-]}$

\section{Research recommendation}

- Consider clinical trials of radical treatment for patients with $\mathrm{T} 1-4 \mathrm{~N} 3 \mathrm{M} 0$ disease.

\subsubsection{M1 disease}

M1a designation is assigned to the presence of distant metastases by virtue of a separate tumour nodule in the contralateral lung, tumour with pleural nodules or malignant pericardial or pleural effusion. The results of surgery for multifocal lung cancer are discussed in section 1.2.6. The management of patients with positive cytology of pleural or pericardial effusion is palliative.

M1b designation is assigned to distant metastases, and management of this subset is palliative. It is important to note that the survival of patients with pathological stage IV disease is higher than patients with IIIB disease in the seventh edition of the TNM classification of lung tumours. ${ }^{5[\mathrm{~N} / \mathrm{A}]}$ This phenomenon may be explained by the selection of specific subgroups who underwent surgical management.

\section{Research recommendation}

- Consider clinical trials of radical treatment for patients with M1a and M1b disease.

\subsubsection{Bronchioloalveolar carcinoma}

Considerable interest has been generated in this tumour subtype of adenocarcinoma, particularly after its redefinition in $1999 .{ }^{88[\mathrm{~N} / \mathrm{A}]}$ Specifically, Noguchi et al reported 100\% 5-year survival ${ }^{89[2+]}$ in patients with this tumour subtype, underpinning the reclassification of bronchioloalveolar carcinoma (BAC) as essentially adenocarcinoma-in-situ. Since true BAC cannot be confidently diagnosed on anything other than a complete resection, allowing full lesion examination to rule out invasion in the tumour, a preoperative diagnosis of BAC is presumptive 
and based on appropriate radiology (pure localised 'ground glass' lesions) and, in some cases, consistent pathology. It is also worth noting that, if limited small biopsy samples are available, a mucinous BAC pattern adenocarcinoma carries a higher risk of being multifocal/more advanced than non-mucinous BAC. Numerous reports have been published, affirming excellent postoperative survival in patients, not only with pure true BAC as currently defined, but also in those with small peripheral tumours $^{90[2+], 91[3], 92[3], 93[3]}$ in which a BAC component was prominent, and in resected multifocal BAC pattern disease. ${ }^{94[3]}$

Based on these reports, opinions are emerging to suggest that that this tumour subtype has a better than expected prognosis by current staging classification, and lesser (sublobar resections) forms of management ${ }^{95[3]}$ may be acceptable for multifocal disease. ${ }^{96[3]}$ It is important to recognise that good results are not uniform ${ }^{97[2-]}$ and are critically dependent on accurate contemporaneous classification and reporting. ${ }^{93[3]}$ It must also be realised that older reports on BAC will not refer to tumours as currently defined.

It is worth noting that a joint IASLC/ATS/ERS working group has proposed a significant change to the nomenclature and classification of adenocarcinoma. This proposal was driven by the historical multiplicity of different meanings for the term BAC which has caused considerable confusion. The recommendations include dropping the term BAC, as currently defined, in favour of adenocarcinoma-in-situ, referring to the BAC pattern of adenocarcinoma in all other instances as 'lepidic growth' and introducing a category of minimally invasive adenocarcinoma. At the time of writing is seems highly likely that these proposals will be incorporated into the next WHO Lung Cancer classification.

\section{Recommendations}

- Offer suitable patients with single-site bronchioloalveolar carcinoma anatomical lung resection. [C]

- Consider multiple wedge resections in suitable patients with a limited number of sites of bronchioloalveolar carcinoma. [C]

\subsubsection{Open and close thoracotomy}

In the UK, open and close thoracotomy rates have been steadily declining from more than $20 \%$ in the early 1980 s to a national average of approximately $6 \%$ in $2005 .{ }^{98[\mathrm{~N} / \mathrm{A}]}$ This has been attributed to improvements in preoperative imaging and hence case selection. While the declining proportion represents an improvement, a reduction to $0 \%$ would imply extreme case selection, and patients who may be technically surgically resectable would be denied the opportunity for surgery, especially where there are difficulties in differentiating between T3 and T4 (section 1.1.1.2). The current national average is approximately $5 \%$.

\section{Recommendation}

- Surgical units should have an open and close thoracotomy rate of around $5 \%$. [D]

\section{SECTION 2: SURGERY}

\subsection{Assessment of the risks of surgery}

In this section a tripartite risk assessment model is presented that considers risks of operative mortality, risk of perioperative myocardial events and risk of postoperative dyspnoea (figure 2). Unlike previous guidelines, the recommendations facilitate the calculation and assessment of individual outcomes that may be discussed by the MDT and with the patient.

\subsubsection{Risk assessment for operative mortality}

The ability to estimate the risk of in-hospital death is one of the most important considerations for surgeons and patients when

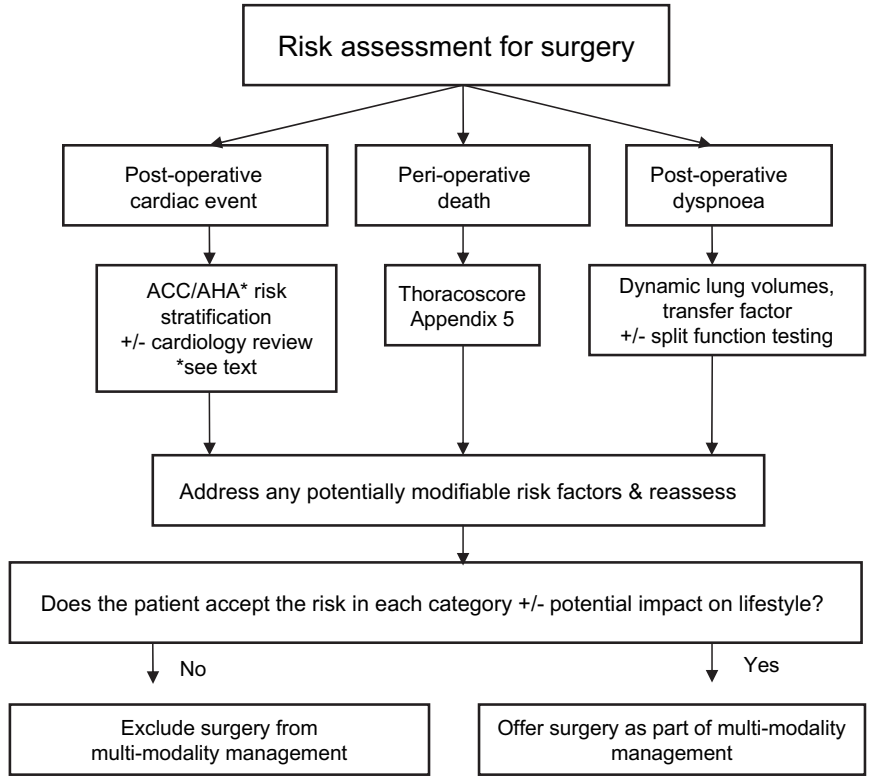

Figure 2 Tripartite risk assessment. ACC, American College of Cardiology; AHA, American Heart Association.

evaluating the option of surgery for lung cancer. In-hospital death after lobectomy for cancer in the UK was reported as $2.6 \%$ in $2003 .{ }^{99[2+]}$ The 30-day mortality for lobectomy and pneumonectomy in England from the National Lung Cancer Audit is $2.3 \%$ and $5.8 \%$. respectively.

An ideal model to estimate the risk of death would have a high degree of discrimination within the applied population, be simple to use and be reproducible. As the in-hospital mortality rates are low, large numbers (multi-institutional or multinational studies) would be required to develop these models. Risk stratification for death in thoracic surgery thus remains relatively rudimentary. While there is a large body of work on factors that influence death after thoracic surgery, most either explore only individual variables (not a global risk model), have composite outcomes (rather than death alone) or do not contain sufficiently large numbers to produce a robust model. Among the largest series are the European Society of Thoracic Surgeons (ESTS) risk model that had 3426 patients with 66 deaths ${ }^{100[2+]}$ and the Veterans Affairs model with 3516 patients with 184 deaths. ${ }^{101[2+]}$

Thoracoscore is currently the largest and most discriminating model, and was developed by the French Society of Thoracic and Cardiovascular Surgery on 15183 patients with 338 deaths with a corresponding c-index of 0.86 in the validation dataset. ${ }^{102[2+]}$ Apart from internal validation, it has also been validated in a North American cohort with a similar c-index of $0.84 .^{103[2+]}$ It is a logistic regression-derived model with nine variables (age, sex, American Society of Anesthesiologists (ASA) score, performance status, dyspnoea score, priority of surgery, extent of surgery, malignant diagnosis and a composite comorbidity score, see appendix 5). The performance of Thoracoscore exceeds that of the logistic EuroSCORE, ${ }^{104[2++]}$ a widely used model in cardiac surgery.

Although a number of studies report an association with increasing age and risk of hospital death and complications, ${ }^{102[2+]}$ age alone should not exclude a patient from surgery as good outcomes have been reported with appropriate case selection. ${ }^{105[2-]}$ A recent study has reported that elderly patients, while being aware of their lower health status preoperatively (they had poorer ECOG performance status and 
ASA scores compared with the younger subjects), had no significant differences in their quality of life at 3 months after surgery. ${ }^{106[2+]}$

\section{Recommendation}

- Consider using a global risk score such as Thoracoscore to estimate the risk of death when evaluating and consenting patients with lung cancer for surgery. [C]

\subsubsection{Risk assessment for cardiovascular morbidity Clinical assessment and risk stratification}

Myocardial infarction is a major cause of mortality after non-cardiac surgery. The risk of cardiac death or non-fatal myocardial infarction associated with lung resection is generally $1-5 \%$ and is ranked as intermediate risk by the revised 2007 American College of Cardiology and the American Heart Association (ACC/AHA) guidelines on cardiovascular evaluation before non-cardiac surgery. ${ }^{107[\mathrm{~N} / \mathrm{A}]}$ The current evidence base that guides clinical management of the specific thoracic surgical patient with coronary artery disease is limited.

The history (including assessment of functional status), physical examination and resting ECG are prerequisites for cardiac risk assessment as defined by the ACC/AHA in 2007. ${ }^{108[\mathrm{~N} / \mathrm{A}]}$ All patients with an audible murmur or unexplained dyspnoea should also have an echocardiogram. The first step in cardiac risk assessment is to identify patients with an active cardiac condition, as they all require evaluation by a cardiologist and correction before surgery (table 3 ).

In patients who do not have an active cardiac condition, risk assessment is performed using the revised cardiac index (table 4), a validated model with receiver operator characteristic (ROC) area under the curve (AUC) of 0.81. ${ }^{109[2++]}$

Patients with $\leq 2$ risk factors and good cardiac functional capacity (able to climb a flight of stairs without cardiac symptoms) can proceed to surgery without further investigations. Patients with poor cardiac functional capacity or with $\geq 3$ risk factors should have further investigations to screen for reversible cardiac ischaemia (eg, exercise stress testing, exercise thallium scan) and, if necessary, cardiology review prior to surgery.

\section{Recommendations}

- Use the American College of Cardiology guidelines 2007 as a basis for assessing perioperative cardiovascular risk. [C]

- Avoid lung resection within 30 days of myocardial infarction. [B]

- Seek a cardiology review in patients with an active cardiac condition or $\geq 3$ risk factors or poor cardiac functional capacity. [C]

- Offer surgery without further investigations to patients with $\leq 2$ risk factors and good cardiac functional capacity. [B]

\section{Optimising medical therapy}

Patients with coronary disease should have their medical therapy and secondary prophylaxis optimised well in advance of the surgery. Although the ACC/AHA 2007 recommendations advocate the use of perioperative $\beta$ blockers, the results from a meta-analysis of 33 trials failed to demonstrate any significant reduction in mortality or heart failure. ${ }^{110[1++]}$ The results indicated a decrease in non-fatal myocardial infarction and ischaemia at the expense of an increase in non-fatal strokes. However, precipitous withdrawal of ongoing $\beta$ blocker therapy is not recommended as this may be hazardous. ${ }^{111[3]}$ Further studies are required to guide the management of patients with coexisting coronary disease who are undergoing thoracic surgery.
Table 3 Active cardiac conditions

\begin{tabular}{ll}
\hline Condition & Examples \\
\hline $\begin{array}{l}\text { Unstable coronary } \\
\text { syndromes }\end{array}$ & $\begin{array}{l}\text { Unstable or severe angina-CCS class III or IV* } \\
\text { Recent MI† }\end{array}$ \\
$\begin{array}{l}\text { Decompensated heart } \\
\text { failure }\end{array}$ & $\begin{array}{l}\text { NYHA functional class IV } \\
\text { Worsening heart failure } \\
\text { New onset heart failure }\end{array}$ \\
Significant & $\begin{array}{l}\text { High-grade atrioventricular block } \\
\text { arrhythmias }\end{array}$ \\
& $\begin{array}{l}\text { Mobitz II atrioventricular block } \\
\text { Third degree atrioventricular heart block } \\
\end{array}$ \\
& $\begin{array}{l}\text { Symptomatic ventricular arrhythmias } \\
\text { Supraventricular arrhythmias including atrial fibrillation with } \\
\text { uncontrolled ventricular rate: HR }>100 \text { beats/min at rest }\end{array}$ \\
& Symptomatic bradycardia \\
& Newly recognised ventricular tachycardia
\end{tabular}

Severe heart valve Severe aortic stenosis: mean pressure gradient disease

$>40 \mathrm{~mm} \mathrm{Hg}$, aortic valve area $<1.0 \mathrm{~cm}^{2}$ or symptomatic Symptomatic mitral stenosis: progressive dyspnoea on exertion, exertional presyncope or heart failure

*May include 'stable' angina in patients who are unusually sedentary.

†The American College of Cardiology National Database Library defines recent $\mathrm{MI}$ as

$>7$ days but $\leq 1$ month within 30 days.

CCS, Canadian Cardiovascular Society grading for angina pectoris; HR, heart rate;

MI, myocardial infarction; NYHA, New York Heart Association.

\section{Recommendations}

- Begin optimisation of medical therapy and secondary prophylaxis for coronary disease as early in the patient pathway as possible. [C]

- Continue anti-ischaemic treatment in the perioperative period including aspirin, statins and $\beta$ blockade. [B]

\section{Revascularisation}

Thoracic surgery was found to be among the highest risk operation in patients identified with suspected coronary disease in the non-randomised CASS registry but, for patients who had undergone prior coronary bypass surgery, the risk of death and myocardial infarction was observed to be reduced from $5.8 \%$ and $1.9 \%$ to $2.4 \%$ and $1.2 \%$, respectively. ${ }^{112[2-]}$ Randomised studies in vascular surgery ${ }^{113[1-], 114[1-]}$ have not suggested improved outcomes in patients randomised to elective revascularisation prior to surgery and, as no such trials exist in thoracic surgery, it seems reasonable to extrapolate this indirect evidence in patients who otherwise do not have conventional indications for revascularisation. ${ }^{115}$

Preoperative percutaneous coronary intervention (PCI) is associated with a major risk of acute myocardial infarction and stent thrombosis. Should this be required prior to thoracic surgery, the use of balloon angioplasty alone or a bare metal

Table 4 Revised cardiac risk index

\begin{tabular}{ll}
\hline $\begin{array}{l}\text { Number } \\
\text { of factors }\end{array}$ & $\begin{array}{l}\text { Risk of major } \\
\text { cardiac complication* }\end{array}$ \\
\hline 0 & $0.4 \%$ \\
1 & $1 \%$ \\
2 & $7 \%$ \\
$\geq 3$ & $11 \%$ \\
\hline
\end{tabular}

Risk factors: high-risk type of surgery (includes all thoracic surgery), ischaemic heart disease, history of congestive cardiac failure, history of cerebrovascular disease, insulin therapy for diabetes, preoperative serum creatinine $>177 \mu \mathrm{mol} / \mathrm{l}$.

*Cardiac complications defined as myocardial infarction, pulmonary oedema, ventricular fibrillation or primary cardiac arrest, complete heart block. The risks have been quoted from the validation cohort. 
stent should be considered to avoid dual antiplatelet therapy (aspirin and clopidogrel) at the time of lung resection.

\section{Recommendations}

- Discuss management of patients with a coronary stent with a cardiologist to determine perioperative antiplatelet management. [C]

- Consider patients with chronic stable angina and conventional ACC/AHA indications for treatment (coronary artery bypass grafting and percutaneous coronary intervention) for revascularisation prior to thoracic surgery. [C]

\subsubsection{Assessment of lung function}

Evaluation of lung function is an important aspect of preoperative assessment to estimate the risk of operative mortality and impact of lung resection on quality of life, especially in relation to unacceptable post-resection dyspnoea (see section 2.2.1.1 for estimation of predicted postoperative lung function in relation to extent of resection).

A large number of studies have been published addressing the contribution of lung function to operative mortality risk, most citing an optimum cut-off of postoperative predicted forced expiratory volume in $1 \mathrm{~s}\left(\mathrm{FEV}_{1}\right)$ of $40 \%{ }^{116[2-]}$ However, many were conducted with sample sizes too small to provide any precision to ascertain the independent impact of $\mathrm{FEV}_{1}$ on in-hospital mortality. Results from over 15000 patients undergoing thoracic surgery in the French registry ${ }^{102[2+]}$ suggested $\mathrm{FEV}_{1}$ as a surrogate for performance status rather than an independent predictive factor for perioperative death (see section 2.1.1). This section focuses primarily on the utility of lung function as a predictor of postoperative dyspnoea.

\section{Dynamic lung volumes and transfer factor}

Both $\mathrm{FEV}_{1}$ and carbon monoxide transfer factor (TLCO) have been previously identified as important predictors of postoperative morbidity and death. ${ }^{117[2+], 118[2+]}$ Recent data revealed poor correlation (coefficient 0.38 ) between $\mathrm{FEV}_{1}$ and $\mathrm{TLCO}_{\mathrm{LC}}$, reflecting the fact that they measure very different aspects of lung function. ${ }^{119[2+]}$ It has been suggested that lung function tests alone overestimate the decrease in functional capacity after lung resection. ${ }^{120[2+]}$ Studies now suggest that transfer factor is an important predictor of postoperative morbidity despite normal spirometry. ${ }^{121[2+]}$ In light of this evidence, spirometry alone cannot be considered sufficient unless within normal limits in patients who also have good exercise tolerance. The GDC therefore chose to recommend the measurement of TLCO in all patients.

Previous guidelines advocated a stepwise approach in assessment of lung function prior to resection. $1[\mathrm{~N} / \mathrm{A}], 122[\mathrm{~N} / \mathrm{A}], 123[\mathrm{~N} / \mathrm{A}]$ The 2001 BTS guidelines were based on recommendations on a lower limit of postoperative predicted $\mathrm{FEV}_{1}$ of $40 \%$, but studies have since reported poor correlation between postoperative predicted $\mathrm{FEV}_{1}$ and TLCO with composite quality of life score. ${ }^{124[2+]}$ These data led the GDC to question the $40 \%$ lower limit. Currently there are few data that provide guidance on a lower limit of lung function which predicts an acceptable degree of postoperative dyspnoea and quality of life. A study of 253 consecutive patients using a lower cut-off point of postoperative predicted $\mathrm{FEV}_{1}$ and TLCO of $30 \%$ for the selection of patients undergoing lung resection reported an acceptable mortality rate of $4 \%$, and observed that actual postoperative $\mathrm{FEV}_{1}$ and TLCO are higher than predicted postoperative values achieved using the method of segment counting. ${ }^{119[2+]}$ However, this study did not specifically address the risk of unacceptable postoperative dyspnoea.
The risk of postoperative morbidity is a decision that has to be tailored to the expectations and wishes of the patient; lowering lung function thresholds allows more patients to undergo surgery but increases the risk of unacceptable postoperative dyspnoea and impaired quality of life. Any recommendations must therefore reflect the degree of risk rather than a firm cut-off.

\section{Recommendations}

- Measure lung carbon monoxide transfer factor (TLCO) in all patients regardless of spirometric values. [C]

- Offer surgical resection to patients with low risk of postoperative dyspnoea. [C]

- Offer surgical resection to patients at moderate to high risk of postoperative dyspnoea if they are aware of and accept the risks of dyspnoea and associated complications. [D]

\subsubsection{Split lung function testing}

Different techniques have been used to predict postoperative lung function including spirometry, quantitative ventilation and perfusion scintigraphy. $\left({ }^{120[2+], 125[3], 126[2-]}\right.$ In practice there are difficulties in interpreting the contribution of individual lobes to overall ventilation or perfusion and lack of additional information compared with segment counting alone for patients being considered for lobectomy. ${ }^{127[2-], 128[2-], 129[3], 130[2-]}$ There is also considerable uncertainty about the accuracy of quantitative perfusion to predict the postoperative $\mathrm{FEV}_{1}$ in patients undergoing pneumonectomy. ${ }^{127[2-], 129[3], 131[2-], 132[3], 133[3], 134[3], 135[3], 136[2+]}$ However, scintigraphy can be especially useful where an assessment has suggested that any further loss of lung function would be unacceptable if it is shown that no further (or minimal) lung function would be lost by operating. This applies where there may be compression of a pulmonary artery or marked emphysema in the lobe containing cancer.

Either ventilation ${ }^{136[2+]}$ or perfusion scintigraphy ${ }^{129[3], 133[3], 134[3]}$ can be used to predict postoperative lung function; there is no additional benefit in performing both. ${ }^{136[2+]}$ It is important to bear in mind that scintigraphy results may underestimate actual postoperative values. ${ }^{127[2-], 131[2-], 134[3]}$

Although quantitative CT scanning has been reported to be simpler and more accurate in the prediction of postoperative $\mathrm{FEV}_{1}$ in patients undergoing pulmonary resection, ${ }^{137[2-], 138[2-]}$ dynamic perfusion MRI currently has the best reported test performance compared with qualitative CT and perfusion SPECT and may be at least as accurate as quantitative $C T^{139[2+]}$

\section{Recommendations}

- Consider using ventilation scintigraphy or perfusion scintigraphy to predict postoperative lung function if a ventilation or perfusion mismatch is suspected. [C]

- Consider using quantitative CT or MRI to predict postoperative lung function if the facility is available. [C]

\subsubsection{Exercise testing}

To assist the prediction of surgical outcome, a range of cardiopulmonary exercise tests has been used. These include assessments of exercise capacity such as walk tests and stair climbing and formal measurements of cardiopulmonary function such as measurement of peak oxygen consumption $\left(\mathrm{VO}_{2} \mathrm{max}\right)$.

6 and 12 min walk tests. Good performance on the 6 min walk test and stair climbing have been associated with improving surgical outcomes ${ }^{140[3]}$ and have been reported to be similar predictors of mortality to formal exercise testing in patients with chronic obstructive pulmonary disease (COPD) $)^{141[2+]}$ and pulmonary hypertension. ${ }^{142[2+]}$

The distance walked in $12 \mathrm{~min}$ was reported to be a reliable approximation to formal oxygen consumption $\left(\mathrm{VO}_{2}\right)$ estimation 
in patients with COPD and more closely correlated than 6, 4 or 2 min walking tests. ${ }^{143[2+]}$ However, the distance achieved on the 12 min walk test has not been reported to be predictive of complications after lung resection. ${ }^{116[2-], 144[3]}$

Shuttle walk test. The shuttle walk test is the distance measured by walking a $10 \mathrm{~m}$ distance usually between two cones at a pace that is progressively increased. This test has good reproducibility and correlates well with formal cardiopulmonary exercising testing $\left(\mathrm{VO}_{2} \mathrm{max}\right) .{ }^{145[2-], 146[4]}$ Previous BTS recommendations that the inability to walk 25 shuttles classifies patients as high risk has not been reproduced by prospective study. ${ }^{147[2+]}$ Some authors report that shuttle walk distance may be useful to stratify low-risk groups (ability to walk $>400 \mathrm{~m}$ ) who would not need further formal cardiopulmonary exercise testing. ${ }^{148[2+]}$

Stair climbing. A number of authors have reported on the association between stair climbing and surgical outcomes. ${ }^{140[2-], 149[2-], 150[4] 151[2-], 152[2+]}$ However, the data are difficult to interpret as there is a lack of standardisation of the height of the stairs, the ceiling heights, different parameters used in the assessment (eg, oxygen saturations, extent of lung resection) and different outcomes.

Cardiopulmonary exercise testing. Formal cardiopulmonary exercise testing can be performed using treadmill (walking) or cycling and the

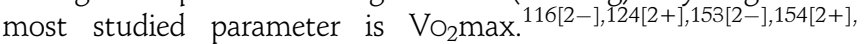
$155[2-], 156[2+], 157[2-], 158[2-], 159[2-], 160[3], 161[2-], 162[2-], 163[2-], 164[4]$,

$165[2-], 166[3], 167[2+], 168[2-]$ A complete review of the primary evidence was undertaken to define the role of cardiopulmonary exercise testing. Currently, there are no good data to inform on the discriminating value of $\mathrm{VO}_{2}$ max to predict the development of unacceptable postoperative dyspnoea.

Meta-analysis has confirmed the finding that lower levels of $\mathrm{VO}_{2}$ max are associated with increasing 'complications' after lung resection. ${ }^{169[2++]}$ However, numerous values have been used to define 'prohibitive risk' for lung surgery, and the studies are difficult to interpret owing to the widespread use of composite endpoints. When scrutinised, individual endpoints included lobar collapse, high levels of carbon dioxide tension $\left(\mathrm{PCO}_{2}\right)$, arrhythmia and readmission to ICU. It is doubtful that many patients would consider the risk of developing these complications as 'prohibitive' for surgical resection.

With sample sizes ranging from 8 to 160 patients ${ }^{169[2++]}$ and an average death rate of $2.6 \%$ for lobectomy, the discriminating cut-off points for $\mathrm{VO}_{2}$ max to predict death is likely to be poor and, without valid risk adjustment, it is not possible to estimate an independent contribution of $\mathrm{VO}_{2} \max$. The arbitrary use of cut-off values for defining patient groups with no adverse outcome carries a large degree of imprecision; for example, the $95 \%$ binomial CI of no adverse outcomes in a typical sample of 30 patients would be $0-13.6 \%$.

Perhaps the best conducted study was the Cancer and Leukemia Group B (CALBG) Protocol 9238 in which 403 patients were classified into low, high and very high risk groups. Of the 68 patients in the very high risk group $\left(\mathrm{Vo}_{2} \max <15 \mathrm{ml} /\right.$ $\mathrm{kg} / \mathrm{min}$ ), surgery was only undertaken at the 'physician's discretion' with an operative mortality rate of $4 \%$ and no difference in postoperative complication rate. A central message from this study was that, in patients in the very high risk subgroup who underwent lung resection, the median survival was 36 months compared with 15.8 months for those in the same risk group who did not undergo surgical resection $(p<0.001) .{ }^{170[2+]}$ The evidence for cardiopulmonary exercise testing providing a useful definition of 'high risk' is therefore limited and there are no data available to show how it can help predict unacceptable levels of postoperative dyspnoea.

\section{Recommendations}

- Consider using shuttle walk testing as functional assessment in patients with moderate to high risk of postoperative dyspnoea using a distance walked of $>400 \mathrm{~m}$ as a cut-off for good function. [C]

- Consider cardiopulmonary exercise testing to measure peak oxygen consumption as functional assessment in patients with moderate to high risk of postoperative dyspnoea using $>15 \mathrm{ml} / \mathrm{kg} / \mathrm{min}$ as a cut-off for good function. [D]

\section{Research recommendation}

- Further studies with specific outcomes are required to define the role of exercise testing in the selection of patients for surgery.

\subsubsection{Postoperative quality of life/dyspnoea}

Lung cancer is associated with the most disruption to quality of life compared with other chronic diseases ${ }^{171[3]}$ or cancers, ${ }^{172[3]}$ and the reduction may persist for more than 5 years. ${ }^{173[3]}$ The physical domains of quality of life deteriorate early after lung cancer surgery but improve to near baseline by 6 months. ${ }^{174[3], 175[2+], 176[3], 177[2+], 178[2+], 179[2-] \quad \text { Pneumonec- }}$ tomy, however, is associated with both a poorer quality of life $\mathrm{ing}^{172-], 180[2+]}$ for a longer duration ${ }^{178[2+], 179[2-], 181[3]}$ compared with lobectomy or bilobectomy. When pneumonectomy can be avoided but there is the potential for an increased risk of recurrence, this should be explained to patients so that they can make a choice.

Traditional parameters used to assess the postoperative cardiorespiratory function do not correlate well with the quality of life reported by patients. ${ }^{178[2+]}$ Although it has been suggested that quality of life after surgery may be related to cardiopulmonary fitness, ${ }^{182[3]}$ pulmonary function assessment alone is a poor predictor of patients' perceptions of physical disruptions in day-to-day activities. ${ }^{120[2+], 181[3]}$ Currently, it is thought that respiratory symptom burden rather than ventilatory impairment contributes to diminished quality of life. ${ }^{183[3]}$ As discrepancies may exist between patients' perception about their residual physical and emotional status and objective functional measures, lung function tests and exercise tests cannot be taken as sole surrogates for quality of life evaluation. A quality of life instrument should always be used.

Other identified risks factors for poor postoperative quality of life include preoperative dyspnoea and the administration of postoperative chemotherapy. ${ }^{184[2-]}$ The influence of increasing age is less clear, with some studies reporting that elderly patients fail to make a complete recovery ${ }^{185[3]}$ and others reporting no difference compared with their younger counterparts. ${ }^{106[2+]} \mathrm{A}$ risk assessment algorithm for postoperative dyspnoea is shown in figure 3 .

\section{Recommendations}

- Avoid pneumonectomy where possible by performing bronchoangioplastic resection or non-anatomical resection. [C]

- Avoid taking pulmonary function and exercise tests as sole surrogates for quality of life evaluation. [C]

-When estimating quality of life, use a validated instrument. [D] 


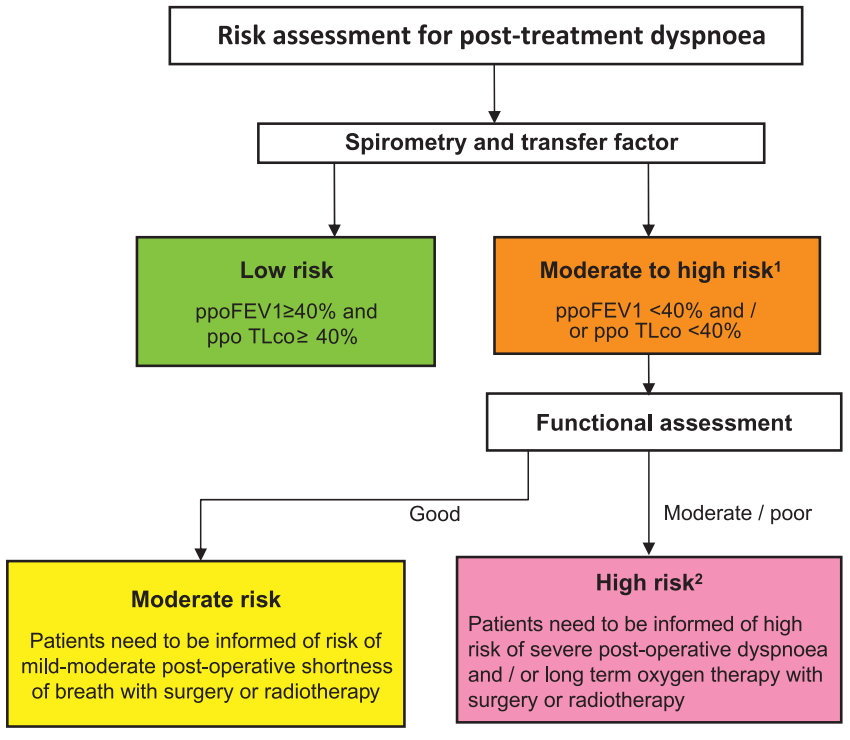

1. Consider split lung function testing for patients in this group if there is any suspicion of a ventilation perfusion mismatch (e.g. compression of a pulmonary artery or marked emphysema in the lobe with cancer) to allow more accurate estimation of post-operative values.

2. Patients in this sub-group are at high risk of ventilator dependency after surgery. It is important to ensure that criteria for LVRS have been considered as lung function can improve in appropriately selected patients.

Figure 3 Risk assessment for post-treatment dyspnoea. FEV ${ }_{1}$, forced expiratory volume in $1 \mathrm{~s}$; LVRS, lung volume reduction surgery; ppo, projected postoperative; TLCo, lung carbon monoxide transfer factor.

\subsection{Surgical approach}

\subsubsection{Pulmonary resection}

\subsubsection{Estimating post-resection lung function}

Postoperative lung function is estimated by the method of segment counting. ${ }^{1}$ The total number of segments is 19 (10 right, 9 left). The total number of obstructed segments as measured by imaging $(\mathrm{O})$ is subtracted from 19 to obtain the number of functioning segments $(\mathrm{T})$.

$$
\mathrm{T}=19-\mathrm{O}
$$

\section{$\mathrm{R}=\mathrm{T}$ - functioning segments to be resected}

The number of segments to be resected is: right upper lobe $=3$, middle lobe $=2$, right lower lobe $=5$, left upper lobe $=5$ ( 3 upper division, 2 lingula) and left lower lobe $=4$.

The predicted postoperative (ppo) lung function is then estimated by:

$$
\text { ppoValue }=\frac{\text { Preoperative value }}{\mathrm{T}} \times \mathrm{R}
$$

While for the majority of patients the predicted postoperative values are estimated for lobectomy and pneumonectomy, it is important to recognise that the ability to perform segmental and bronchoangioplastic resections allows fewer segments to be resected and may allow surgery to be offered to patients who would not tolerate a lobectomy. For example, lung parenchymal sparing surgery can be considered for patients with a tumour in the left upper lobe that extends into the apical segment of the lower lobe by performing a left upper lobectomy and lower apical segmentectomy (6 segments) as opposed to pneumonectomy (9 segments).

\section{Recommendations}

- Employ segment counting to estimate postoperative lung function as part of risk assessment for postoperative dyspnoea. [D]
- Consider patients with moderate to high risk of postoperative dyspnoea for lung parenchymal sparing surgery. [D]

\subsubsection{Bronchoplastic and angioplastic resections}

Bronchoplastic resection refers to the resections that include the main bronchus or bronchus intermedius, usually with a complete ring of airway with continuity restored by the re-anastomosis of proximal and distal airway lumens. Angioplastic resections refer to resections that involve the main pulmonary artery with continuity restored by end-to-end anastomosis or reconstruction.

Bronchoplastic resection is usually used in the setting of low-grade airway tumours such as typical carcinoid tumour (bronchial sleeve resection) or to spare lung parenchyma-for example, in the setting of lung cancer to avoid pneumonectomy (sleeve lobectomy). Lower mortality and lower local recurrence rates have been reported in a series comparing the outcomes of sleeve lobectomy with pneumonectomy. ${ }^{186[2-]}$ Angioplastic resections are usually employed in the setting of lung parenchymal sparing surgery. ${ }^{187[3], 188[3]}$

While there may be technical advantages to lung parenchymal sparing surgery, the use of this range of procedures is generally uncommon and may be technically challenging.

\section{Recommendation}

- Consider bronchoangioplastic procedures in suitable patients to preserve pulmonary function. [D]

\subsubsection{Sublobar resections}

Sublobar resections generally refer to wedge resections and segmental resections. They are usually performed as an alternative to lobectomy in patients with peripheral tumours with limited pulmonary reserve. Wedge resection entails the macroscopic clearance of the tumour with a surrounding margin of normal lung tissue and does not follow anatomical boundaries, whereas segmental resection involves the division of vessels and bronchi to a distinct anatomical segment(s). Segmental resection removes draining lymphatics and veins and might therefore result in lower recurrence rates, although there is no evidence for this. Segmental resection may not always be technically feasible and is best suited to the left upper lobe (lingula, apicoposterior and anterior segments) and the apical segment of both lower lobes. Sublobar resections for patients with multiple foci of bronchioloalveolar carcinoma have been discussed in section 1.2.6.

In the only randomised trial comparing lobectomy with sublobar resection in patients with T1N0 tumours, the authors report similar overall survival but increased local recurrence at 3 years with limited resection. ${ }^{189[1-]}$ Thus, sublobar resection is only an acceptable alternative to formal lobectomy in patients with suboptimal respiratory function.

\section{Recommendation}

- Consider patients with limited pulmonary reserve for sublobar resection as an acceptable alternative to lobectomy. [B]

\section{Research recommendation}

- Consider randomised trials of segmental resection versus wedge resection.

\subsubsection{Combined lung volume reduction surgery}

Randomised trials of lung volume reduction surgery report improved lung function after surgical resection in patients with severe heterogeneous emphysema. $190[1++], 191[1+], 192[1+], 193[1+]$ Entry criteria in the largest clinical trial to date included patients with a preoperative $\mathrm{FEV}_{1}$ of only $20-40 \%$ predicted, and lung 
function was shown to improve after surgical resection. Therefore, if lung cancer is isolated to an area of severe heterogeneous emphysema, it seems reasonable to use criteria currently used for lung volume reduction surgery (preoperative $\mathrm{FEV}_{1}$ or TLCO $>20 \%$ predicted) to select patients for lung resection. ${ }^{194[1++]}$ Potential benefit should be both improvement in symptoms due to emphysema and curative resection.

\section{Recommendation}

- Consider patients with concomitant lung cancer within severe heterogeneous emphysema for lung resection based on lung volume reduction surgery criteria. [B]

\subsubsection{Lymph node management}

Intuitively, surgeons should be moving towards increasing the accuracy of cancer staging by systematic nodal dissection. However, there is considerable variation in practice, from no lymph node sampling through lobe-specific sampling to systematic nodal dissection. Postoperative morbidity is usually cited against the use of routine systematic nodal dissection and, in response to this, the results of the American ACOSOG Z30 trial confirm that patients randomised to complete mediastinal lymphadenectomy had little added morbidity compared with those who underwent lymph node sampling. ${ }^{195[1+]}$ Two trials comparing systematic nodal dissection with lymph node sampling reported better survival in patients randomised to systematic nodal dissection. ${ }^{196[1+], 197[1+]}$

Currently, the International Union Against Cancer (UICC) recommends that at least six lymph node stations should be removed or sampled before the confirmation of $\mathrm{pN} 0$ status. ${ }^{61[\mathrm{~N} / \mathrm{A}]}$ Three of these nodes/stations should be mediastinal (including the subcarinal station) and three should be from N1 stations.

\section{Recommendations}

- Perform systematic nodal dissection in all patients undergoing resection for lung cancer. [A]

- Remove or sample a minimum of six lymph nodes or stations. [D]

\subsection{Chemotherapy}

\subsubsection{Preoperative chemotherapy}

Preoperative (neoadjuvant/induction) chemotherapy offers the opportunity to downstage the tumour prior to surgery, assess the response to chemotherapy and thereby prognosis, and potentially control micrometastatic disease at an earlier time point including mitigation of any pro-oncogenic effects of surgery. ${ }^{198[4], 199[3]}$ This paradigm has been adopted in other cancers (breast, gastric, oesophageal and rectal) with considerable success. However, studies with non-small cell lung cancer have been dogged by poor accrual, perhaps due to an inherent belief that early surgery is required to prevent disease progression.

A number of studies of preoperative chemotherapy (versus surgery alone) were closed early due to large survival benefits reported for patients randomised to preoperative chemotherapy. ${ }^{200[1+], 201[1-]}$ Subsequent studies continued to demonstrate a survival advantage for preoperative chemotherapy, albeit not reaching statistical significance, and were likely to have been underpowered to detect even modest effects. ${ }^{202[1++]}$

The largest trial comparing preoperative chemotherapy and surgery versus surgery alone randomised 519 patients, confirming the feasibility of this approach with $75 \%$ of patients completing the full course of chemotherapy, with a progression rate of only $2 \% .^{203[1+]}$ However, there was no difference in survival between the two groups (HR 1.02, 95\% CI 0.8 to 1.31, $\mathrm{p}=0.86$ ) although $64 \%$ of patients in the chemotherapy arm had stage I disease, probably less likely to benefit from chemotherapy. ${ }^{204[\mathrm{~N} / \mathrm{A}], 205[4]}$ Pooled results with all other preoperative studies by meta-analysis obtained borderline significance with an overall reduction in $\mathrm{HR}$ of death by $12 \%$ (HR $0.88,95 \% \mathrm{CI}$ 0.76 to $1.01, p=0.07),{ }^{202[1++]}$ which is similar to that of postoperative chemotherapy. ${ }^{204[\mathrm{~N} / \mathrm{A}]}$

Given the relatively small number of studies of preoperative chemotherapy compared with the evidence base for postoperative chemotherapy, residual uncertainties about the overall benefits on pooled data and concern of progression on treatment, routine clinical administration of preoperative chemotherapy is not recommended.

\section{Recommendation}

- Patients with resectable lung cancer should not routinely be offered preoperative chemotherapy. [B]

\subsubsection{Postoperative chemotherapy}

Data from five multicentre studies have established the survival benefit of postoperative (adjuvant) platinum-based chemotherapy in selected patients. ${ }^{79[1++], 206[1+], 207[1-], 208[1+], 209[1+]}$ Currently, the evidence in this section has been collated from clinical trials that have used the 6th Edition of the TNM classification of lung cancer, so it is important to appreciate the limitations with respect to the application of the recommendation of patients by stage criteria. There is no evidence of benefit of postoperative chemotherapy in stage IA non-small cell lung cancer in a western population. ${ }^{204[\mathrm{~N} / \mathrm{A}]}$

For stage IB non-small cell lung cancer, the evidence is controversial. Kato et al report a survival benefit in patients with adenocarcinoma treated with Uracil-Tegafor, but it is thought that that this may reflect a local epiphenomenon as this study was based on a pharmacogenetically distinct (Japanese) population. ${ }^{206[1+]}$ The CALGB 9633 study was terminated early due to interim analysis demonstrating significant improvement in overall and disease-free survival; however, more mature data showed no ongoing benefit to overall survival, although the benefits were maintained with disease-free survival except in tumours of $>4 \mathrm{~cm}$ where a survival benefit was observed. ${ }^{210[1+]}$ In the IB subgroups from larger trials, no benefit was observed on individual patient data meta-analysis. ${ }^{84[1+]}$ Treatment should be considered on an individual basis (eg, patients with tumours $>4 \mathrm{~cm}$ ), noting the differences between the 6 th and 7 th edition TNM staging systems. It should be noted that there are few data to guide on the use of chemotherapy in patients who are found to have 7th edition TNM T4 tumours by virtue of additional tumour in a different ipsilateral lobe. Such patients should, intuitively, receive postoperative chemotherapy, but the GDC felt there was insufficient evidence to make a recommendation.

For stage II and III non-small cell lung cancer, there is a strong body of evidence supporting the use of postoperative adjuvant chemotherapy with an HR of overall survival ranging from 0.74 to $0.89 .^{84[1+], 211[1+], 212[1++], 213[1+], 214[1+], 215[1+]}$ Despite the role of adjuvant chemotherapy in potentially curatively resected non-small cell lung cancer, survival remains relatively poor and efforts aimed at accruing patients into clinical trials of novel therapeutics are warranted.

\section{Selection of chemotherapy regimen}

Current evidence supports the use of cisplatin-based chemotherapy, and the Lung Adjuvant Cisplatin Evaluation (LACE) meta-analysis suggested that cisplatin and vinorelbine may be the superior regimen. ${ }^{84[1+]}$ In the current postoperative trials 
3-4 cycles of chemotherapy were used with scheduling based on 4- or 3-weekly cycles depending on the chosen regimen. The JBR10 study reported that chemotherapy was poorly tolerated with only $48 \%$ completing four cycles of treatment. ${ }^{209[1+], 216[1+]}$ Currently, the cisplatin-vinorelbine combination is the most widely adopted postoperative schedule in the UK. In vinorelbinebased studies, ${ }^{209[1+], 217[1++]}$ vinorelbine was given 4-weekly with cisplatin. However, a 3-weekly day 1 and day 8 schedule (already used in many parts of the UK for advanced disease) may be more convenient, better tolerated and have similar efficacy. ${ }^{218[1+]}$

Although comorbidities increase with age, pooled data from LACE indicate that elderly patients also benefit from postoperative chemotherapy, although the starting and total dose of cisplatin may be significantly lower than their younger counterparts. ${ }^{84[1+]}$

\section{Recommendations}

- Offer postoperative chemotherapy to patients with TNM 7th edition T1-3N1-2M0 non-small cell lung cancer. [A]

- Consider postoperative chemotherapy in patients with TNM 7th edition T2-3N0M0 non-small cell lung cancer with tumours $>4 \mathrm{~cm}$ diameter. [B]

- Use a cisplatin-based conjunction therapy regimen in postoperative chemotherapy. [A]

\section{Research recommendation}

- Consider further trials of novel chemotherapeutic agents in conjunction with surgical resection.

\subsection{Postoperative radiotherapy}

Effective adjuvant radiotherapy is routinely offered for breast and rectal cancer improving both local control and survival. The effectiveness of postoperative radiotherapy (PORT) remains controversial in patients with non-small cell lung cancer.

The PORT Meta-analysis Trialists Group analysed individual patient data from nine randomised trials (2128 patients) that compared surgery followed by PORT with surgery alone. ${ }^{219[1++]}$ The authors reported a $21 \%$ relative increase in the risk of death at 2 years with PORT, reducing the overall survival from $55 \%$ to $48 \%$ (mortality HR 1.21, 95\% CI 1.08 to $1.34, \mathrm{p}=0.001$ ). Subgroup analyses suggested that PORT could be deleterious in terms of overall survival, predominantly among patients with stage I/II and $\mathrm{pN} 0$ or $\mathrm{pN} 1$ disease whereas, for those with N2 disease, there was no clear evidence of an adverse effect. It is important to note that the radiotherapy used in these trials would be regarded as suboptimal by current standards (no CT scan-based radiotherapy planning, two-dimensional radiotherapy, use of cobalt-60 equipment, use of spinal cord block, use of controversial doses and fractionations).

The PORT meta-analysis was updated in 2005 adding the Trodella study ${ }^{20[1+]}$ which addressed the role of PORT in patients with stage I disease. ${ }^{221[1++]}$ The results continued to show PORT to be detrimental overall, with an $18 \%$ relative increase in the risk of death at 2 years. The updated meta-analysis confirmed that there was no clear evidence of a detriment in patients with stage III disease treated with PORT.

Two studies not included in the original or updated PORT meta-analysis showed no treatment-related mortality, a reduction in local recurrence but no difference in survival. $222[1+], 223[3]$ The results from a non-randomised subanalysis of the Adjuvant Navelbine International Trialist Association (ANITA) trial ${ }^{79[1++]}$ and from a Surveillance Epidemiology and End Results (SEER) retrospective study ${ }^{224[2-]}$ suggest the benefit of PORT in stage IIIA disease.

It should be noted that the role of PORT in the context of mediastinal dissection as opposed to mediastinal sampling is not known.
In summary, there is no indication for PORT based on nodal status in completely resected disease. However, this is an area of active research and patients should be offered participation in randomised trials wherever possible.

The role of PORT in patients with a positive resection margin ( $\mathrm{R} 1$ resection) is unknown as there are no randomised trials examining the role of radiotherapy in this group of patients. $^{225[3], 226[4]}$ PORT is often given in routine practice if pathological examination shows tumour at the resection margin on the basis of retrospective series showing a reduction in the local recurrence rates following PORT ${ }^{227[4], 228[3], 229[3], 230[3] 231[4]}$ or an excess of local recurrence rates without PORT. ${ }^{232[3]}$ However, some retrospective series have shown high local recurrence rates despite the use of PORT. ${ }^{230[3], 233[4]}$ It should also be noted that a retrospective study showed an adverse impact of radiotherapy on survival in patients irradiated for positive margins. $^{227[4]}$

Microscopic residual disease includes bronchial and extrabronchial residual disease. Furthermore, bronchial residual disease can be divided into mucosal (subdivided into infiltrative carcinoma or carcinoma-in-situ) and peribronchial (outside the cartilage) microscopic residual disease. Poorer survival has been reported in patients with peribronchial disease. ${ }^{234[3]}$ However, it should be noted that the majority of patients with submucosal and peribronchial disease have N2 or N3 lymph node metastasis. ${ }^{227[4], 233[4]}$ A literature review on this topic suggested that patients with stage I and II disease and positive margins are more likely to benefit from PORT than patients with stage III disease. $^{225[3]}$ Indeed, survival of patients with stage I and II nonsmall cell lung cancer and an R1 resection of the bronchial resection margin is significantly worse compared with the stagecorrected survival after radical surgery. ${ }^{235[4]}$ In the former, survival is limited due to local recurrence. ${ }^{232[3], 236[3], 237[3]}$ The negative effect of microscopic residual disease at the bronchial resection margin in stage III non-small cell lung cancer is less pronounced. These patients probably die due to disseminated disease before local recurrence occurs. ${ }^{237[3]}$ Similarly, patients with submucosal and peribronchial disease are unlikely to benefit from PORT. It is not possible based on the current literature to recommend PORT for all patients with residual microscopic disease at the bronchial resection margin, particularly for stage III non-small cell lung cancer. The potential benefit of this treatment in terms of reduction of the risk of local recurrence rate has to be weighed carefully against the risk of morbidity and mortality related to PORT.

After surgical resection of lung cancer, when delivering PORT it is crucial to keep the dose to the normal lung tissue to a minimum. ${ }^{238[4]}$ Ideally, the volume at risk should be delineated on the radiotherapy planning scan by a clinical oncologist specialised in thoracic malignancies with the input of the thoracic surgeon who performed the operation. The optimal dose/fractionation for PORT is not known, but modern studies suggest that a dose in the range of 50-55 Gy using conventional fractionation should be used. ${ }^{220[1+], 239[4]}$

There are few randomised data investigating the benefit of PORT and its optimal sequencing in the context of adjuvant chemotherapy. In adjuvant chemotherapy trials allowing the use of PORT, the radiotherapy was delivered after completion of adjuvant chemotherapy and did not seem to offset the beneficial effect of adjuvant chemotherapy. ${ }^{79[1++], 208[1+], 207[1+]}$

\section{Recommendations}

- Postoperative radiotherapy (PORT) is not indicated after R0 complete resection. [A] 
- Consider PORT for patients with residual microscopic disease at the resection margin where the benefit of reduction in local recurrence outweighs the risk of mortality and morbidity related to PORT. [C]

- Use CT-planned three-dimensional conformal radiotherapy for patients receiving PORT. [B]

- Consider PORTafter completion of adjuvant chemotherapy. [B]

\section{Research recommendation}

- Randomised trials looking at the effect of PORT in pN2 non-small cell lung cancer are recommended.

\section{SECTION 3: RADICAL RADIOTHERAPY \\ 3.1 Assessment of the risks of radiotherapy \\ 3.1.1 Risks of radical radiotherapy}

When planning radical radiotherapy to the thorax it is crucial to take into account the dose delivered to the normal lung tissue, oesophagus, spinal cord and heart. In order to ensure the maximum sparing of normal tissues, three-dimensional treatment planning is mandatory. ${ }^{238[4]}$ However, defining limits of dose tolerated by these tissues is complex as these limits vary according to the total dose delivered, fractionation regimen and use of concurrent chemotherapy. ${ }^{240[4], 241[4], 242[3], 243[3]}$ The risk of developing radiotherapy-induced lung toxicity can be estimated by calculating the dose-volume histogram of the lungs, including $\mathrm{V}_{20}$ and mean lung dose. ${ }^{244[4], 245[3]}$

\subsubsection{Lung function assessment}

The greatest limitation of thoracic radiotherapy is radiotherapyinduced lung toxicity. ${ }^{244[4], 245[3], 246[3], 247[1-]}$ It is generally assumed that patients with pre-existing pulmonary disease (particularly COPD) are at increased risk of radiation morbidity, ${ }^{248[3], 249[3]}$ but the data relating premorbid physiology to radiation toxicity are limited. Knowledge of the risks of radiotherapy is usually used to guide the design of radiotherapy treatment plans rather than to decide whether or not to treat. ${ }^{250[4]}$ However, in many chemoradiotherapy trials, pulmonary function limits (similar to the limits used for surgical patients) are set for exclusion of patients.

Safe lower limits of respiratory function ( $\mathrm{FEV}_{1}$ or TLCO) for radical radiotherapy have not been established and current evidence is insufficient to determine safe lower limits. ${ }^{246[3], 251[3], 252[3], 253[3], 254[3], 255[3], 256[3], 257[3], 258[3]}$ Radiotherapy planning parameters such as $\mathrm{V}_{20}$ and mean lung dose are effective tools for predicting radiation pneumonitis. ${ }^{244[4], 245[3]}$ Models based on a combination of radiotherapy planning parameters, lung function tests and lung perfusion imaging may have a higher predictive value than dosimetry alone and should be addressed in further research. In the interim, it seems appropriate to use risk criteria for postoperative dyspnoea when deciding on radical radiotherapy. The clinical oncologist will need to discuss the risks and benefits with the patient.

\section{Recommendations}

- Perform three-dimensional treatment planning in patients undergoing radical thoracic radiotherapy. [B]

- A clinical oncologist specialising in lung oncology should determine suitability for radical radiotherapy, taking into account performance status and comorbidities. [D]

\section{Research recommendation}

- Clinical trials of radical radiotherapy should include measures of lung function, outcome and toxicity.

\subsection{Radiotherapy and chemoradiotherapy regimens}

\subsubsection{Early stage disease}

Usually patients with early disease are considered for radiotherapy owing to the unacceptable risk of perioperative death, surgical complications or postoperative dyspnoea. In stage I non-small cell lung cancer, conventional radiotherapy is associated with long-term survival rates of $5-30 \%$ and local failure rates of $40-70 \% .{ }^{259[3],} 4^{260[4], 261[3], 262[4], 263[4], 264[3], 265[3], 266[3]} \mathrm{A}$ Cochrane review of 2003 patients with stage I/IIA non-small cell lung cancer from 26 non-randomised studies and 563 patients from a randomised controlled trial concluded that 'radical radiotherapy appears to result in a better survival than might be expected had treatment not been given'. ${ }^{267[2+], 268[1+]}$ However, the optimal dose and treatment technique could not be defined.

A clinical trial randomised 563 patients with stage I-IIIB non-small cell lung cancer to either CHART (54 Gy in 36 fractions over 12 days) or conventionally fractionated radiotherapy (60 Gy in 30 fractions over 6 weeks) and reported an improvement in 5-year survival in favour of CHART from $7 \%$ to $12 \% .^{268[1+]}$ Subgroup analysis of 169 patients with stage I/IIA disease also showed a similar benefit in favour of CHART, improving the 2 -year survival from $24 \%$ to $37 \%$. Dose escalation studies investigating doses $>60$ Gy have not established the optimal radiotherapy dose that achieves a balance between local control and side effects. ${ }^{269[2+], 270[3], 271[2+]}$

Hypofractionated radiotherapy regimens commonly used in the UK such as 55 Gy in 20 fractions have not been compared with conventional fractionation in patients with early stage medically inoperable disease. The use of hypofractionated stereotactic radiotherapy in patients with stage I and II disease is associated with local control rates of $80-98 \%$ at $2-5$ years with

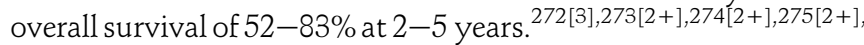
$276[2+], 277[2-], 278[2+], 279[3]$ The largest series to date reported 5 -year overall survival of $71 \%$ and local control rate of $84 \% .^{276[2+]} \mathrm{A}$ variety of doses and fractionations have been used, ranging

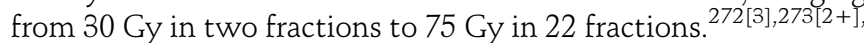
$274[2+], 275[2+], 276[2+], 277[2-], 278[2+], 279[3]$ Treatment of tumours adjacent to a primary or secondary bronchus should be avoided as acute toxicity and symptomatic bronchial stenosis have been reported. ${ }^{280[3], 281[3], 282[3]}$ The optimal stereotactic radiotherapy regimen has not yet been defined, nor has stereotactic radiotherapy been compared with standard radiotherapy or surgery in randomised trials

\section{Recommendations}

- Offer radical radiotherapy to patients with early stage non-small cell lung cancer who have an unacceptable risk of surgical complications. [B]

- Consider CHART as a treatment option in patients with early stage non-small cell lung cancer and unacceptable risk of surgical complications. [A]

- Consider stereotactic body irradiation in patients with early stage non-small cell lung cancer and unacceptable risk of surgical complications. [C]

\subsubsection{Locally advanced disease}

\subsubsection{Patients eligible for concurrent chemoradiotherapy}

The literature supports the use of concurrent chemoradiotherapy in patients aged $<75$ years (patients aged $>75$ years have not been included in clinical trials), performance status $0-1$, with reasonable lung function, without major comorbidities, and for whom the radiotherapy plan produces acceptable normal tissue doses. ${ }^{283[1+], 284[1+], 285[1+]}$ 
A body of evidence supports that, in patients with inoperable stage III non-small cell lung cancer, survival is improved when cisplatin-based chemotherapy is given at the same time as radiotherapy (concurrent chemoradiotherapy). ${ }^{286[1++]}$

A Cochrane review reported improved survival with cisplatinbased concurrent chemoradiotherapy among patients with inoperable stage III non-small cell lung cancer compared with sequential treatment (RR $0.86,95 \%$ CI 0.78 to $0.95, \mathrm{p}=0.003$ ) at the expense of increased radiation oesophagitis. ${ }^{287[1++]}$ Improved 3-year survival in favour of concurrent chemoradiotherapy has also been reported by individual patient data meta-analysis with an absolute improvement of $6.6 \%$ from $18.2 \%$ with sequential chemoradiotherapy to $24.8 \%$ with concurrent chemoradiotherapy. ${ }^{288[1-]}$

There is currently no consensus on the optimal chemotherapy regimen when combined with radiotherapy. There are data to support the combination of cisplatin-based chemotherapy. A number of regimens have been reported to show acceptable outcome and toxicity profiles. ${ }^{289[1-], 290[3], 291[1+], 292[1-]}$

The choice of chemotherapy regimen with concurrent thoracic radiotherapy should be considered based on individual patient characteristics, toxicity profile and local experience.

A meta-analysis of six concurrent chemoradiotherapy trials reported that increasing radiation dose improved both local control and overall survival; however, the optimal radiotherapy regimen has not been defined. ${ }^{293[2+]}$

To date, no studies have demonstrated any benefit of induction chemotherapy prior to concurrent chemoradiotherapy. ${ }^{289[1-], 290[3]}$ There have been initial reports that the addition of consolidation docetaxel after concurrent treatment was associated with median survival in excess of 20 months in stage III non-small cell lung cancer, ${ }^{247[1-], 284[1+]}$ but this was subsequently refuted in a phase III randomised study. ${ }^{294[1-]}$

\subsubsection{Patients not eligible for concurrent chemoradiotherapy}

Sequential chemoradiotherapy with platinum-based chemotherapy is the standard of care in patients with locally advanced non-small cell lung cancer not suitable for concurrent chemoradiotherapy. Three systematic reviews reported superior survival for patients treated with chemotherapy and radiation therapy compared with radiation therapy alone. ${ }^{295[1++], 296[1++]}$, $297[1+]$ The Non-Small Cell Lung Cancer Collaborative Group reported on 22 trials (3033 patients) and showed a 13\% reduction in risk of death, equivalent to an absolute benefit of $5 \%$ at 5 years, when cisplatin-based chemotherapy was combined with radiation therapy compared with radiation therapy alone. ${ }^{295[1++] \text {, }}$ $296[1++], 297[1+]$ The meta-analysis did not provide an answer to the question of the optimal radiotherapy or chemotherapy regimen.

\section{Recommendations}

- Offer chemoradiotherapy to patients with locally advanced non-small cell lung cancer and good performance status who are unsuitable for surgery. [A]

- Offer selected patients with good performance status concurrent chemoradiotherapy with a cisplatin-based chemotherapy combination. [A]

- Offer patients unsuitable for concurrent chemoradiotherapy sequential chemoradiotherapy. [A]

\subsubsection{Patients not eligible for chemotherapy}

Patients who are not candidates for chemotherapy because of significant comorbidity (eg, cardiovascular disease, renal impairment) or poor performance status should be offered radical radiotherapy.
The CHART trial included $60 \%$ of patients with stage III-IV disease who reported improved survival with hyperfractionated accelerated radiotherapy compared with conventional radiotherapy. ${ }^{268[1+]}$ However, due to logistic reasons, the CHART regimen is not used in the majority of UK centres.

There are currently no strong data supporting hyperfractionated radiotherapy over conventional radiotherapy. The hypofractionated radiotherapy regimen used widely in the UK consisting of 55 Gy in 20 fractions has not been compared with conventional radiotherapy in patients with locally advanced unresectable non-small cell lung cancer. $^{298[4]}$

A German trial compared $60 \mathrm{~Gy} / 40 \mathrm{f} / 2.5 \mathrm{w}$ (CHARTWEL) or $66 \mathrm{~Gy} / 33 \mathrm{f} / 6.5 \mathrm{w}$ in patients with stage I-III non-small cell lung cancer (84\% stage III). No significant difference in local control and overall survival was reported between the CHARTWEL arm and the conventional fractionation arm. ${ }^{299[1+]}$

\section{Recommendation}

- Consider CHART as a treatment option for patients with locally advanced non-small cell lung cancer. [A]

\subsection{Other radical treatment}

In early stage disease where patients have significant comorbidities or poor lung function, other radical treatments should be considered and discussed with patients as a valid alternative to high risk of death or postoperative dyspnoea. The evidence base for these approaches is very limited because it has been difficult ethically to justify randomised trials. This should no longer be the case in high-risk patients and properly designed studies in this area are strongly recommended.

\section{Research recommendation}

- Randomised controlled trials are recommended comparing conventional radical treatment (surgery, radical radiotherapy) with other radical treatments where there is evidence of efficacy in case series.

\subsubsection{Radiofrequency ablation}

Radiofrequency ablation (RFA) for primary lung tumours has developed as a minimally invasive treatment for both radical treatment and palliation. It is well tolerated and complication rates are low. The treatment can be delivered in a single session, usually requiring only a short admission. RFA is suitable for small tumours, usually of $3 \mathrm{~cm}$ diameter or less, although larger lesions may be considered suitable in certain circumstances. The medium- and long-term follow-up data suggest survival figures similar to other non-surgical treatment modalities with which it may be combined.

Patients should be selected by the MDT and are usually non-surgical candidates because of the site of the tumour or more commonly because of comorbidity (especially limited cardiorespiratory function). Occasionally patients may simply refuse major surgical treatment or radiotherapy. FDG-PET staging prior to choosing the appropriate treatment modality should be mandatory.

No data have been published so far on the combination of RFA with chemotherapy for early stage non-small cell lung cancer. In studies with attempted RFA for radical management of early stage non-small cell lung cancer, survival data are significantly better than for the patient population treated with a palliative intent. Recently reported long-term survival rates after percutaneous RFA of stage I non-small cell lung cancer were $78 \%$ at 1 year, $57 \%$ at 2 years, $36 \%$ at 3 years, $27 \%$ at 4 years and $27 \%$ at 5 years. ${ }^{300[3]}$ These figures are superior to the survival rates from external beam 
radiation, showing 2 - and 5-year overall survival rates of $39 \%$ and $13 \%{ }^{266[3]}$ These promising survival data only apply to T1N0 stage I non-small cell lung cancer. Recent advances in the field of radiation therapy with hypofractionated high-dose proton beam therapy show competitive survival results, ${ }^{301[3]}$ as does stereotactic radiosurgery. ${ }^{302[3]}$ A combination of RFA and conventional radiotherapy has already shown better local control and survival rates than radiotherapy alone, with cumulative survival rates of $50 \%$ and $39 \%$ at the end of 2 years and 5 years, respectively. ${ }^{303[3]}$

\subsubsection{Radical brachytherapy}

Radical brachytherapy uses high-dose radiotherapy delivered via a catheter inserted at flexible bronchoscopy. Case series have shown that this technique is curative where disease is limited to early mucosal or submucosal disease. Lesions up to $4 \mathrm{~mm}$ in depth may be suitable and this technique offers a low morbidity alternative to surgery. Lesions suitable for this treatment are uncommon with current surveillance techniques. The results of randomised trials of autofluorescence bronchoscopy are awaited.

\section{Recommendations}

- Consider alternative radical treatment in early stage lung cancer in patients at high risk of morbidity and mortality with conventional radical treatment. [D]

- Consider radical brachytherapy in patients with early invasive mucosal or submucosal non-small cell lung cancer. [D]

\section{SECTION 4: SMALL CELL LUNG CANCER 4.1 Chemoradiotherapy}

In general, patients with limited stage small cell lung cancer should be treated with a combination chemotherapy and radiotherapy. ${ }^{304[1+], 305[1+]}$ The standard chemotherapy regimen is cisplatin and etoposide. ${ }^{304[1+], 306[1+], 307[1+]}$

\subsubsection{Patients eligible for concurrent chemoradiotherapy}

The literature supports the use of concurrent chemoradiotherapy in patients aged $<75$ years (patients aged $>75 y$ ears have not been included in clinical trials), performance status $0-1$, without major comorbidities and for whom the radiotherapy plan produces acceptable normal tissue doses. $^{308[2-], 309[1+], 310[2+], 311[1+]}$

Clinical trials have reported better survival in patients randomised to concurrent chemoradiotherapy compared with sequential chemoradiotherapy. ${ }^{308[2-], 309[1+]}$ Based on data obtained by meta-analysis, radiotherapy should start before the third cycle of chemotherapy but it is currently unclear if thoracic radiotherapy should commence with the first or the second cycle. $^{312[1+], 313[1+]}$

Options for radical radiotherapy in the concurrent setting include twice daily thoracic radiotherapy (45 Gy in 3 weeks ${ }^{310[1+]}$ and 40 Gy once daily delivered in 3 weeks. ${ }^{311[1+]}$ High doses of radiation ( $\geq 66 \mathrm{~Gy}$ ) delivered once daily concurrently with CT are currently under evaluation.

There are limited data supporting the use of conformal radiotherapy without elective nodal irradiation to decrease acute toxicity, an area that should be explored within the context of randomised trials. ${ }^{314[2++], 315[2-]}$ Patients with any response to chemotherapy or stable disease should be given prophylactic cranial irradiation. $^{316[1+]}$

\subsubsection{Patients not eligible for concurrent chemoradiotherapy}

Patients who are not suitable for concurrent chemoradiotherapy, as outlined above, but eligible for platinum-based chemotherapy should be treated with sequential chemoradiotherapy.
Patients who are not eligible for concurrent chemotherapy should receive 4-6 cycles of platinum-etoposide chemotherapy followed by radical thoracic radiotherapy. ${ }^{304[1++], 305[1+]}$ and prophylactic cranial irradiation. ${ }^{316[1+]}$ The current UK hypofractionated regimen of 50-55 Gy in 20 fractions has not been formally compared with conventional radiotherapy. ${ }^{317[3]}$

\section{Recommendations}

- Offer selected patients with T1-4N0-3M0 limited stage small cell lung cancer both chemotherapy and radiotherapy. [A]

- Offer patients with T1-4N0-3M0 limited stage small cell lung cancer and good performance status concurrent chemoradiotherapy. [A]

- Recommended treatment options for concurrent chemoradiotherapy are twice daily thoracic radiotherapy (45 Gy in 3 weeks) with cisplatin and etoposide and 40 Gy once daily delivered in 3 weeks. [A]

- Offer patients unsuitable for concurrent chemoradiotherapy sequential chemoradiotherapy. [A]

- Offer prophylactic cranial irradiation to patients with response to treatment and stable disease. [A]

\subsection{Surgery}

The role of surgery for the treatment of limited stage small cell lung carcinoma has been considered inappropriate due to poor overall survival. The only trial to evaluate the role of primary surgery concluded no benefit compared with radiotherapy. ${ }^{318[1-]}$ In this study, patients were recruited based on bronchial biopsies and complete resection was only achieved in $48 \%$ of patients, possibly reflecting the unavailability of CT scanning and non-use of mediastinoscopy. The results were further limited; on intention-to-treat analysis, more than half of the patients in the surgical arm underwent exploratory thoracotomy or no surgery. In view of these limitations, and as it was conducted in an era before the use of CT, the results of this trial cannot be extrapolated into today's practice.

The only trial to evaluate the role of surgery after response to initial chemotherapy concluded no benefit of adjuvant surgery. ${ }^{319[1+]}$ Patients who were diagnosed with small cell lung cancer on bronchoscopy, where the origin of the tumour could be identified preoperatively and who responded to initial chemotherapy were randomised to surgery or no additional treatment with an overall 2-year survival of $20 \%$ in both arms.

Following from these two trials published in 1972 and 1994, evidence for the role of surgery has been limited to case series, some reporting 5-year survival as high as $52 \%{ }^{320[3], 321[3]}$ The selection criteria and estimated benefit for surgery in current clinical practice remains undefined, and wide differences in opinions currently exist with regard to appropriate surgical selection. To address the role of surgery, patients should be considered for entry into clinical trials when applicable.

\section{Recommendations}

- Consider patients with T1-3N0-1M0 small cell lung cancer for surgery as part of multi-modality management. [D]

- Surgical management of patients with T1-3N2M0 small cell lung cancer should only be considered in the context of a clinical trial. [C]

\section{SECTION 5: PROVISION OF TREATMENT OPTIONS}

In this guideline, every effort has been made to ensure pragmatic and feasible recommendations in the NHS. It is recognised that delivery of radical treatment in the UK is below that in many equivalent healthcare systems. This guideline supports 
advancement of effective radical treatment and has recommended some treatments that may not be available in all institutions. It is hoped that this will encourage the development of services so that these treatments can be accessed by all patients. The concept of a tripartite risk assessment with this presented to patients to make an informed choice may present some difficulties if the clinician is not willing to undertake the risks of treatment or if complexity of the proposed management cannot be provided locally. With the development of improved services this situation is mitigated but, in the interim, clinicians must be prepared to refer to colleagues who can provide these services. Where radical treatments that push the boundaries are the subject of research, this should be discussed with patients and referrals made for entry into clinical trials.

\section{Recommendation}

- All available treatment options, including those that are the subject of research, should be discussed with patients and their carers and the risks and benefits presented so that they may make an informed choice. [D]

Acknowledgements The GDC is grateful to Lisa Stirk who created search strategies and carried out the online literature searching that formed the evidence base for this document.

Funding Committee meeting expenses were funded by the British Thoracic Society.

Competing interests JE, DW and TW are authors of some of the research evidence used. SaP has received honoraria from Pierre-Fabre. The other authors have no competing interests.

Contributors EL is Chair of the Guideline Development Committee, performed initial literature review, wrote many sections of the document and edited the document; DB set up and chaired the initial meetings, contributed to several sections, edited the document, produced the quick reference guide and summary of recommendations; $\mathrm{MB}$ attended meetings, commented on several sections of the document and contributed the section relating to physiology; JD attended meetings and commented on several sections of the document; JE attended meetings and contributed predominantly to the radiology section; KK commented on the document and wrote the section relating to pathological issues; CF-F attended meetings and contributed to several sections of the document, especially radical radiotherapy; AM attended meetings and contributed to several sections of the document, especially cardiac risk assessment; JMcG attended meetings and commented on the document; SiP contributed the section of radiofrequency ablation; SaP authored/co-authored several sections and commented on the drafts; NS co-authored the imaging section and commented on the drafts; MS attended meetings and contributed to several sections of the document, especially radical radiotherapy; DW attended meetings, wrote sections on N2 disease and surgery and commented on the final draft; CW contributed to the initial set-up of the group and contributed to the writing of several sections; TW attended meetings and contributed to the risk assessment for surgery sections.

Provenance and peer review The Guideline Development Group held regular meetings over the period from December 2007 to January 2010. The draft guideline was presented at the BTS Winter Meeting in December 2009 and circulated to a number of stakeholders for consultation and review. The revised draft guideline was submitted to the BTS Standards of Care Committee for review and published online for a month (in March 2010) to allow for BTS member and public consultation. All the feedback was reviewed and discussed by the Guideline Committee and incorporated into the revised draft guideline.

\section{REFERENCES}

1. British Thoracic Society. Guidelines on the selection of patients with lung cancer for surgery. Thorax 2001;56:89-108.

2. National Lung Cancer Audit. Report for the audited period 2006: the information centre, National Lung Cancer Audit. 2007.

3. Verdecchia A, Francisci $\mathrm{S}$, Brenner $\mathrm{H}$, et al. Recent cancer survival in Europe: a 2000-02 period analysis of EUROCARE-4 data. Lancet Oncol 2007:8:784-96

4. General Medical Council. Consent: patients and doctors making decisions together. London: General Medical Council, 2008.

5. Goldstraw P, Crowley J, Chansky K, et al. The IASLC Lung Cancer Staging Project: proposals for the revision of the TNM stage groupings in the forthcoming (seventh) edition of the TNM classification of malignant tumours. $J$ Thorac Oncol 2007:2:706-14.

6. Shepherd FA, Crowley J, Van Houtte P, et al. The International Association for the Study of Lung Cancer lung cancer staging project: proposals regarding the clinical staging of small cell lung cancer in the forthcoming (seventh) edition of the tumor, node, metastasis classification for lung cancer. J Thorac Oncol 2007;2:1067-77.

7. Travis WD, Giroux DJ, Chansky K, et al. The IASLC Lung Cancer Staging Project: proposals for the inclusion of broncho-pulmonary carcinoid tumors in the forthcoming (seventh) edition of the TNM Classification for Lung Cancer. J Thorac Oncol 2008;3:1213-23.

8. Good CA, Wilson TW. The solitary circumscribed pulmonary nodule; study of seven hundred five cases encountered roentgenologically in a period of three and one-half years. JAMA 1958; 166:210-15.

9. Laroche C, Fairbairn I, Moss $\mathrm{H}$, et al. Role of computed tomographic scanning of the thorax prior to bronchoscopy in the investigation of suspected lung cancer. Thorax 2000;55:359-63.

10. Higashino T, Ohno Y, Takenaka D, et al. Thin-section multiplanar reformats from multidetector-row CT data: utility for assessment of regional tumor extent in non-small cell lung cancer. Eur J Radiol 2005;56:48-55.

11. Lardinois D, Weder W, Hany TF, et al. Staging of non-small-cell lung cancer with integrated positron-emission tomography and computed tomography. N Engl J Med 2003;348:2500-7.

12. Antoch G, Stattaus J, Nemat AT, et al. Non-small cell lung cancer: dual-modality PET/CT in preoperative staging. Radiology 2003;229:526-33.

13. Halpern BS, Schiepers C, Weber WA, et al. Presurgical staging of non-small cell lung cancer: positron emission tomography, integrated positron emission tomography/CT, and software image fusion. Chest 2005;128:2289-97.

14. Bradley J, Thorstad WL, Mutic S, et al. Impact of FDG-PET on radiation therapy volume delineation in non-small-cell lung cancer. Int J Radiat Oncol Biol Phys 2004;59:78-86

15. De Ruysscher $\mathbf{D}$, Wanders $\mathrm{S}$, van Haren E, et al. Selective mediastinal node irradiation based on FDG-PET scan data in patients with non-small-cell lung cancer: a prospective clinical study. Int J Radiat Oncol Biol Phys 2005;62:988-94.

16. van Der Wel A, Nijsten $S$, Hochstenbag $M$, et al. Increased therapeutic ratio by 18FDG-PET CT planning in patients with clinical CT stage N2-N3M0 non-small-cell lung cancer: a modeling study. Int J Radiat Oncol Biol Phys 2005;61:649-55.

17. Leung AN, Muller NL, Miller RR. CT in differential diagnosis of diffuse pleural disease. AJR Am J Roentgenol 1990:154:487-92.

18. Heelan RT, Demas BE, Caravelli JF, et al. Superior sulcus tumors: CT and MR imaging. Radiology 1989;170:637-41.

19. Butler AR, Leo JS, Lin JP, et al. The value of routine cranial computed tomography in neurologically intact patients with primary carcinoma of the lung. Radiology 1979:131:399-401.

20. Cole $\mathbf{F H} \mathbf{J r}$, Thomas JE, Wilcox AB, et al. Cerebral imaging in the asymptomatic preoperative bronchogenic carcinoma patient: is it worthwhile? Ann Thorac Surg 1994; 57:838-40.

21. Colice GL, Birkmeyer JD, Black WC, et al. Cost-effectiveness of head CT in patients with lung cancer without clinical evidence of metastases. Chest 1995:108:1264-71.

22. Rusch VW, Asamura $\mathrm{H}$, Watanabe $\mathrm{H}$, et al. The IASLC lung cancer staging project: a proposal for a new international lymph node map in the forthcoming seventh edition of the TNM classification for lung cancer. J Thorac Oncol 2009;4:568-77.

23. Shim SS, Lee KS, Kim BT, et al. Non-small cell lung cancer: prospective comparison of integrated FDG PET/CT and CT alone for preoperative staging. Radiology 2005;236:1011-19.

24. Berghmans T, Dusart $\mathrm{M}$, Paesmans $\mathrm{M}$, et al. Primary tumor standardized uptake value (SUVmax) measured on fluorodeoxyglucose positron emission tomography (FDG-PET) is of prognostic value for survival in non-small cell lung cancer (NSCLC): a systematic review and meta-analysis (MA) by the European Lung Cancer Working Party for the IASLC Lung Cancer Staging Project. J Thorac Oncol 2008;3:6-12

25. De Leyn $\mathbf{P}$, Stroobants S, De Wever W, et al. Prospective comparative study of integrated positron emission tomography-computed tomography scan compared with remediastinoscopy in the assessment of residual mediastinal lymph node disease after induction chemotherapy for mediastinoscopy-proven stage IIIA-N2 non-small-cell lung cancer: a Leuven Lung Cancer Group Study. J Clin Oncol 2006;24:3333-9.

26. Facey K, Bradbury I, Laking G, et al. Overview of the clinical effectiveness of positron emission tomography imaging in selected cancers. Health Technol Assess 2007:11:iii-iv, xi-267.

27. Jacobs L, Kinkel WR, Vincent RG. 'Silent' brain metastasis from lung carcinoma determined by computerized tomography. Arch Neurol 1977;34:690-3.

28. Mintz BJ, Tuhrim S, Alexander S, et al. Intracranial metastases in the initial staging of bronchogenic carcinoma. Chest 1984;86:850-3.

29. Ferrigno D, Buccheri G. Cranial computed tomography as a part of the initial staging procedures for patients with non-small-cell lung cancer. Chest 1994;106:1025-9.

30. Kormas P, Bradshaw JR, Jeyasingham K. Preoperative computed tomography of the brain in non-small cell bronchogenic carcinoma. Thorax 1992; 47:106-8.

31. Win T, Laroche CM, Groves AM, et al. The value of performing head CT in screening for cerebral metastases in patients with potentially resectable non-small cell lung cancer: experience from a UK cardiothoracic centre. Clin Radiol 2004;59:935-8

32. Yokoi K, Kamiya $\mathrm{N}$, Matsuguma $\mathrm{H}$, et al. Detection of brain metastasis in potentially operable non-small cell lung cancer: a comparison of CT and MRI. Chest 1999;115:714-19.

33. Davis PC, Hudgins PA, Peterman SB, et al. Diagnosis of cerebral metastases: double-dose delayed CT vs contrast-enhanced MR imaging. AJNR Am J Neuroradiol 1991;12:293-300. 
34. Oliver TW Jr, Bernardino ME, Miller Jl, et al. Isolated adrenal masses in nonsmallcell bronchogenic carcinoma. Radiology 1984;153:217-18.

35. Yun M, Kim W, Alnafisi N, et al. 18F-FDG PET in characterizing adrenal lesions detected on CT or MRI. J Nucl Med 2001:42:1795-9.

36. Erasmus JJ, Patz EF Jr, McAdams HP, et al. Evaluation of adrenal masses in patients with bronchogenic carcinoma using 18F-fluorodeoxyglucose positron emission tomography. AJR Am J Roentgenol 1997;168:1357-60.

37. Maurea S, Klain M, Mainolfi C, et al. The diagnostic role of radionuclide imaging in evaluation of patients with nonhypersecreting adrenal masses. J Nucl Med 2001;42:884-92

38. Maurea S, Mainolfi C, Bazzicalupo L, et al. Imaging of adrenal tumors using FDG PET: comparison of benign and malignant lesions. AJR Am J Roentgenol 1999;173:25-9.

39. Gupta NC, Graeber GM, Tamim WJ, et al. Clinical utility of PET-FDG imaging in differentiation of benign from malignant adrenal masses in lung cancer. Clin Lung Cancer 2001;3:59-64.

40. Boland GW, Goldberg MA, Lee MJ, et al. Indeterminate adrenal mass in patients with cancer: evaluation at PET with 2-[F-18]-fluoro-2-deoxy-D-glucose. Radiology 1995;194:131-4

41. Blake MA, Slattery JM, Kalra MK, et al. Adrenal lesions: characterization with fused PET/CT image in patients with proved or suspected malignancy-initial experience. Radiology 2006;238:970-7.

42. Heinz-Peer G, Honigschnabl S, Schneider B, et al. Characterization of adrenal masses using MR imaging with histopathologic correlation. AJR Am J Roentgenol 1999:173:15-22

43. Macari M, Rofsky NM, Naidich DP, et al. Non-small cell lung carcinoma: usefulness of unenhanced helical CT of the adrenal glands in an unmonitored environment. Radiology 1998:209:807-12.

44. Boland GW, Hahn PF, Pena C, et al. Adrenal masses: characterization with delayed contrast-enhanced CT. Radiology 1997;202:693-6.

45. Nielsen ME Jr, Heaston DK, Dunnick NR, et al. Preoperative CT evaluation of adrenal glands in non-small cell bronchogenic carcinoma. AJR Am J Roentgenol 1982:139:317-20.

46. Hsia TC, Shen YY, Yen RF, et al. Comparing whole body 18F-2-deoxyglucose positron emission tomography and technetium-99m methylene diophosphate bone scan to detect bone metastases in patients with non-small cell lung cancer. Neoplasma 2002; 49:267-71.

47. Hauber HP, Bohuslavizki $\mathrm{KH}$, Lund $\mathrm{CH}$, et al. Positron emission tomography in the staging of small-cell lung cancer: a preliminary study. Chest 2001:119:950-4.

48. Blum R, MacManus MP, Rischin D, et al. Impact of positron emission tomography on the management of patients with small-cell lung cancer: preliminary experience. Am J Clin Oncol 2004:27:164-71.

49. Bradley JD, Dehdashti F, Mintun MA, et al. Positron emission tomography in limitedstage small-cell lung cancer: a prospective study. J Clin Oncol 2004:22:3248-54.

50. Brink I, Schumacher T, Mix M, et al. Impact of [18F]FDG-PET on the primary staging of small-cell lung cancer. Eur J Nucl Med Mol Imaging 2004;31:1614-20.

51. Kamel EM, Zwahlen D, Wyss MT, et al. Whole-body (18)F-FDG PET improves the management of patients with small cell lung cancer. J Nucl Med 2003:44:1911-17.

52. Shen YY, Shiau YC, Wang JJ, et al. Whole-body 18F-2-deoxyglucose positron emission tomography in primary staging small cell lung cancer. Anticancer Res 2002;22:1257-64.

53. Habets JM, van Oosterhout AG, ten Velde GP, et al. Diagnostic value of CT in the detection of brain metastasis in small cell lung cancer patients. J Belge Radio 1992; 75:179-81

54. Levitan N, Hong WK, Byrne RE, et al. Role of computerized cranial tomography in the staging of small cell carcinoma of the lung. Cancer Treat Rep 1984:68:1375-7.

55. Crane JM, Nelson MJ, Inde DC, et al. A comparison of computed tomography and radionuclide scanning for detection of brain metastases in small cell lung cancer. J Clin Oncol 1984;2:1017-24.

56. Johnson DH, Windham WW, Allen JH, et al. Limited value of CT brain scans in the staging of small cell lung cancer. AJR Am J Roentgenol 1983:140:37-40.

57. Hochstenbag MM, Twijnstra A, Wilmink JT, et al. Asymptomatic brain metastases (BM) in small cell lung cancer (SCLC): MR-imaging is useful at initial diagnosis. J Neurooncol 2000:48:243-8.

58. Le Jeune I, Baldwin D. Measuring the success of transbronchial needle aspiration in everyday clinical practice. Respir Med 2007:101:670-5.

59. Gu P, Zhao YZ, Jiang LY, et al. Endobronchial ultrasound-guided transbronchial needle aspiration for staging of lung cancer: a systematic review and meta-analysis. Eur J Cancer 2009:45:1389-96.

60. Adams K, Shah P, Edmonds L, et al. Test performance of endobronchial ultrasound and transbronchial needle aspiration biopsy for mediastinal staging in patients with lung cancer: systematic review and meta-analysis. Thorax 2009;64:757-62.

61. Goldstraw P. International Association for the Study of Lung Cancer staging handbook in thoracic oncology. Florida, USA: Editorial Rx Press, 2009

62. Goldstraw P. International Association for the Study of Lung Cancer staging manual in thoracic oncology. Florida, USA: Editorial Rx Press, 2009.

63. Rusch VW, Crowley J, Giroux DJ, et al. The IASLC Lung Cancer Staging Project: proposals for the revision of the $\mathrm{N}$ descriptors in the forthcoming seventh edition of the TNM classification for lung cancer. J Thorac Oncol 2007;2:603-12.

64. Wright G, Manser RL, Byrnes G, et al. Surgery for non-small cell lung cancer: systematic review and meta-analysis of randomised controlled trials. Thorax 2006;61:597-603.
65. Henschke Cl, Yankelevitz DF, Libby DM, et al. Survival of patients with stage I lung cancer detected on CT screening. N Engl J Med 2006;355:1763-71.

66. Morrison R, Deeley TJ, Cleland WP. The treatment of carcinoma of the bronchus: a clinical trial to compare surgery and supervoltage radiotherapy. Lancet 1963;281:667-82

67. Matsuoka H, Nishio W, Okada M, et al. Resection of chest wall invasion in patients with non-small cell lung cancer. Eur J Cardiothorac Surg 2004;26:1200-4.

68. Doddoli C, D'Journo B, Le Pimpec-Barthes F, et al. Lung cancer invading the chest wall: a plea for en-bloc resection but the need for new treatment strategies. Ann Thorac Surg 2005;80:2032-40.

69. Burkhart HM, Allen MS, Nichols FC 3rd, et al. Results of en bloc resection for bronchogenic carcinoma with chest wall invasion. J Thorac Cardiovasc Surg 2002;123:670-5.

70. Battafarano RJ, Meyers BF, Guthrie TJ, et al. Surgical resection of multifocal non-small cell lung cancer is associated with prolonged survival. Ann Thorac Surg 2002; 74:988-94.

71. Rostad H, Strand TE, Naalsund A, et al. Resected synchronous primary malignant lung tumors: a population-based study. Ann Thorac Surg 2008;85:204-9.

72. DeMeester TR, Albertucci M, Dawson PJ, et al. Management of tumor adherent to the vertebral column. J Thorac Cardiovasc Surg 1989:97:373-8.

73. Grunenwald DH, Mazel C, Girard P, et al. Radical en bloc resection for lung cancer invading the spine. J Thorac Cardiovasc Surg 2002:123:271-9.

74. de Perrot M, Fadel E, Mercier 0, et al. Long-term results after carinal resection for carcinoma: does the benefit warrant the risk? J Thorac Cardiovasc Surg 2006;131:81-9.

75. Regnard JF, Perrotin C, Giovannetti R, et al. Resection for tumors with carinal involvement: technical aspects, results, and prognostic factors. Ann Thorac Surg 2005:80:1841-6.

76. Tsuchiya R, Asamura $\mathrm{H}$, Kondo $\mathrm{H}$, et al. Extended resection of the left atrium, great vessels, or both for lung cancer. Ann Thorac Surg 1994;57:960-5.

77. Pottgen C, Eberhardt W, Bildat S, et al. Induction chemotherapy followed by concurrent chemotherapy and definitive high-dose radiotherapy for patients with locally advanced non-small-cell lung cancer (stages IIla/lllb): a pilot phase I/II trial. Ann Oncol 2002:13:403-11.

78. Stupp R, Mayer M, Kann R, et al. Neoadjuvant chemotherapy and radiotherapy followed by surgery in selected patients with stage IIIB non-small-cell lung cancer: a multicentre phase II trial. Lancet Oncol 2009;10:785-93.

79. Douillard JY, Rosell R, De Lena M, et al. Adjuvant vinorelbine plus cisplatin versus observation in patients with completely resected stage IB-IIIA non-small-cell lung cancer (Adjuvant Navelbine International Trialist Association [ANITA]): a randomised controlled trial. Lancet Oncol 2006;7:719-27.

80. Shepherd FA, Johnston MR, Payne D, et al. Randomized study of chemotherapy and surgery versus radiotherapy for stage IIIA non-small-cell lung cancer: a National Cancer Institute of Canada Clinical Trials Group Study. Br J Cancer 1998;78:683-5

81. Johnstone DW, Byhardt RW, Ettinger D, et al. Phase III study comparing chemotherapy and radiotherapy with preoperative chemotherapy and surgical resection in patients with non-small-cell lung cancer with spread to mediastinal lymph nodes (N2); final report of RTOG 89-01. Radiation Therapy Oncology Group. Int J Radiat Oncol Biol Phys 2002:54:365-9.

82. van Meerbeeck JP, Kramer GW, Van Schil PE, et al. Randomized controlled trial of resection versus radiotherapy after induction chemotherapy in stage IIIA-N2 non-small-cell lung cancer. J Natl Cancer Inst 2007:99:442-50.

83. Albain KS, Swann RS, Rusch VW, et al. Radiotherapy plus chemotherapy with or without surgical resection for stage III non-small-cell lung cancer: a phase III randomised controlled trial. Lancet 2009;374:379-86.

84. Pignon JP, Tribodet H, Scagliotti GV, et al. Lung adjuvant cisplatin evaluation: a pooled analysis by the LACE Collaborative Group. J Clin Oncol 2008; 26:3552-9

85. Albain KS, Swann RS, Rusch VR, et al. Phase III study of concurrent chemotherapy and radiotherapy (CT/RT) vs CT/RT followed by surgical resection for stage IIIA (pN2) non-small cell lung cancer (NSCLC): Outcomes update of North American Intergroup 0139 (RTOG 9309) (abstract). J Clin Oncol 2005;23:7014.

86. Grunenwald DH, Andre F, Le Pechoux C, et al. Benefit of surgery after chemoradiotherapy in stage IIIB (T4 and/or N3) non-small cell lung cancer. J Thorac Cardiovasc Surg 2001;122:796-802.

87. Yokomise H, Gotoh M, Okamoto $\mathrm{T}$, et al. Induction chemoradiotherapy carboplatin-taxane and concurrent 50-Gy radiation for bulky cN2, N3 non-small cell lung cancer. J Thorac Cardiovasc Surg 2007;133:1179-85.

88. Travis WD, Müller-Hermelink HK, Harris CC, et al. Pathology and genetics of tumours of the lung, pleura, thymus and heart. Geneva: IARC Press, 2004.

89. Noguchi M, Morikawa A, Kawasaki M, et al. Small adenocarcinoma of the lung Histologic characteristics and prognosis. Cancer 1995;75:2844-52.

90. Grover FL, Piantadosi S. Recurrence and survival following resection of bronchioloalveolar carcinoma of the lung-The Lung Cancer Study Group experience. Ann Surg 1989;209:779-90.

91. Breathnach OS, Kwiatkowski DJ, Finkelstein DM, et al. Bronchioloalveolar carcinoma of the lung: recurrences and survival in patients with stage I disease. $J$ Thorac Cardiovasc Surg 2001;121:42-7.

92. Rena 0, Papalia E, Ruffini E, et al. Stage I pure bronchioloalveolar carcinoma: recurrences, survival and comparison with adenocarcinoma of the lung. Eur J Cardiothorac Surg 2003;23:409-14. 
93. Sakurai H, Dobashi Y, Mizutani E, et al. Bronchioloalveolar carcinoma of the lung 3 centimeters or less in diameter: a prognostic assessment. Ann Thorac Surg 2004;78:1728-33.

94. Roberts PF, Straznicka M, Lara PN, et al. Resection of multifocal non-small cell lung cancer when the bronchioloalveolar subtype is involved. J Thorac Cardiovasc Surg 2003;126:1597-602

95. Rusch VW, Tsuchiya R, Tsuboi M, et al. Surgery for bronchioloalveolar carcinoma and "very early" adenocarcinoma: an evolving standard of care? J Thorac Oncol 2006;1:S27-31.

96. Watanabe S, Watanabe $T$, Arai $K$, et al. Results of wedge resection for focal bronchioloalveolar carcinoma showing pure ground-glass attenuation on computed tomography. Ann Thorac Surg 2002;73:1071-5.

97. Damhuis RA, Schutte PR, Varin OC, et al. Poor results after surgery for bronchioloalveolar carcinoma. Eur J Surg Oncol 2006;32:573-6.

98. Page R, Keogh B. National Thoracic Surgery Activity and Outcomes Report. Oxford: Dendrite Clinical Systems Ltd, 2008

99. Treasure T, Utley M, Bailey A. Assessment of whether in-hospital mortality for lobectomy is a useful standard for the quality of lung cancer surgery: retrospective study. BMJ 2003;327:73

100. Berrisford R, Brunelli A, Rocco G, et al. The European Thoracic Surgery Database project: modelling the risk of in-hospital death following lung resection. Eur J Cardiothorac Surg 2005;28:306-11.

101. Harpole DH Jr, DeCamp MM Jr, Daley J, et al. Prognostic models of thirty-day mortality and morbidity after major pulmonary resection. J Thorac Cardiovasc Surg 1999:117:969-79.

102. Falcoz PE, Conti M, Brouchet L, et al. The Thoracic Surgery Scoring System (Thoracoscore): risk model for in-hospital death in 15,183 patients requiring thoracic surgery. J Thorac Cardiovasc Surg 2007:133:325-32.

103. Chamogeorgakis TP, Connery CP, Bhora F, et al. Thoracoscore predicts midterm mortality in patients undergoing thoracic surgery. J Thorac Cardiovasc Surg 2007; 134:883-7.

104. Michel P, Roques F, Nashef SA. Logistic or additive EuroSCORE for high-risk patients? Eur J Cardiothorac Surg 2003;23:684-7.

105 Massard G, Moog R, Wihlm JM, et al. Bronchogenic cancer in the elderly: operative risk and long-term prognosis. Thorac Cardiovasc Surg 1996;44:40-5

106. Salati M, Brunelli A, Xiume F, et al. Quality of life in the elderly after major lung resection for lung cancer. Interact Cardiovasc Thorac Surg 2009:8:79-83.

107. Fleisher LA, Beckman JA, Brown KA, et al. ACC/AHA 2007 Guidelines on perioperative cardiovascular evaluation and care for noncardiac surgery: a report of the American College of Cardiology/American Heart Association Task Force on Practice Guidelines (Writing Committee to Revise the 2002 Guidelines on Perioperative Cardiovascular Evaluation for Noncardiac Surgery) developed in collaboration with the American Society of Echocardiography, American Society of Nuclear Cardiology, Heart Rhythm Society, Society of Cardiovascular Anesthesiologists, Society for Cardiovascular Angiography and Interventions, Society for Vascular Medicine and Biology, and Society for Vascular Surgery. J Am Coll Cardiol 2007:50:e159-242.

108. Fleisher LA, Beckman JA, Brown KA, et al. ACC/AHA 2007 guidelines on perioperative cardiovascular evaluation and care for noncardiac surgery: a report of the American College of Cardiology/American Heart Association Task Force on Practice Guidelines (Writing Committee to Revise the 2002 Guidelines on Perioperative Cardiovascular Evaluation for Noncardiac Surgery) developed in collaboration with the American Society of Echocardiography, American Society of Nuclear Cardiology, Heart Rhythm Society, Society of Cardiovascular Anesthesiologists, Society for Cardiovascular Angiography and Interventions, Society for Vascular Medicine and Biology, and Society for Vascular Surgery. J Am Coll Cardiol 2007;50:e159-241.

109. Lee TH, Marcantonio ER, Mangione CM, et al. Derivation and prospective validation of a simple index for prediction of cardiac risk of major noncardiac surgery. Circulation 1999;100:1043-9.

110. Bangalore S, Wetterslev J, Pranesh S, et al. Perioperative beta blockers in patients having non-cardiac surgery: a meta-analysis. Lancet 2008;372:1962-76.

111. Shammash JB, Trost JC, Gold JM, et al. Perioperative beta-blocker withdrawal and mortality in vascular surgical patients. Am Heart J 2001:141:148-53.

112. Eagle KA, Rihal CS, Mickel MC, et al. Cardiac risk of noncardiac surgery: influence of coronary disease and type of surgery in 3368 operations. Circulation 1997:96:1882-7.

113. McFalls EO, Ward HB, Moritz TE, et al. Coronary-artery revascularization before elective major vascular surgery [erratum appears in N Engl J Med 2005;95:19]. N Engl J Med 2004;351:2795-804.

114. Poldermans D, Schouten 0 , Vidakovic R, et al. A clinical randomized trial to evaluate the safety of a noninvasive approach in high-risk patients undergoing major vascular surgery: the DECREASE-V pilot study. J Am Coll Cardiol 2007;49:1763-9.

115. Eagle KA, Guyton RA, Davidoff R, et al. ACC/AHA 2004 guideline update for coronary artery bypass graft surgery: summary article. A report of the American College of Cardiology/American Heart Association Task Force on Practice Guidelines (Committee to Update the 1999 Guidelines on Coronary Artery Bypass Graft Surgery). Circulation 2004;110:1168-76.

116. Markos J, Mullan BP, Hillman DR, et al. Preoperative assessment as a predictor of mortality and morbidity after lung resection. Am Rev Respir Dis 1989;139:902-10.

117. Wang J, Olak J, Ferguson MK. Diffusing capacity predicts operative mortality but not long-term survival after resection for lung cancer. J Thorac Cardiovasc Surg 1999;117:581-6; discussion 86-7.
118. Ferguson MK, Little L, Rizzo L, et al. Diffusing capacity predicts morbidity and mortality after pulmonary resection. J Thorac Cardiovasc Surg 1988;96:894-900.

119. Brunelli A, Refai M, Salati M, et al. Predicted versus observed FEV1 and DLCO after major lung resection: a prospective evaluation at different postoperative periods. Ann Thorac Surg 2007:83:1134-9

120. Bolliger CT, Jordan $\mathrm{P}$, Soler $\mathrm{M}$, et al. Pulmonary function and exercise capacity after lung resection. Eur Respir J 1996;9:415-21.

121. Ferguson MK, Vigneswaran WT. Diffusing capacity predicts morbidity after lung resection in patients without obstructive lung disease. Ann Thorac Surg 2008;85:1158-64; discussion 64-5.

122. Beckles MA, Spiro SG, Colice GL, et al. The physiologic evaluation of patients with lung cancer being considered for resectional surgery. Chest 2003;123:105S-14.

123. Colice GL, Shafazand S, Griffin JP, et al. Physiologic evaluation of the patient with lung cancer being considered for resectional surgery: ACCP evidenced-based clinica practice guidelines (2nd edition). Chest 2007:132:161-77S.

124. Win T, Jackson A, Sharples $L$, et al. Cardiopulmonary exercise tests and lung cancer surgical outcome. Chest 2005;127:1159-65.

125. Giordano A, Calcagni ML, Meduri G, et al. Perfusion lung scintigraphy for the prediction of postlobectomy residual pulmonary function. Chest 1997;111:1542-7.

126. Wernly JA, DeMeester TR, Kirchner PT, et al. Clinical value of quantitative ventilation-perfusion lung scans in the surgical management of bronchogenic carcinoma. J Thorac Cardiovasc Surg 1980;80:535-43.

127. Zeiher BG, Gross TJ, Kern JA, et al. Predicting postoperative pulmonary function in patients undergoing lung resection. Chest 1995;108:68-72.

128. Ali MK, Mountain CF, Ewer MS, et al. Predicting loss of pulmonary function after pulmonary resection for bronchogenic carcinoma. Chest 1980:77:337-42.

129. Cordiner A, De Carlo F, De Gennaro R, et al. Prediction of postoperative pulmonary function following thoracic surgery for bronchial carcinoma. Angiology 1991:42:985-9.

130. Juhl B, Frost N. A comparison between measured and calculated changes in the lung function after operation for pulmonary cancer. Acta Anaesthesiol Scand Suppl 1975:57:39-45.

131. Williams AJ, Cayton RM, Harding LK, et al. Quantitative lung scintigrams and lung function in the selection of patients for pneumonectomy. Br J Dis Chest 1984:78:105-12.

132. Bria WF, Kanarek DJ, Kazemi H. Prediction of postoperative pulmonary function following thoracic operations. Value of ventilation-perfusion scanning. J Thorac Cardiovasc Surg 1983;86:186-92.

133. Corris PA, Ellis DA, Hawkins T, et al. Use of radionuclide scanning in the preoperative estimation of pulmonary function after pneumonectomy. Thorax 1987; 42:285-91.

134. Olsen GN, Block AJ, Tobias JA. Prediction of postpneumonectomy pulmonary function using quantitative macroaggregate lung scanning. Chest 1974;66:13-16.

135. Hirose $\mathbf{Y}$, Imaeda $\mathrm{T}$, Doi $\mathrm{H}$, et al. Lung perfusion SPECT in predicting postoperative pulmonary function in lung cancer. Ann Nucl Med 1993;7:123-6.

136. Win T, Tasker AD, Groves AM, et al. Ventilation-perfusion scintigraphy to predict postoperative pulmonary function in lung cancer patients undergoing pneumonectomy. AJR Am J Roentgenol 2006;187:1260-5.

137. Wu MT, Chang JM, Chiang AA, et al. Use of quantitative CT to predict postoperative lung function in patients with lung cancer. Radiology 1994;191:257-62.

138. Wu MT, Pan HB, Chiang AA, et al. Prediction of postoperative lung function in patients with lung cancer: comparison of quantitative CT with perfusion scintigraphy. AJR Am J Roentgenol 2002;178:667-72

139. Ohno Y, Koyama H, Nogami M, et al. Postoperative lung function in lung cancer patients: comparative analysis of predictive capability of MRI, CT, and SPECT. AJR Am J Roentgenol 2007:189:400-8.

140. Holden DA, Rice TW, Stelmach K, et al. Exercise testing, 6-min walk, and stair climb in the evaluation of patients at high risk for pulmonary resection. Chest 1992:102:1774-9.

141. Cote CG, Pinto-Plata V, Kasprzyk K, et al. The 6-min walk distance, peak oxygen uptake, and mortality in COPD. Chest 2007:132:1778-85.

142. Oudiz RJ, Barst RJ, Hansen JE, et al. Cardiopulmonary exercise testing and six-minute walk correlations in pulmonary arterial hypertension. Am J Cardiol 2006:97:123-6.

143. Bernstein ML, Despars JA, Singh NP, et al. Reanalysis of the 12-minute walk in patients with chronic obstructive pulmonary disease. Chest 1994;105:163-7.

144. Bagg LR. The 12-min walking distance: its use in the pre-operative assessment of patients with bronchial carcinoma before lung resection. Respiration 1984;46:342-5

145. Singh SJ, Morgan MD, Hardman AE, et al. Comparison of oxygen uptake during a conventional treadmill test and the shuttle walking test in chronic airflow limitation. Eur Respir J 1994; 7:2016-20.

146. Morgan AD. Simple exercise testing. Respir Med 1989:83:383-7.

147. Win T, Jackson A, Groves AM, et al. Relationship of shuttle walk test and lung cancer surgical outcome. Eur J Cardiothorac Surg 2004;26:1216-19.

148. Win T, Jackson A, Groves AM, et al. Comparison of shuttle walk with measured peak oxygen consumption in patients with operable lung cancer. Thorax 2006;61:57-60

149. Olsen GN, Bolton JW, Weiman DS, et al. Stair climbing as an exercise test to predict the postoperative complications of lung resection. Two years' experience. Chest 1991:99:587-90.

150. Van Nostrand D, Kjelsberg MO, Humphrey EW. Preresectional evaluation of risk from pneumonectomy. Surg Gynecol Obstet 1968;127:306-12. 
151. Girish M, Trayner E Jr, Dammann 0, et al. Symptom-limited stair climbing as a predictor of postoperative cardiopulmonary complications after high-risk surgery. Chest 2001;120:1147-51.

152. Brunelli A, Al Refai M, Monteverde M, et al. Stair climbing test predicts cardiopulmonary complications after lung resection. Chest 2002;121:1106-10.

153. Bechard D, Wetstein L. Assessment of exercise oxygen consumption as preoperative criterion for lung resection. Ann Thorac Surg 1987:44:344-9.

154. Bolliger CT, Jordan P, Soler M, et al. Exercise capacity as a predictor of postoperative complications in lung resection candidates. Am J Respir Crit Care Med 1995;151:1472-80.

155. Boysen PG, Clark CA, Block AJ. Graded exercise testing and postthoracotomy complications. J Cardiothorac Anesth 1990;4:68-72.

156. Brunelli A, Belardinelli R, Refai $M$, et al. Peak oxygen consumption during cardiopulmonary exercise test improves risk stratification in candidates to major lung resection. Chest 2009;135:1260-7.

157. Brutsche MH, Spiliopoulos A, Bolliger CT, et al. Exercise capacity and extent of resection as predictors of surgical risk in lung cancer. Eur Respir $\mathrm{J}$ 2000;15:828-32.

158. Epstein SK, Faling LJ, Daly BD, et al. Predicting complications after pulmonary resection. Preoperative exercise testing vs a multifactorial cardiopulmonary risk index. Chest 1993;104:694-700.

159. Richter Larsen K, Svendsen UG, Milman N, et al. Exercise testing in the preoperative evaluation of patients with bronchogenic carcinoma. Eur Respir $J$ 1997; 10:1559-65.

160. Morice RC, Peters EJ, Ryan MB, et al. Exercise testing in the evaluation of patients at high risk for complications from lung resection. Chest 1992;101:356-61.

161. Smith TP, Kinasewitz GT, Tucker WY, et al. Exercise capacity as a predictor of post-thoracotomy morbidity. Am Rev Respir Dis 1984;129:730-4.

162. Torchio R, Gulotta C, Parvis M, et al. Gas exchange threshold as a predictor of severe postoperative complications after lung resection in mild-to-moderate chronic obstructive pulmonary disease. Monaldi Arch Chest Dis 1998:53:127-33.

163. Villani F, Busia A. Preoperative evaluation of patients submitted to pneumonectomy for lung carcinoma: role of exercise testing. Tumori 2004:90:405-9.

164. Wang JS. Pulmonary function tests in preoperative pulmonary evaluation. Respir Med 2004:98:598-605.

165. Wang J, Olak J, Ultmann RE, et al. Assessment of pulmonary complications after lung resection. Ann Thorac Surg 1999;67:1444-7.

166. Akkoca 0, Eris Gulbay B, Kaya A, et al. [The importance of exercise testing for the functional assessment of lung resectional candidates]. Tuberk Toraks 2004; 52:307-14.

167. Gomibuchi M, Fujisaki T, Tanaka S, et al. [Exercise test to predict postoperative complications in patients with impairment of pulmonary function]. Nippon Kyobu Geka Gakkai Zasshi 1993;41:403-8.

168. Bayram AS, Candan T, Gebitekin C. Preoperative maximal exercise oxygen consumption test predicts postoperative pulmonary morbidity following major lung resection. Respirology 2007;12:505-10.

169. Benzo R, Kelley GA, Recchi L, et al. Complications of lung resection and exercise capacity: a meta-analysis. Respir Med 2007;101:1790-7.

170. Loewen GM, Watson D, Kohman L, et al. Preoperative exercise $\mathrm{V}_{2}$ measurement for lung resection candidates: results of Cancer and Leukemia Group B Protocol 9238. J Thorac Oncol 2007;2:619-25

171. Yabroff KR, McNeel TS, Waldron WR, et al. Health limitations and quality of life associated with cancer and other chronic diseases by phase of care. Med Care 2007; 45:629-37.

172. Schag CA, Ganz PA, Wing DS, et al. Quality of life in adult survivors of lung, colon and prostate cancer. Qual Life Res 1994;3:127-41.

173. Ko CY, Maggard M, Livingston EH. Evaluating health utility in patients with melanoma, breast cancer, colon cancer, and lung cancer: a nationwide, population-based assessment. J Surg Res 2003;114:1-5.

174. Sugimura H, Yang P. Long-term survivorship in lung cancer: a review. Chest 2006;129:1088-97.

175. Dales RE, Belanger R, Shamji FM, et al. Quality-of-life following thoracotomy for lung cancer. J Clin Epidemiol 1994;47:1443-9.

176. Zieren HU, Muller JM, Hamberger U, et al. Quality of life after surgical therapy of bronchogenic carcinoma. Eur J Cardiothorac Surg 1996;10:233-7.

177. Win T, Sharples L, Wells FC, et al. Effect of lung cancer surgery on quality of life. Thorax 2005;60:234-8.

178. Brunelli A, Socci L, Refai M, et al. Quality of life before and after major lung resection for lung cancer: a prospective follow-up analysis. Ann Thorac Surg 2007;84:410-16.

179. Balduyck B, Hendriks J, Lauwers $\mathbf{P}$, et al. Quality of life evolution after lung cancer surgery: a prospective study in 100 patients. Lung Cancer 2007;56:423-31.

180. Schulte T, Schniewind B, Dohrmann P, et al. The extent of lung parenchyma resection significantly impacts long-term quality of life in patients with non-small cell lung cancer. Chest 2009;135:322-9.

181. Larsen KR, Svendsen UG, Milman N, et al. Cardiopulmonary function at rest and during exercise after resection for bronchial carcinoma. Ann Thorac Surg 1997;64:960-4.

182. Peddle CJ, Jones LW, Eves ND, et al. Effects of presurgical exercise training on quality of life in patients undergoing lung resection for suspected malignancy: a pilot study. Cancer Nurs 2009;32:158-65
183. Sarna L, Evangelista L, Tashkin D, et al. Impact of respiratory symptoms and pulmonary function on quality of life of long-term survivors of non-small cell lung cancer. Chest 2004;125:439-45.

184. Paull DE, Thomas ML, Meade GE, et al. Determinants of quality of life in patients following pulmonary resection for lung cancer. Am J Surg 2006;192:565-71.

185. Schulte T, Schniewind B, Walter J, et al. Age-related impairment of quality of life after lung resection for non-small cell lung cancer. Lung Cancer 2010;68:115-20.

186. Deslauriers J, Gregoire J, Jacques LF, et al. Sleeve lobectomy versus pneumonectomy for lung cancer: a comparative analysis of survival and sites or recurrences. Ann Thorac Surg 2004;77:1152-6.

187. Rendina EA, Venuta F, De Giacomo $T$, et al. Sleeve resection and prosthetic reconstruction of the pulmonary artery for lung cancer. Ann Thorac Surg 1999:68:995-1001.

188. Venuta F, Ciccone AM. Reconstruction of the pulmonary artery. Semin Thorac Cardiovasc Surg 2006;18:104-8.

189. Ginsberg RJ, Rubinstein L. The comparison of limited resection to lobectomy for T1N0 non-small cell lung cancer. LCSG 821. Chest 1994;106:318-19S.

190. National Emphysema Treatment Trial Research Group. A randomized tria comparing lung-volume-reduction surgery with medical therapy for severe emphysema. N Engl J Med 2003;348:2059-73

191. Lim E, Ali A, Cartwright N, et al. Effect and duration of lung volume reduction surgery: mid-term results of the Brompton trial. Thorac Cardiovasc Surg 2006;54:188-92.

192. Geddes D, Davies M, Koyama $\mathrm{H}$, et al. Effect of lung-volume-reduction surgery in patients with severe emphysema. N Engl J Med 2000;343:239-45.

193. Criner GJ, Cordova FC, Furukawa S, et al. Prospective randomized trial comparing bilateral lung volume reduction surgery to pulmonary rehabilitation in severe chronic obstructive pulmonary disease. Am J Respir Crit Care Med 1999;160:2018-27.

194. Patients at high risk of death after lung-volume-reduction surgery. $N$ Engl J Med 2001:345:1075-83.

195. Allen MS, Darling GE, Pechet $\Pi$, et al. Morbidity and mortality of major pulmonary resections in patients with early-stage lung cancer: initial results of the randomized prospective ACOSOG Z0030 trial. Ann Thorac Surg 2006;81:1013-19; discussion $19-20$

196. Izbicki JR, Passlick B, Karg O, et al. Impact of radical systematic mediastinal lymphadenectomy on tumor staging in lung cancer. Ann Thorac Surg 1995; 59:209-14.

197. Wu Y, Huang ZF, Wang SY, et al. A randomized trial of systematic nodal dissection in resectable non-small cell lung cancer. Lung Cancer 2002;36:1-6.

198. Demicheli R, Retsky MW, Hrushesky WJ, et al. The effects of surgery on tumo growth: a century of investigations. Ann Oncol 2008;19:1821-8.

199. Fisher B, Saffer E, Rudock C, et al. Effect of local or systemic treatment prior to primary tumor removal on the production and response to a serum growth-stimulating factor in mice. Cancer Res 1989;49:2002-4.

200. Roth JA, Fossella F, Komaki R, et al. A randomized trial comparing perioperative chemotherapy and surgery with surgery alone in resectable stage IIIA non-small-cell lung cancer. J Natl Cancer Inst 1994;86:673-80.

201. Rosell R, Gómez CJ, Camps C, et al. A randomized trial comparing preoperative chemotherapy plus surgery with surgery alone in patients with non-small-cell lung cancer. N Engl J Med 1994;330:153-8.

202. Burdett S, Stewart LA, Rydzewska L. A systematic review and meta-analysis of the literature: chemotherapy and surgery versus surgery alone in non-small cell lung cancer. J Thorac Oncol 2006;1:611-21.

203. Gilligan D, Nicolson M, Smith I, et al. Preoperative chemotherapy in patients with resectable non-small cell lung cancer: results of the MRC LU22/NVALT 2/EORTC 08012 multicentre randomised trial and update of systematic review. Lancet 2007:369:1929-37.

204. Pisters KM, Evans WK, Azzoli CG, et al. Cancer Care Ontario and American Society of Clinical Oncology adjuvant chemotherapy and adjuvant radiation therapy for stages I-IIIA resectable non small-cell lung cancer guideline. J Clin Oncol 2007;25:5506-18.

205. Bradbury PA, Shepherd FA. Chemotherapy and surgery for operable NSCLC Lancet 2007;369:1903-4.

206. Kato $\mathbf{H}$, Ichinose $\mathrm{Y}$, Ohta $\mathbf{M}$, et al. A randomized trial of adjuvant chemotherapy with Uracil-Tegafur for adenocarcinoma of the lung. $N$ Engl J Med 2004;350:1713-21.

207. Scagliotti GV, Fossati R, Torri V, et al. Randomized study of adjuvant chemotherapy for completely resected stage I, II, or IIIA non-small-cell lung cancer J Natl Cancer Inst 2003;95:1453-61.

208. Arriagada R, Bergman B, Dunant A, et al. Cisplatin-based adjuvant chemotherapy in patients with completely resected non-small-cell lung cancer. $N$ Engl J Med 2004;350:351-60

209. Winton T, Livingston R, Johnson D, et al. Vinorelbine plus cisplatin vs. observation in resected non-small-cell lung cancer. N Engl J Med 2005;352:2589-97.

210. Strauss GM, Herndon J, Maddaus MA, et al. Adjuvant chemotherapy in stage IB non-small cell lung cancer (NSCLC): update of Cancer and Leukemia Group B (CALGB) protocol 9633 (abstract). J Clin Oncol 2006;24(18S):7007.

211. Study Group of Adjuvant Chemotherapy for Lung Cancer (Chubu J. A randomized trial of postoperative adjuvant chemotherapy in non-small cell lung cancer (the second cooperative study). The Study Group of Adjuvant Chemotherapy for Lung Cancer (Chubu, Japan). Eur J Surg Oncol 1995;21:69-77. 
212. Sedrakyan A, Van Der Meulen J, O'Byrne K et al. Postoperative chemotherapy for non-small cell lung cancer: a systematic review and meta-analysis. J Thorac Cardiovasc Surg 2004;128:414-19.

213. Hotta K, Matsuo K, Ueoka $\mathrm{H}$, et al. Role of adjuvant chemotherapy in patients with resected non-small-cell lung cancer: reappraisal with a meta-analysis of randomized controlled trials. J Clin Oncol 2004:22:3860-7.

214. Hamada C, Tanaka F, Ohta M, et al. Meta-analysis of postoperative adjuvant chemotherapy with tegafur-uracil in non-small-cell lung cancer. J Clin Oncol 2005:23:4999-5006.

215. Alam N, Darling G, Evans WK, et al. Adjuvant chemotherapy for completely resected non-small cell lung cancer: a systematic review. Crit Rev Oncol Hematol 2006;58:146-55

216. Alam N, Shepherd FA, Winton T, et al. Compliance with post-operative adjuvant chemotherapy in non-small cell lung cancer. An analysis of National Cancer Institute of Canada and intergroup trial JBR10 and a review of the literature. Lung Cancer 2005; 47:385-94

217. Douillard J, Rosell R, Delena $\mathrm{M}$, et al. Phase III adjuvant vinorelbine (N) and cisplatin (P) versus observation (OBS) in completely resected (stage I-III) non-small-cell lung cancer (NSCLC) patients (pts): final results after 70-month median follow-up. On behalf of the Adjuvant Navelbine International Trialist Association. J Clin Oncol 2005;23(16S):abstract 7013.

218. Gebbia V, Galetta D, Lorusso V, et al. Cisplatin plus weekly vinorelbine versus cisplatin plus vinorelbine on days 1 and 8 in advanced non-small cell lung cancer: a prospective randomized phase III trial of the G.O.I.M. (Gruppo Oncologico Italia Meridionale). Lung Cancer 2008;61:369-77.

219. Anon. Postoperative radiotherapy in non-small-cell lung cancer: systematic review and meta-analysis of individual patient data from nine randomised controlled trials. PORT Meta-analysis Trialists Group. Lancet 1998;352:257-63.

220. Trodella L, Granone P, Valente S, et al. Adjuvant radiotherapy in non-small cell lung cancer with pathological stage I: definitive results of a phase III randomized trial. Radiother Oncol 2002:62:11-19.

221. Burdett S, Stewart L. Postoperative radiotherapy in non-small-cell lung cancer: update of an individual patient data meta-analysis. Lung Cance 2005; 47:81-3

222. Feng $\mathbf{0 F}$, Wang $\mathbf{M}$, Wang LJ, et al. A study of postoperative radiotherapy in patients with non-small-cell lung cancer: a randomized trial. Int J Radiat Oncol Biol Phys 2000; $47: 925-9$

223. Mayer R, Smolle-Juettner FM, Szolar D, et al. Postoperative radiotherapy in radically resected non-small cell lung cancer. Chest 1997:112:954-9.

224. Lally BE, Zelterman D, Colasanto JM, et al. Postoperative radiotherapy for stage II or III non-small-cell lung cancer using the surveillance, epidemiology, and end results database. J Clin Oncol 2006;24:2998-3006.

225. Wind J, Smit EJ, Senan S, et al. Residual disease at the bronchial stump after curative resection for lung cancer. Eur J Cardiothorac Surg 2007:32:29-34.

226. Jassem J. The role of radiotherapy in lung cancer: where is the evidence? Radiother Oncol 2007;83:203-13

227. Massard G, Doddoli C, Gasser B, et al. Prognostic implications of a positive bronchial resection margin. Eur J Cardiothorac Surg 2000;17:557-65.

228. Kimura H, Yamaguchi Y. Survival of noncuratively resected lung cancer. Lung Cancer 1994:11:229-42.

229. Ghiribelli C, Voltolini L, Paladini P, et al. Treatment and survival after lung resection for non-small cell lung cancer in patients with microscopic residual disease at the bronchial stump. Eur J Cardiothorac Surg 1999:16:555-9.

230. Gebitekin C, Gupta NK, Satur CM, et al. Fate of patients with residual tumour at the bronchial resection margin. Eur J Cardiothorac Surg 1994;8:339-42; discussion 42-4.

231. Heikkila L, Harjula A, Suomalainen RJ, et al. Residual carcinoma in bronchial resection line. Ann Chir Gynaecol 1986;75:151-4.

232. Snijder RJ, Brutel de la Riviere A, Elbers HJ, et al. Survival in resected stage I lung cancer with residual tumor at the bronchial resection margin. Ann Thorac Surg 1998;65:212-16.

233. Kaiser LR, Fleshner P, Keller S, et al. Significance of extramucosal residual tumor at the bronchial resection margin. Ann Thorac Surg 1989;47:265-9.

234. Law MR, Hodson ME, Lennox SC. Implications of histologically reported residual tumour on the bronchial margin after resection for bronchial carcinoma. Thorax 1982;37:492-5.

235. Liewald F, Hatz RA, Dienemann $\mathrm{H}$, et al. Importance of microscopic residual disease at the bronchial margin after resection for non-small-cell carcinoma of the lung. J Thorac Cardiovasc Surg 1992;104:408-12.

236. Anon. Patterns of failure in patients with resected stage I and II non-small-cell carcinoma of the lung. The Ludwig Lung Cancer Study Group. Ann Surg 1987; 205:67-71

237. Hofmann HS, Taege C, Lautenschlager C, et al. Microscopic (R1) and macroscopic (R2) residual disease in patients with resected non-small cell lung cancer. Eur J Cardiothorac Surg 2002;21:606-10.

238. Senan S, De Ruysscher D, Giraud P, et al. Literature-based recommendations for treatment planning and execution in high-dose radiotherapy for lung cancer Radiother Oncol 2004;71:139-46.

239. Bogart JA, Aronowitz JN. Localized non-small cell lung cancer: adjuvant radiotherapy in the era of effective systemic therapy. Clin Cancer Res 2005; 11:5004s-10.
240. Milano MT, Constine LS, Okunieff P. Normal tissue tolerance dose metrics for radiation therapy of major organs. Semin Radiat Oncol 2007;17:131-40.

241. Schultheiss TE, Kun LE, Ang KK, et al. Radiation response of the central nervous system. Int J Radiat Oncol Biol Phys 1995;31:1093-112.

242. van Baardwijk A, Bosmans G, Bentzen SM, et al. Radiation dose prescription for non-small-cell lung cancer according to normal tissue dose constraints: an in silico clinical trial. Int J Radiat Oncol Biol Phys 2008;71:1103-10.

243. van Baardwijk A, Bosmans G, Boersma L, et al. Individualized radical radiotherapy of non-small-cell lung cancer based on normal tissue dose constraints: a feasibility study. Int J Radiat Oncol Biol Phys 2008;71:1394-401.

244. Graham MV, Purdy JA, Emami B, et al. Clinical dose-volume histogram analysis for pneumonitis after 3D treatment for non-small cell lung cancer (NSCLC). Int J Radiat Oncol Biol Phys 1999;45:323-9.

245. Kwa SL, Lebesque JV. Theuws JC, et al. Radiation pneumonitis as a function of mean lung dose: an analysis of pooled data of 540 patients. Int J Radiat Oncol Biol Phys 1998;42:1-9.

246. Roach M 3rd, Gandara DR, Yuo HS, et al. Radiation pneumonitis following combined modality therapy for lung cancer: analysis of prognostic factors. J Clin Oncol 1995;13:2606-12.

247. Gandara DR, Chansky K, Albain KS, et al. Consolidation docetaxel after concurrent chemoradiotherapy in stage IIIB non-small-cell lung cancer: phase II Southwest Oncology Group Study S9504. J Clin Oncol 2003;21:2004-10.

248. Borst GR, De Jaeger K, Belderbos JS, et al. Pulmonary function changes after radiotherapy in non-small-cell lung cancer patients with long-term disease-free survival. Int J Radiat Oncol Biol Phys 2005;62:639-44.

249. Rancati T, Ceresoli GL, Gagliardi G, et al. Factors predicting radiation pneumonitis in lung cancer patients: a retrospective study. Radiother Oncol 2003;67:275-83.

250. Miller KL, Shafman TD, Marks LB. A practical approach to pulmonary risk assessment in the radiotherapy of lung cancer. Semin Radiat Oncol 2004;14:298-307.

251. Abratt RP, Willcox PA, Smith JA. Lung cancer in patients with borderline lung functions - zonal lung perfusion scans at presentation and lung function after high dose irradiation. Radiother Oncol 1990;19:317-22.

252. Choi NC, Kanarek DJ. Toxicity of thoracic radiotherapy on pulmonary function in lung cancer. Lung Cancer 1994;10(Suppl 1):S219-30.

253. Fujino M, Shirato $\mathrm{H}$, Onishi $\mathrm{H}$, et al. Characteristics of patients who developed radiation pneumonitis requiring steroid therapy after stereotactic irradiation for lung tumors. Cancer J 2006;12:41-6.

254. Marks LB, Munley MT, Bentel GC, et al. Physical and biological predictors of changes in whole-lung function following thoracic irradiation. Int J Radiat Oncol Biol Phys 1997;39:563-70.

255. Tsujino K, Hirota $\mathrm{S}$, Endo $\mathrm{M}$, et al. Predictive value of dose-volume histogram parameters for predicting radiation pneumonitis after concurrent chemoradiation for lung cancer. Int J Radiat Oncol Biol Phys 2003;55:110-15.

256. Robnett TJ, Machtay M, Vines EF, et al. Factors predicting severe radiation pneumonitis in patients receiving definitive chemoradiation for lung cancer Int J Radiat Oncol Biol Phys 2000;48:89-94.

257. Kocak Z, Borst GR, Zeng J, et al. Prospective assessment of dosimetric/ physiologic-based models for predicting radiation pneumonitis. Int J Radiat Oncol Biol Phys 2007:67:178-86.

258. Henderson M, McGarry R, Yiannoutsos C, et al. Baseline pulmonary function as a predictor for survival and decline in pulmonary function over time in patients undergoing stereotactic body radiotherapy for the treatment of Stage I non-smallcell lung cancer. Int J Radiat Oncol Biol Phys 2008;72:404-9.

259. Cooper JD, Pearson G, Todd TR, et al. Radiotherapy alone for patients with operable carcinoma of the lung. Chest 1985:87:289-92.

260. Coy $\mathbf{P}$, Kennelly GM. The role of curative radiotherapy in the treatment of lung cancer. Cancer 1980:45:698-702.

261. Dosoretz DE, Katin MJ, Blitzer PH, et al. Radiation therapy in the management of medically inoperable carcinoma of the lung: results and implications for future treatment strategies. Int J Radiat Oncol Biol Phys 1992:24:3-9.

262. Gauden S, Ramsay J, Tripcony L. The curative treatment by radiotherapy alone of stage I non-small cell carcinoma of the lung. Chest 1995;108:1278-82.

263. Graham PH, Gebski VJ, Langlands A0. Radical radiotherapy for early nonsmall cell lung cancer. Int J Radiat Oncol Biol Phys 1995;31:261-6.

264. Haffty BG, Goldberg NB, Gerstley J, et al. Results of radical radiation therapy in clinical stage I, technically operable non-small cell lung cancer. Int J Radiat Oncol Biol Phys 1988;15:69-73.

265. Noordijk EM, vd Poest Clement E, Hermans J, et al. Radiotherapy as an alternative to surgery in elderly patients with resectable lung cancer. Radiother Oncol 1988;13:83-9.

266. Sibley GS, Jamieson TA, Marks LB, et al. Radiotherapy alone for medically inoperable stage I non-small-cell lung cancer: the Duke experience. Int J Radiat Oncol Biol Phys 1998;40:149-54

267. Rowell NP, Williams CJ. Radical radiotherapy for stage $\mathrm{I} / \mathrm{I}$ non-small cell lung cancer in patients not sufficiently fit for or declining surgery (medically inoperable) a systematic review. Thorax 2001;56:628-38.

268. Saunders $\mathbf{M}$, Dische S, Barrett A, et al. Continuous, hyperfractionated, accelerated radiotherapy (CHART) versus conventional radiotherapy in non-small cell lung cancer: mature data from the randomised multicentre trial. CHART Steering committee. Radiother Oncol 1999;52:137-48. 
269. Bradley J, Graham MV, Winter K, et al. Toxicity and outcome results of RTOG 9311: a phase I-II dose-escalation study using three-dimensional conformal radiotherapy in patients with inoperable non-small-cell lung carcinoma. Int $J$ Radiat Oncol Biol Phys 2005;61:318-28.

270. Chen M, Hayman JA, Ten Haken RK, et al. Long-term results of high-dose conformal radiotherapy for patients with medically inoperable T1-3NO non-smallcell lung cancer: is low incidence of regional failure due to incidental nodal irradiation? Int J Radiat Oncol Biol Phys 2006;64:120-6.

271. Rosenzweig KE, Fox JL, Yorke E, et al. Results of a phase I dose-escalation study using three-dimensional conformal radiotherapy in the treatment of inoperable nonsmall cell lung carcinoma. Cancer 2005;103:2118-27.

272. Baumann P, Nyman J, Lax I, et al. Factors important for efficacy of stereotactic body radiotherapy of medically inoperable stage I lung cancer. A retrospective analysis of patients treated in the Nordic countries. Acta Oncol 2006;45:787-95.

273. Lagerwaard FJ, Haasbeek CJ, Smit EF, et al. Outcomes of risk-adapted fractionated stereotactic radiotherapy for stage I non-small-cell lung cancer. Int J Radiat Oncol Biol Phys 2008:70:685-92.

274. Nagata Y, Takayama K, Matsuo Y, et al. Clinical outcomes of a phase $\mathrm{I} / \mathrm{ll}$ study of 48 Gy of stereotactic body radiotherapy in 4 fractions for primary lung cancer using a stereotactic body frame. Int J Radiat Oncol Biol Phys 2005:63:1427-31.

275. Nyman J, Johansson KA, Hulten U. Stereotactic hypofractionated radiotherapy for stage I non-small cell lung cancer: mature results for medically inoperable patients. Lung Cancer 2006:51:97-103.

276. Onishi H, Shirato H, Nagata Y, et al. Hypofractionated stereotactic radiotherapy (HypoFXSRT) for stage I non-small cell lung cancer: updated results of 257 patients in a Japanese multi-institutional study. J Thorac Oncol 2007;2(7 Suppl 3):S94-100.

277. Salazar OM, Sandhu TS, Lattin PB, et al. Once-weekly, high-dose stereotactic body radiotherapy for lung cancer: 6-year analysis of 60 early-stage, 42 locally advanced, and 7 metastatic lung cancers. Int J Radiat Oncol Biol Phys 2008;72:707-15.

278. Timmerman RD, Park C, Kavanagh BD. The North American experience with stereotactic body radiation therapy in non-small cell lung cancer. J Thorac Oncol 2007;2(7 Suppl 3):S101-12

279. Uematsu M, Shioda A, Suda A, et al. Computed tomography-guided frameless stereotactic radiotherapy for stage I non-small cell lung cancer: a 5-year experience. Int J Radiat Oncol Biol Phys 2001:51:666-70.

280. Onishi H, Araki T, Shirato H, et al. Stereotactic hypofractionated high-dose irradiation for stage I nonsmall cell lung carcinoma: clinical outcomes in 245 subjects in a Japanese multinstitutional study. Cancer 2004;101:1623-31.

281. Timmerman R, McGarry R, Yiannoutsos C, et al. Excessive toxicity when treating central tumors in a phase II study of stereotactic body radiation therapy for medically inoperable early-stage lung cancer. J Clin Oncol 2006:24:4833-9.

282. Uno T, Aruga T, Isobe $\mathrm{K}$, et al. Radiation bronchitis in lung cancer patient treated with stereotactic radiation therapy. Radiat Med 2003;21:228-31.

283. Fournel P, Robinet G, Thomas P, et al. Randomized phase III trial of sequential chemoradiotherapy compared with concurrent chemoradiotherapy in locally advanced non-small-cell lung cancer: Groupe Lyon-Saint-Etienne d'Oncologie Thoracique-Groupe Francais de Pneumo-Cancerologie NPC 95-01 Study. J Clin Oncol 2005;

23:5910-7.

284. Kelly K, Chansky K, Gaspar LE, et al. Phase III trial of maintenance gefitinib or placebo after concurrent chemoradiotherapy and docetaxel consolidation in inoperable stage III non-small-cell lung cancer: SWOG SO023. J Clin Oncol 2008;26:2450-6.

285. Hanna N, Neubauer M, Yiannoutsos C, et al. Phase III study of cisplatin, etoposide, and concurrent chest radiation with or without consolidation docetaxel in patients with inoperable stage III non-small-cell lung cancer: the Hoosier Oncology Group and U.S. Oncology. J Clin Oncol 2008;26:5755-60.

286. Auperin A, Curran WJ. Concomitant radio-chemotherapy (RT-CT) versus sequential RT-CT in locally advanced non-small cell lung cancer (NSCLC): a meta-analysis using individual patient data (IPD) from randomised clinical trials. J Thorac Oncol 2007;2(Suppl 4):S310.

287. Rowell NP, O'Rourke NP. Concurrent chemoradiotherapy in non-small cell lung cancer. Cochrane Database Syst Rev 2004:(4):CD002140.

288. Auperin A, Rolland E, Curran WJ, et al. Concomitant radio-chemotherapy (RT-CT) versus sequential RT-CT in locally adnvanced non-small cell lung cancer (NSCLC) a meta-analysis using individual patient data form randomised clinical trials. $J$ Thorac Oncol 2007; 2:S310

289. Belani CP, Choy H, Bonomi P, et al. Combined chemoradiotherapy regimens of paclitaxel and carboplatin for locally advanced non-small-cell lung cancer: a randomized phase II locally advanced multi-modality protocol. J Clin Oncol 2005;23:5883-91.

290. Vokes EE, Herndon JE 2nd, Crawford J, et al. Randomized phase II study of cisplatin with gemcitabine or paclitaxel or vinorelbine as induction chemotherapy followed by concomitant chemoradiotherapy for stage IIIB non-small-cell lung cancer: cancer and leukemia group B study 9431. J Clin Oncol 2002:20:4191-8.

291. Zatloukal P, Petruzelka L, Zemanova M, et al. Concurrent versus sequential chemoradiotherapy with cisplatin and vinorelbine in locally advanced non-small cell lung cancer: a randomized study. Lung Cancer 2004:46:87-98.

292. Krzakowski M, Provencio M, Utracka-Hutka B, et al. Oral vinorelbine and cisplatin as induction chemotherapy and concomitant chemo-radiotherapy in stage III non-small cell lung cancer: final results of an international phase II trial. J Thorac Oncol 2008;3:994-1002

293. Machtay M, Swann S, Komaki R, et al. Higher BED is associated with improved local-regional control and survival for NSCLC treated with chemoradiotherapy: an RTOG analysis. Int J Rad Oncol Biol Phys 2005;63(Suppl 1):S40.
294. Hanna NH, Neubauer M, Ansari R, et al. Phase III trial of cisplatin (P) plus etoposide (E) plus concurrent chest radiation (XRT) with or without consolidation docetaxel (D) in patients (pts) with inoperable stage III non-small cell lung cancer (NSCLC): HOG LUN 01-24/USO-023. 2007 ASCO Annual Meeting Proceedings Part I. J Clin Oncol 2007;25(Suppl 18S):7512.

295. Anon. Chemotherapy in non-small cell lung cancer: a meta-analysis using updated data on individual patients from 52 randomised clinical trials. Non-small Cell Lung Cancer Collaborative Group. BMJ 1995;311:899-909.

296. Buccheri G, Ferrigno D. Therapeutic options for regionally advanced non-small cell lung cancer. Lung Cancer 1996;14:281-300.

297. Marino P, Preatoni A, Cantoni A. Randomized trials of radiotherapy alone versus combined chemotherapy and radiotherapy in stages Illa and Illb nonsmall cell lung cancer. A meta-analysis. Cancer 1995;76:593-601.

298. Lester JF, Macbeth FR, Brewster AE, et al. CT-planned accelerated hypofractionated radiotherapy in the radical treatment of non-small cell lung cancer. Lung Cancer 2004;45:237-42.

299. Baumann M, Herrmann T, Koch R. Final results of the randomised phase III CHARTWL trial comparing hyperfractionated accelerated vs conventionally fractionated radiotherapy in non small cell lung cancer. Eur $J$ Cancer 2009;7(3 Suppl):4

300. Simon CJ, Dupuy DE, DiPetrillo TA, et al. Pulmonary radiofrequency ablation: long-term safety and efficacy in 153 patients. Radiology 2007;243:268-75.

301. Hata M, Tokuuye K, Kagei K, et al. Hypofractionated high-dose proton beam therapy for stage I non-small-cell lung cancer: preliminary results of a phase I/ll clinical study. Int J Radiat Oncol Biol Phys 2007;68:786-93.

302. Abbas G, Schuchert MJ, Pennathur A, et al. Ablative treatments for lung tumors: radiofrequency ablation, stereotactic radiosurgery, and microwave ablation. Thorac Surg Clin 2007;17:261-71.

303. Grieco CA, Simon CJ, Mayo-Smith WW, et al. Percutaneous image-guided therma ablation and radiation therapy: outcomes of combined treatment for 41 patients with inoperable stage 1/II non-small-cell lung cancer. J Vasc Intervent Radiol 2006:17:1117-24.

304. Pignon JP, Arriagada R, Inde DC, et al. A meta-analysis of thoracic radiotherapy for small-cell lung cancer. N Engl J Med 1992;327:1618-24.

305. Warde P, Payne D. Does thoracic irradiation improve survival and local control in limited-stage small-cell carcinoma of the lung? A meta-analysis. J Clin Oncol 1992:10:890-5.

306. Mascaux C, Paesmans M, Berghmans T, et al. A systematic review of the role of etoposide and cisplatin in the chemotherapy of small cell lung cancer with methodology assessment and meta-analysis. Lung Cancer 2000:30:23-36.

307. Pujol JL, Carestia L, Daures JP. Is there a case for cisplatin in the treatment of small-cell lung cancer? A meta-analysis of randomized trials of a cisplatin-containing regimen versus a regimen without this alkylating agent. Br J Cancer 2000:83:8-15.

308. Jeremic B, Shibamoto Y, Acimovic L, et al. Initial versus delayed accelerated hyperfractionated radiation therapy and concurrent chemotherapy in limited small-cell lung cancer: a randomized study. J Clin Oncol 1997:15:893-900.

309. Takada M, Fukuoka M, Kawahara M, et al. Phase III study of concurrent versus sequential thoracic radiotherapy in combination with cisplatin and etoposide for limited-stage small-cell lung cancer: results of the Japan Clinical Oncology Group Study 9104. J Clin Oncol 2002;20:3054-60.

310. Turrisi AT, Kim K, Blum $\mathrm{R}$, et al. Twice-daily compared with once-daily thoracic radiotherapy in limited small-cell lung cancer treated concurrently with cisplatin and etoposide. N Engl J Med 1999;340:265-71.

311. Murray N, Coy P. Pater JL, et al. Importance of timing for thoracic irradiation in the combined modality treatment of limited-stage small-cell lung cancer. The National Cancer Institute of Canada Clinical Trials Group. J Clin Oncol 1993:11:336-44.

312. Fried DB, Morris DE, Poole C, et al. Systematic review evaluating the timing of thoracic radiation therapy in combined modality therapy for limited-stage small-cell lung cancer. J Clin Oncol 2004:22:4837-45.

313. Pijls-Johannesma M, De Ruysscher D, Vansteenkiste J, et al. Timing of chest radiotherapy in patients with limited stage small cell lung cancer: a systematic review and meta-analysis of randomised controlled trials. Cancer Treat Rev 2007:33:461-73

314. Baas P, Belderbos JS, Senan S, et al. Concurrent chemotherapy (carboplatin, paclitaxel, etoposide) and involved-field radiotherapy in limited stage small cell lung cancer: a Dutch multicenter phase II study. Br J Cancer 2006;94:625-30.

315. De Ruysscher D, Bremer RH, Koppe F, et al. Omission of elective node irradiation on basis of CT-scans in patients with limited disease small cell lung cancer: a phase II trial. Radiother Oncol 2006;80:307-12.

316. Auperin A, Arriagada R, Pignon JP, et al. Prophylactic cranial irradiation for patients with small-cell lung cancer in complete remission. Prophylactic Cranial Irradiation Overview Collaborative Group. N Engl J Med 1999;341:476-84.

317. Lester JF, Hudson E, Flubacher $\mathrm{M}$, et al. Small cell lung cancer treated in southeast Wales. Clin Oncol 2006;18:378-82.

318. Fox W, Scadding JG. Medical Research Council comparative trial of surgery and radiotherapy for primary treatment of small-celled or oat-celled carcinoma of bronchus. Ten-year follow-up. Lancet 1973;2:63-5.

319. Lad T, Piantadosi S, Thomas P, et al. A prospective randomized trial to determine the benefit of surgical resection of residual disease following response of small cell lung cancer to combination chemotherapy. Chest 1994;106(6 Suppl):320-3S.

320. Lim E, Belcher $E$, Yap YK, et al. The role of surgery in the treatment of limited disease small cell lung cancer: time to reevaluate. J Thorac Oncol 2008:3:1267-71. 
321. Vallieres E, Shepherd FA, Crowley J, et al. The IASLC Lung Cancer Staging Project: proposals regarding the relevance of TNM in the pathologic staging of small cell lung cancer in the forthcoming (seventh) edition of the TNM classification for lung cancer. J Thorac Oncol 2009;4:1049-59.

\section{APPENDIX 1}

\section{Topics identified for scope of guideline}

1. Diagnosis and staging: How should patients potentially suitable for radical treatment be managed? Include:

a. Imaging

b. Bronchscopic procedures

c. Endobronchial and endoscopic ultrasound

d. Mediastinoscopy

e. Video-assisted thorascopic surgery

2. Management of specific disease subsets: How should patients potentially suitable

for radical treatment in specific disease subsets be managed? Subsets include:

a. Early stage disease

b. T3 disease

c. N2 disease

d. Locally advanced disease

3. Assessment of risk: How should patients potentially suitable for radical treatment be assessed for risk? Include:

a. Operative mortality

b. Postoperative morbidity

c. Radical radiotherapy

4. Surgery: What surgical techniques should be used for patients?

5. Chemotherapy and radiotherapy: How should patients suitable for radical treatment be treated with chemotherapy and radiotherapy? Include:

a. Radical radiotherapy/chemoradiotherapy

b. Preoperative and postoperative radiotherapy

c. Preoperative and postoperative chemotherapy

6. Small cell lung cancer: How should patients with small cell lung cancer be managed if potentially suitable for radical treatment? Include:

a. Surgery

b. Radiotherapy

c. Chemotherapy

Further topics were added after the initial meeting defining scope:

7. Other radical treatments to include:
a. Stereotactic radiotherapy
b. Radiofrequency ablation
c. Radical brachytherapy

\section{APPENDIX 2}

Search strategy

Appendix 2 is available online at http://thorax.bmj.com.

\section{APPENDIX 3}

\section{Grading of evidence}

Studies that were obviously not relevant were excluded in an initial screening process

of abstracts. Studies selected for review were appraised as below:

1. Relevance

a. Is the population studied the same as that covered by the guideline?

b. Are the outcome measures appropriate and meaningful?

c. Is the study contemporary enough?

d. Was the study of adequate size and power?

2. Randomised trials

a. Was the randomisation process adequate?

b. Were patients analysed in their randomised groups?

c. What was the blinding process, if applied?

d. Were there any differences between the groups compared at baseline?

3. Case-control trials

a. Were the cases and controls similar at baseline?

b. Were outcomes measured in the same way for cases and controls?

c. Were cases selected differently from controls?

4. Studies of diagnostic tests

a. Was the finding compared with a laudable gold standard?

b. Was the result of the test blind to the gold standard?

c. Was the gold standard obtained in all cases?

5. Prognosis or prognostic index studies

a. Was a relevant group of patients defined at the start?

b. Was the follow-up period adequate?

c. Was the prognostic index tested on a fresh set of cases?

\section{Scottish Intercollegiate Guidelines Network (SIGN) levels of} evidence

\begin{tabular}{ll}
\hline $1++$ & $\begin{array}{l}\text { High quality meta-analyses, systematic reviews of randomised } \\
\text { controlled trials (RCTs) or RCTs with a very low risk of bias } \\
1+\end{array}$ \\
Well-conducted meta-analyses, systematic reviews or RCTs with \\
a low risk of bias \\
Meta-analyses, systematic reviews or RCTs with a high risk of bias \\
High quality systematic reviews of case-control or cohort or \\
studies High quality case-control or cohort studies with a very low \\
risk of confounding or bias and a high probability that the \\
relationship is causal \\
Well-conducted case-control or cohort studies with a low risk of \\
confounding or bias and a moderate probability that the relationship \\
is causal \\
Case-control or cohort studies with a high risk of confounding or \\
bias and a significant risk that the relationship is not causal \\
Non-analytic studies, for example case reports, case series \\
3
\end{tabular}

Scottish Intercollegiate Guidelines Network (SIGN) grades of recommendations

\begin{tabular}{|c|c|}
\hline Grade & Type of evidence \\
\hline A & $\begin{array}{l}\text { At least one meta-analysis, systematic review or randomised } \\
\text { controlled trial (RCT) rated as } 1++ \text { and directly applicable to the } \\
\text { target population or } \\
\text { A systematic review of RCTs or a body of evidence consisting } \\
\text { principally of studies rated as } 1+\text { directly applicable to the target } \\
\text { population and demonstrating overall consistency of results }\end{array}$ \\
\hline B & $\begin{array}{l}\text { A body of evidence including studies rated as } 2++ \text { directly } \\
\text { applicable to the target population and demonstrating overall } \\
\text { consistency of results or } \\
\text { Extrapolated evidence from studies rated as } 1++ \text { or } 1+\end{array}$ \\
\hline C & $\begin{array}{l}\text { A body of evidence including studies rated as } 2+\text { directly applicable } \\
\text { to the target population and demonstrating overall consistency of } \\
\text { results or } \\
\text { Extrapolated evidence from studies rated as } 2++\end{array}$ \\
\hline$D$ & $\begin{array}{l}\text { Evidence level } 3 \text { or } 4 \text { or } \\
\text { Extrapolated evidence from studies rated as } 2+ \\
\text { Important practical points for which there is no, nor is there likely to } \\
\text { be, any research evidence }\end{array}$ \\
\hline
\end{tabular}

Additional considerations

The SIGN 50 guidelines take into account grading of comparative versus noncomparative primary evidence. There is no clear guidance on how non-diagnostic studies are listed. In addition, important government statements or reports (eg, GMC guidance, BTS guidelines) come under the "4" category. The GDC felt that this diminishes what are often very influential documents and therefore has classified them as below:

\begin{tabular}{|c|c|}
\hline Type of publication & Grade \\
\hline Government/professional body statements or reports & $\mathrm{N} / \mathrm{A}$ \\
\hline Books & $\mathrm{N} / \mathrm{A}$ \\
\hline Phase II randomised controlled trial (RCT) with primary comparison & $1-$ \\
\hline Phase II RCT with a non-primary comparative outcome & $2++$ to $2-$ \\
\hline Diagnostic/validation studies reporting results of calibration & $2++$ to $2-$ \\
\hline Cohort (prospective) studies with comparative analyses & $2++$ to $2-$ \\
\hline Economic analyses & $2++$ to $2-$ \\
\hline Subanalyses from RCTs & $2++$ to $2-$ \\
\hline
\end{tabular}

Phase II RCT/diagnostic/validation studies demonstrating 'feasibility'

Cohort (prospective) studies without comparative analyses 3

Studies reporting research methodology 3

Studies reporting results of surveys 3

Editorials, reviews

4 


\section{APPENDIX 4}

Summary of the 7th edition of the TNM staging system in comparison with the 6th edition

\begin{tabular}{lll}
\hline 6th Edition & 7th Edition & \\
\cline { 2 - 3 } Stage modified & New stage & Descriptor \\
\hline T1 & T1a & Maximum dimension $\leq 2 \mathrm{~cm}$ \\
T2 & T1b & Maximum dimension $2-3 \mathrm{~cm}$ \\
& T2a & Maximum dimension $3-5 \mathrm{~cm}$ \\
& T2b & Maximum dimension $5-7 \mathrm{~cm}$ \\
T4 & T3 & Maximum dimension $>7 \mathrm{~cm}$ \\
M1 & T3 & Additional nodule in same lobe \\
M1 & T4 & Additional nodule in ipsilateral different lobe \\
M1 & M1a & Additional nodules in contralateral lung \\
\hline
\end{tabular}

Mx is no longer included in the TNM classification, for any tumour site

\section{Surgical stage groupings in 7th TNM classification}

\begin{tabular}{llll}
\hline Stage group & T & N & M \\
\hline Stage 0 & Tis & N0 & M0 \\
Stage IA & T1a,b & N0 & M0 \\
Stage IB & T2a & N0 & M0 \\
Stage IIA & T1a,b & N1 & M0 \\
& T2a & N1 & M0 \\
Stage IIB & T2b & N0 & M0 \\
& T2b & N1 & M0 \\
Stage IIIA & T3 & N0 & M0 \\
& T1,T2 & N2 & M0 \\
Stage IIIB & T3 & N1,N2 & M0 \\
& T4 & N0,N1 & M0 \\
Stage IV & T4 & N2 & M0 \\
\hline
\end{tabular}

\section{APPENDIX 5}

Thoracoscore

\begin{tabular}{llll}
\hline Variable & Value & Code & $\beta$-coefficient \\
\hline Age & $<55$ years & 0 & \\
& $55-65$ years & 1 & 0.7679 \\
Sex & $>65$ years & 2 & 1.0073 \\
ASA score & Female & 0 & \\
Performance status & $\leq 2$ & 1 & 0.4505 \\
& $\geq 3$ & 0 & \\
Dyspnoea score & $\geq 2$ & 1 & 0.6057 \\
& $\geq 2$ & 0 & \\
Priority of surgery & $\geq 3$ & 1 & 0.689 \\
Procedure class & Elective & 0 & \\
& Urgent or emergency & 1 & 0.9075 \\
Diagnosis group & Other & 0 & \\
& Pneumonectomy & 1 & 0.8443 \\
Comorbidity score & Benign & 0 & \\
& Malignant & 1 & \\
& 0 & 0 & 1.2176 \\
Constant & $\leq 2$ & 1 & \\
\hline
\end{tabular}

Methods for using the logistic regression model to predict the risk of in-hospital death: 1. Odds are calculated with the patient values and the coefficients are determined from the regression equation:

Odds $=\exp [-7.3737+(0.7679$ if code of age is 1 or 1.0073 if code of age is 2$)$ $+(0.4505 \times$ sex score $)+(0.6057 \times$ ASA score $)+(0.6890 \times$ performance status classification) $+(0.9075 \times$ dyspnoea score $)+(0.8443 \times$ code for priority of surgery $)+(1.2176 \times$ procedure class $)+(1.2423 \times$ diagnosis group $)+(0.7447$ if code of comorbidity is 1 or 0.9065 if code of comorbidity is 2)].

2. The odds for the predicted probability of in-hospital death are calculated: probablity + odds $/(1+$ odds $)$.

ASA, American Society of Anesthesiologists. 